\title{
Dual-Mode Scramjet Flameholding Operability Measurements
}

James M. Donohue

United Technologies Research Center

East Hartford, CT 06108 



\section{Table of Contents}

TABLE OF CONTENTS........................................................................................... 1

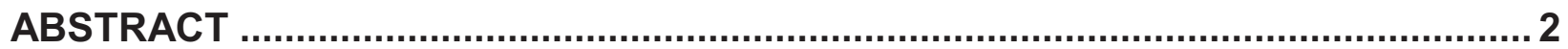

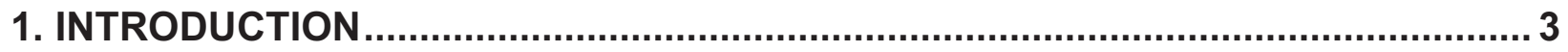

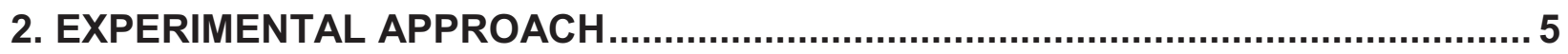

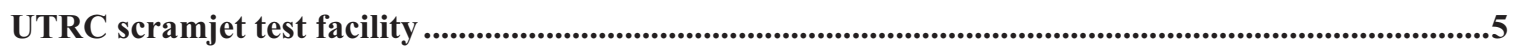

UVa test facility used for vitiation effects testing ..............................................................................................9

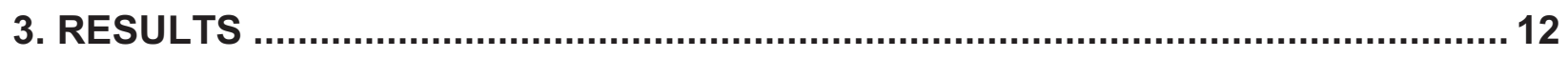

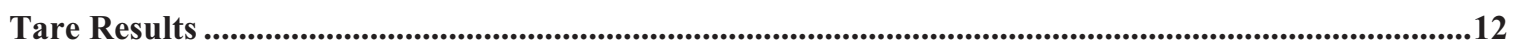

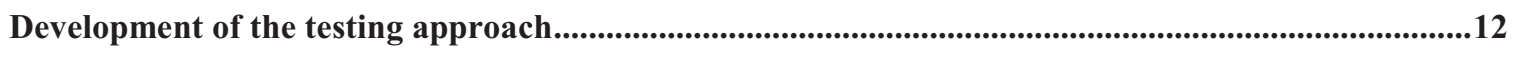

Results showing parametric sensitivities ............................................................................................................13

High speed measurements to capture flowfield dynamics ............................................................................16

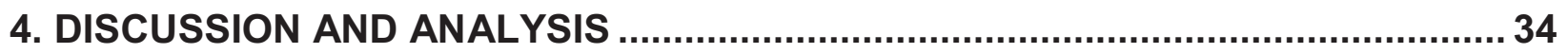

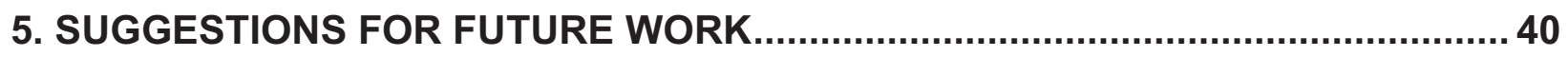

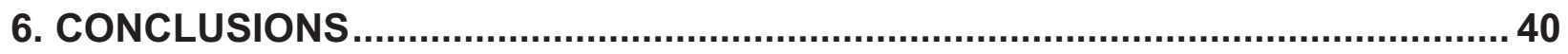

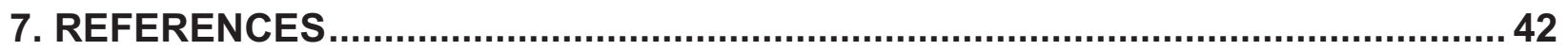

APPENDIX A: TABLE OF TEST CONDITIONS JUST BEFORE BLOWOUT DURING

FLAMEHOLDING LIMIT EXPERIMENTS. ............................................................... 43

APPENDIX B: FACILITY INLET NOZZLE INFORMATION ...................................... 49

APPENDIX C: LIST OF ALL MEASURED AND CALCULATED PARAMETERS IN

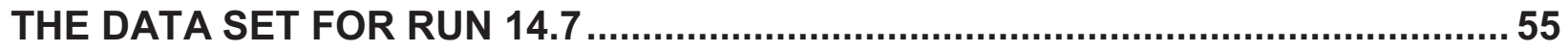

APPENDIX D: UVA REPORT: EXPERIMENTAL STUDY OF VITIATION EFFECTS ON FLAMEHOLDING IN A HYDROCARBON FUELED DUAL-MODE SCRAMJET

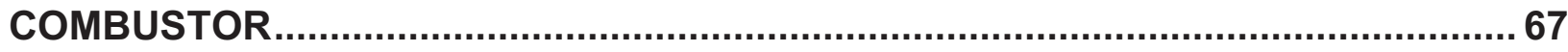




\begin{abstract}
Flameholding measurements were made in two different direct connect combustor facilities that were designed to simulate a cavity flameholder in the flowfield of a hydrocarbon fueled dual-mode scramjet combustor. The presence of a shocktrain upstream of the flameholder has a significant impact on the inlet flow to the combustor and on the flameholding limits. A throttle was installed in the downstream end of the test rigs to provide the needed back-pressurization and decouple the operation of the flameholder from the backpressure formed by heat release and thermal choking, as in a flight engine. Measurements were made primarily with ethylene fuel but a limited number of tests were also performed with heated gaseous JP-7 fuel injection. The flameholding limits were measured by ramping inlet air temperature down until blowout was observed. The tests performed in the United Technologies Research Center (UTRC) facility used a hydrogen fueled vitiated air heater, Mach 2.2 and 3.3 inlet nozzles, a scramjet combustor rig with a 1.666 by 6 inch inlet and a 0.65 inch deep cavity. Mean blowout temperature measured at the baseline condition with ethylene fuel, the Mach 2.2 inlet and a cavity pressure of 21 psia was $1502{ }^{\circ} \mathrm{R}$. Flameholding sensitivity to a variety of parameters was assessed. Blowout temperature was found to be most sensitive to fuel injection location and fuel flowrates and surprisingly insensitive to operating pressure (by varying both back-pressurization and inlet flowrate) and inlet Mach number. Video imaging through both the bottom and side wall windows was collected simultaneously and showed that the flame structure was quite unsteady with significant lateral movements as well as movement upstream of the flameholder. Experiments in the University of Virginia (UVa) test facility used a Mach 2 inlet nozzle with a 1 inch by 1.5 inch exit cross section, an aspect ratio of 1.5 versus 3.6 in the UTRC facility. The UVa facility tests were designed to measure the sensitivity of flameholding limits to inlet air vitiation by using electrically heated air and adding steam at levels to simulate vitiated air heaters. The measurements showed no significant difference in blowout temperature with inlet air mole fractions of steam from 0 to $6.7 \%$.
\end{abstract}




\section{Introduction}

Scramjet engine combustor designs generally utilize recirculation zones as flameholding regions because the flame cannot be maintained in the core of the engine on it's own where flow velocities are high. The flameholding problem is exacerbated with hydrocarbon fuels versus hydrogen fuel due the slower reaction rates. Lower combustor inlet air temperatures seen at lower flight Mach numbers also cause flameholding risks since reaction rates are a strong function of temperature. Several liquid hydrocarbon fueled dual mode scramjet engines have been developed with various flameholding approaches [1,2].

The scramjet combustor design must account for many processes to properly occur in order for the combustor to operate in flight, e.g.: fuel/air mixing in both the core flow and in the flameholder, ignition, flameholding, flame propagation, and for dual mode operation thermal choking. Reduced order design tools and/or empirical data for each of these processes are required by the engine designer, at least to make an initial design before expensive and time consuming 3-D CFD modeling and ground tests are employed to optimize the design. The present study involves designing an experiment to isolate the flameholding process with measurements that are relevant to the dual mode combustor. Figure 1 shows a schematic of the dual mode combustor flowfield with and without combustion. Figure 1-a outlines how before ignition the flowfield characteristics would make it difficult to flamehold. Flow is supersonic through the engine with high velocity, low static temperature and low static pressure; all tend to reduce combustion heat release. Figure 1-b shows that after ignition, with the engine in steady operation, a thermal throat is formed downstream of the fuel injection/flameholder region due to combustion heat release. Combustor pressure increases about 3 to 5 times across the shocktrain so that the flow becomes subsonic in the core flow over the flameholder, decreasing the velocity and increasing static temperature. Boundary layers entering of the combustion zone are thicker. All these attributes make conditions significantly more favorable for combustion and flameholding. The bottom drawing shows the experimental set-up used for the flameholding tests performed here. A mechanical throttle rather than thermal choking is used to generate backpressure so that the backpressure can be controlled independent of the heat release. This allows the formation of an upstream isolator so that a realistic inlet flowfield over the flameholder is generated.

The mechanical throttle approach was designed to decouple the processes that control flameholding from the processes that control bulk flow heat release and back-pressurization (e.g. flame propagation and fuel/air mixing). In the dual-mode flowfield blowout can be caused by either insufficient flameholding capability or due to insufficient bulk flow heat release (causing a loss of the thermal throat). Engine test results generally do not provide a method to identify the primary cause. If the flameholding capability is found to be insufficient it is not clear which design modifications are needed. For example, should fuel/air mixing in the core of the engine be improved or a larger flameholder be employed? The experimental approach used here with the mechanical throttle assumes that the flowfield in and around the flameholder will be close enough to the fully fueled thermally throated flowfield that the results are relevant.

Many previous flameholding studies have been performed where the flow is everywhere subsonic [3-6], and for flows where the core flow is everywhere supersonic [7-9], but the measurements generally do not provide relevant quantitative data for dual mode combustor designs. Examples of important differences include:

1. Inflow turbulence levels and flow unsteadiness is significantly higher in the dual mode combustor where a shocktrain is located upstream of the flameholder. 
2. Large recirculation regions can occur upstream and near the flameholder in a dual mode combustor due to the large adverse pressure gradient in the shocktrain.

Many of the previous studies utilized premixed inflow which is usually not implemented for a dual mode design because of the potential to cause burning in the isolator and inlet unstart. Also, many of the previous studies measure lean blowout but the dual mode scramjet engine flameholder will generally be fueled at stoichiometric levels to optimize flameholding.

A cavity flameholder was chosen for the present study because it is often used in scramjet designs where low drag and a more straightforward thermal structural approach is beneficial. AFRL has recently performed cavity flameholding measurements that included a limited number of tests with backpressurization so that a shock train exists upstream of the flameholder, see reference [10]. The study here selected a cavity flameholder and flowpath geometry that closely matches the AFRL design in an attempt to add to the database and expand it to a wider parameter space. This includes: variations in shock train pressure rise, operating pressure (by varying flowrate to simulate flight dynamic pressure sensitivity), inlet air temperature (to simulate flight Mach number sensitivity), isolator inlet Mach number, and different fuels (by testing with both ethylene and JP-7).

The data base generated in this program is available in the open literature and can be used for validation test cases and for development of flameholding models. The author listed on the front page of this report can be contacted for additional data and details not presented in this report.

\section{a. Before light-off, flow over cavity is supersonic}
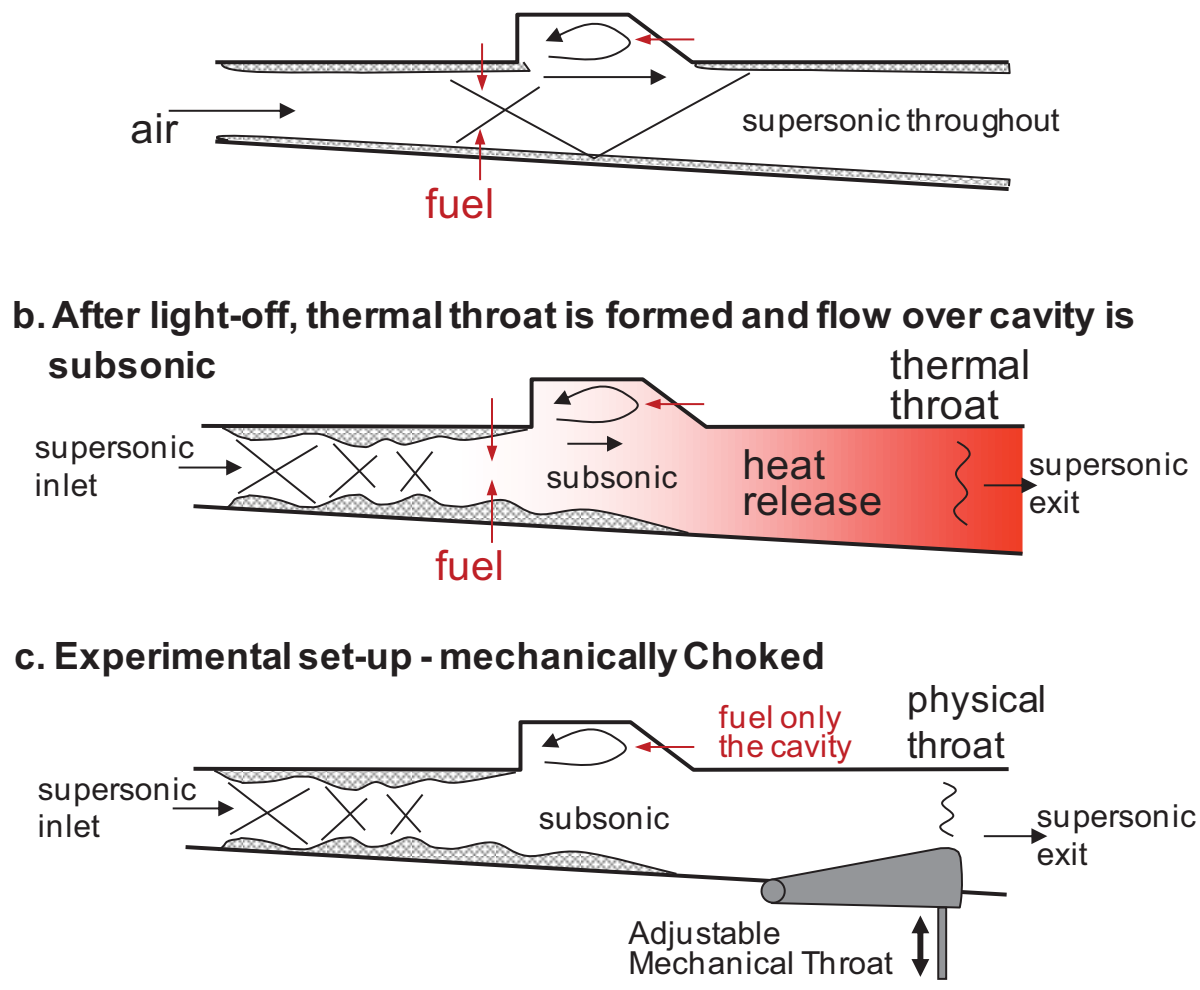

Figure 1.1 Description of the dual-mode scramjet flowfield 


\section{Experimental Approach}

\section{UTRC scramjet test facility}

The UTRC direct connect scramjet test facility in cell 5 west of UTRC's Jet Burner Test Stand was used for the present study. The facility and the test rig has been used in several direct connect scramjet combustor test programs over the past several years $[1,2]$. The facility uses combustion heated air to supply inlet air at elevated temperatures and pressures representative of inlet conditions for a dual mode scramjet engine. The hydrogen fuel burned in the air heater produces steam vitiation at levels of 6 to $10 \%$ mole fraction for the conditions tested here. Make up oxygen is injected into the air heater at a flowrate set to maintain a mole fraction of oxygen of $21 \%$ in the inlet air. Two water cooled supersonic inlet nozzles were used to allow for a range of inlet conditions to be tested. The Mach 2.20 and Mach 3.31 nozzles used in the test program both have a 1.664 by 6.000 inch rectangular cross section at the exit, compatible with the inlet cross section of the test rig. The 2-D test rig is made primarily with uncooled steel walls that provide a heat sink so run durations on the order of 1 to 2 minutes can be performed. Several walls were replaced for the present test program and were made with water cooled OFHC copper to ensure durability. At the exit of the test rig water is sprayed to reduce the temperature of air in the facility exhaust duct. An air driven vacuum ejector is used to maintain a low pressure at the exit plane of the rig to simulate the low back pressure environment in flight.

Ethylene was used to fuel the flameholder for the majority of the tests performed. The ethylene was supplied in compressed gas bottles which were used to fill three piston driven accumulators. Supplying the ethylene from accumulators rather than directly from the compressed gas bottles allows the supply pressure to more closely match the injection pressure and avoid a phase change that can occur when a large pressure drop occurs across a control valve. For JP-7 fueled test cases an electric fuel heater was used to preheat the JP-7 to $900 \mathrm{~F}$ so that the fuel is injected in a gaseous state, but low enough in temperature so that fuel cracking does not occur.

Measurement and control systems

The primary facility control system utilizes a PLC controlled by a PC running RSView software. The facility control system sets inlet flowrates of all fluids, lights and runs the air heater and protects personnel and hardware from damage using an extensive array of shutdown interlocks. Several data systems were utilized for the testing performed. The primary facility data system is LabVIEW based and collects data through a National Instruments SCXI chassis and a Scanivalve pressure scanner. For the test performed 128 temperatures, 128 wall pressures, 32 individual pressure and voltage transducers and 8 frequency channels for flowrates measurements were all recorded at $5 \mathrm{~Hz}$ data rate. Standard video collected at 15 frames per second (fps), high speed video collected at up to 50,000 fps and high speed pressure measurements at $8 \mathrm{kHz}$ were also collected during many runs.

Air, oxygen and hydrogen flowrates into the vitiated air heater were measured using choked venturis with a 3\% uncertainty. Ethylene fuel flowrate was measured using a Micromotion coriolis flowmeter with an uncertainty of 2\%. JP-7 flowrate was measured with a Cox turbine flowmeter with an uncertainty of 2\%. The measurements of equivalence ratio, $\Phi$, presented in this report are overall equivalence ratio values, no local equivalence ratio measurements were made. The local equivalence ratios in the cavity are significantly higher than the overall equivalence ratio values reported because all fuel is injected in the cavity region. The overall equivalence ratio measurements have an uncertainty of $4 \%$ and were calculated from the total gas flowrate into the air heater, the fuel flowrate and the stoichiometric fuel-air ratio. 
Inlet conditions into the test rig are controlled by the shape of the supersonic inlet nozzle, by the flowrates into the air heater and by combustion of hydrogen in the air heater. The stagnation pressure in the air heater, Pt air heater, was measured using a wall pressure tap on the downstream end of the heater, uncertainty is estimated to be $2 \%$. The air heater has an inside diameter of 8 inches. This provides a crosssectional area that is significantly larger than the area of the nozzle throat so that the static pressure measured is within $0.2 \%$ of the stagnation pressure. Stagnation temperature at the inlet, Tt inlet, was not measured directly. It was calculated assuming thermodynamic equilibrium of the measured air, oxygen and hydrogen flows into the air heater with a correction for the heat loss to the water cooled inlet components. The uncertainty of the $\mathrm{Tt}$ inlet value is estimated to be 3\%. During a blowout test $\mathrm{Tt}$ was ramped down $20^{\circ} \mathrm{R}$ per second, so $+/-0.5 \mathrm{sec}$ uncertainty in the time slice selection for the blowout causes an additional $+/-10 \mathrm{~F}$, or $0.5 \%$ uncertainty in $\mathrm{Tt}$ inlet at blowout. The air temperature was ramped down by ramping down the hydrogen and oxygen flowrates to the air heater, but air flowrate was held constant. Therefore the total inlet flowrate decreases about $5 \%$ and the equivalence ratio increases about $5 \%$ during a temperature ramp from $1900 \mathrm{R}$ to $1400 \mathrm{R}$, a range where most of the blowout data was taken.

Wall pressures were measured with the Scanivalve system connected to 0.040 inch diameter pressure taps in the walls of the flowpath and have an uncertainty of $2 \%$. The cavity pressure, Pcavity, was measured from a pressure tap on the center of the floor of the cavity at the $\mathrm{x}=20.38$ inch location. The inlet pressure, Pinlet, was measured from a pressure tap centered on the top wall of the test rig at the $\mathrm{x}=0.5$ inch location. Pratio is the isolator pressure rise and is calculated from the ratio of Pcavity to Pinlet.

Wall temperatures were measured using sheathed $1 / 16^{\text {th }}$ inch diameter thermocouples inserted from the outside of the rig into holes that end close to the inner wall. For the water cooled copper cavity walls, the wall thermocouples are located 0.125 inches from the inner wall. These are estimated to read from 10 to $30{ }^{\circ} \mathrm{F}$ colder than the inner wall temperature. For the heat sink steel wall sections, two thermocouples are used at each location to estimate inner wall temperature. One is located 0.125 inches from the inner surface, the other is in the middle of the wall, 0.563 inches from the inner wall. The steel wall inner temperatures are derived by extrapolating these two measurements to the inner surface, an approach estimated to have an uncertainty of $30^{\circ} \mathrm{F}$.

The throttle height, $\mathrm{h}$ throttle, is the height of the throttle above the flat bottom wall of the rig. The measurement is made with a potentiometer and has an uncertainty of 0.010 inches.

\section{Mechanical design of the UTRC test rig}

The existing UTRC 2-D direct combustor rig, originally built under the HySET program [2] was used for the present test program. Several new wall sections were designed and fabricated. The test rig, shown in Figure 2.1, contains an isolator section on the upstream end, a combustor section with a flameholding /

fuel injection region and a diverging exit area. The bottom wall and both side walls are flat and parallel to the inlet flow direction so that the flowpath has a constant 6 inch width the entire length of the rig. The top wall height is 1.666 inches at the inlet and varies along the flow direction to provide the area divergence typical in a scramjet isolator/combustor. The upper wall of the isolator section diverges at a 0.6 degree angle to account for boundary layer growth. Figure 2.2 shows a 3-D CAD model of the cavity wall assembly designed and fabricated for the present program. The 4130 steel frame, shown in blue, holds the two copper wall sections that form the cavity. The cavity flameholder is 0.65 inches deep and has a 22.5 degree angled closeout surface. Water cooling channels can be seen in the copper walls and the downstream section of the steel wall that touches the flame. 
For the majority of the test runs performed fuel was injected through a row of fuel injectors located on the cavity closeout, these are referred to as cavity closeout (CC) injectors. Fuel is injected in the upstream direction parallel to the cavity floor through 13 equally spaced round sonic $0.031+/-0.0005$ inch orifice injectors midway up the wall of the angled cavity closeout. Note that the fuel flowrates were measured with a flowmeter upstream of the fuel injectors so that the flowrate measurement accuracy is not affected by the tolerance of the injector hole diameter. The injectors are intended to directly fuel the cavity so that the majority of the fuel is mixed with the air that gets entrained into the cavity. An additional fuel injection site is located external to the cavity, centered 0.91 inches upstream of the cavity lip. These are referred to as cavity external (CE) injectors. For this injector site the fuel is injected normal to the wall (jet in cross flow arrangement) through 13 equally spaced round sonic 0.031 inch orifice injectors. The intent of these injectors is to premix some of the fuel and air that flows into the shear layer over the cavity and is entrained into the cavity. A significant fraction of the fuel injected through the CE injectors may penetrate over the cavity into the air in the core of the flowpath and not participate in the flameholding process. For this reason the local equivalence ratio in the cavity may be lower when using $\mathrm{CE}$ versus $\mathrm{CC}$ injectors, at the same overall equivalence ratio. Note that 15 injectors, spaced 0.375 inches apart, were built into the hardware at each fuel site but the two outer injectors at each site were not fueled to account for the lower speed flow close to the sidewalls.

A movable mechanical throttle was added to the flowpath downstream of the cavity flameholder, and allows backpressure to be incrementally applied so that the upstream shocktrain strength and location can be controlled. Figure 2.1 shows the mechanical design of the throttle. The throttle wall frame, shown in pink, holds the throttle and allows movement of the throttle into and out of the flowfield. The throttle is made of water cooled copper and has a hinge located about 8 inches downstream of the cavity closeout. The throttle is moved using a DC motor drive, its position is measured with a potentiometer. A secondary data \& control system was implemented to position the throttle. Closed loop control was used to set the pressure ratio across the isolator, Pratio. Cavity and inlet pressures were measured, the ratio calculated and the motor automatically moved to maintain the ratio of these pressures at the set point as the air temperature was ramped during a run.

Windows are built into both side wall and bottom walls to allow the 3-D flame movement to be imaged. A 45 degree mirror was placed below the test rig so that one camera can be used to see both views simultaneously. Figure 2.1 shows a view of the 6 inch by 6 inch bottom wall window that gives a view of the full width of the flowpath and of the entire cavity as well a small region upstream of the cavity. The side wall window port is seen in Figure 2.2 and provides a view of the region both upstream and downstream of the cavity. Both windows contain steps around the perimeter so that they can be sealed while being mounted flush with inner surface of the flowpath and not perturb the flow. Note that the side wall window comes in direct contact with the flame and eventually gets coated so it is difficult to see through after several runs, particularly in the upstream corner of the cavity. The sidewall window, therefore, was replaced several times during the test program. The bottom wall window is located across the flowfield from the cavity and does not come in direct contact with the flame, so it remained clean throughout the test program.

Details of the rig flowpath geometry and fuel injector sites are shown in Figure 2.3. The width of the flowpath is 6 inches for the entire length of the rig. The bottom wall is flat for the entire length except for the location of the mechanical throttle. The top wall diverges at various angles along the flowpath as shown in the figure, and contains the cavity flameholder. Detailed geometry is shown in the table included in the figure. The axial location of the two fuel injector sites are also noted. The mechanical throttle begins at axial position 30.86 inches, is 8.64 inches long and contains a hinge at the upstream end to allow it to be rotated into and out of the flow. There is a 0.020 inch clearance gap between the side of 
the throttle wall and the side wall to allow the throttle to move freely without friction in case there is thermal distortion of the rig or throttle. The tip of the throttle wall has a 0.25 inch radius to accommodate the high local heat load. An important feature of the flowpath geometry is that the start of the 2.9 degree combustor divergence angle begins upstream of the cavity at the $x=15.125$ location. This allows for area relief from blockage caused by fuel injectors located in the isolator just upstream of the cavity. The increased divergence angle also can produce more pressure recovery at the back of the isolator than would occur in a zero divergence isolator. The area relief also accommodates blockage cause by combustion in this region of the isolator.

Test Procedure

A typical run where a single blowout temperature is determined took approximately 100 seconds to perform. The run duration is limited by the wall temperature limit of the heat sink steel rig walls which are set to stop the run if a wall temperature of $900^{\circ} \mathrm{F}$ is measured. The run procedure includes lighting of the air heater, lighting the flameholder, and ramping the air temperature down till blowout is observed. The list below describes the procedure used and typical durations for each step.

Test procedure with typical timing:

- Preset mechanical throttle position

- Preset valve and regulator positions for start of air temperature ramp

- Preset fuel system setting for desired flowrate

- $\quad-30 \mathrm{sec}$, If heated jet fuel used: start fuel flow to overboard and preheat fuel

- $\quad-25 \mathrm{sec}$, Start inlet air flow

- $0 \mathrm{sec}$, Start oxygen and hydrogen flow and light air heater

- $50 \mathrm{sec}$, Allow air heater conditions to stabilize and rig walls to warm up

- $51 \mathrm{sec}$, Inject fuel into combustor

- $52 \mathrm{sec}$, Turn spark igniter on until the combustor lights

- $53 \mathrm{sec}$, Close the throttle to increase back-pressurization if needed for ignition

- $54 \mathrm{sec}$, Start throttle door automatic control to set Pratio desired

- $69 \mathrm{sec}$, Allow combustor operation to stabilize

- $70 \mathrm{sec}$, Ramp air temperature down by ramping oxygen and hydrogen flows

- $90 \mathrm{sec}$, Continue until combustor blowout is observed in the video

- $100 \mathrm{sec}$, Stop flow of fuel, oxygen and hydrogen

- Post test, Purge all fuel and hydrogen with GN2 into the rig.

When reducing the data to select the time when blowout occurs the cavity pressure rather than the video is used. Synchronization of the video time scale to the data system time scale was done for several runs and it clearly shows that the flame emission disappears at the same time that the cavity pressure suddenly drops.

\section{Test Conditions}

A table of typical test conditions derived using chemical equilibrium calculations is shown in Figure 2.4. The calculations are simple 1-D estimates that assume uniform conditions on a cross section but are useful for better understanding of the flameholder conditions and flow time scales present. The inlet conditions (station 2) are derived from the flowrate setting, total temperature setting and the Mach number of the inlet nozzle being used. The conditions at the exit of the isolator (station 3) are calculated from the flowrate setting, total temperature, the back pressure setting, and by balancing streamthrust across the isolator. There is a small change in streamthrust across the isolator due to pressure forces on 
the slightly diverging isolator wall and due to friction forces on the walls, but these are relatively small effects accounting for less than 1\% percent of the overall streamthrust for the baseline Mach 2.2 test case. The station 3 conditions are the relevant flameholder operating conditions. Velocity over the cavity flameholder can vary from 1200 to $2700 \mathrm{ft} / \mathrm{sec}$ for the Mach 2.2 inlet nozzle and from 2400 to $3400 \mathrm{ft} / \mathrm{sec}$ for the Mach 3.3 inlet nozzle, depending on the pressure ratio across the isolator. A distortion coefficient is used to allow the calculation of 1-D conditions to be performed, an approach that is consistent with previous treatment of flow through an isolator where a shock train and flow separations are expected to occur [11].

\section{UVa test facility used for vitiation effects testing}

The direct connect scramjet combustor facility at the University of Virginia (UVa) was used to measure the sensitivity of flameholding to vitiation. This unique facility is specifically designed to evaluate vitiation effects by using an electrical heater to provide clean air. Vitiates produced in other facility air heaters, such as steam and carbon dioxide, can be added to the inlet air at various levels to directly measure the sensitivity of the combustion process to vitiation. For the present study steam is injected into the air plenum upstream of the facility nozzle at the levels to match what is seen in hydrogen fueled vitiated air heaters. Inlet total temperatures up to $2160{ }^{\circ} \mathrm{R}$ can be provided by the electrical air heater. The facility has a Mach 2 inlet nozzle with a 1 inch high by 1.5 inch wide rectangular exit. The direct connect test rig has a constant area isolator and a diverging combustor that exits into ambient air. One wall of the UVa test rig was modified for the present program to make a cavity flameholder with a geometry that is a $60 \%$ scale version of the UTRC test rig. The height profile of the flowpath is scaled but the width, which is a constant 1.5 inches is not scaled. Note, this width is significantly less than $60 \%$ of the 6 inch wide flowpath at UTRC. The aspect ratio of the inlet to the UVa rig is 1.5 versus the 3.6 aspect ratio of the UTRC rig inlet. Back pressure was applied using an air throttle placed near the exit of the flowpath. Varying flowrate through the air throttle allowed the backpressure level to be set and the shock train positioned at a fixed location in the isolator. All tests were performed with ethylene fuel from a row of 5 fuel injectors located on the center of the cavity closeout, similar to the CC injectors used in the UTRC facility. The details of the UVa facility are included in this report in Appendix D which contains the UVa report for the tests performed for this contract. 


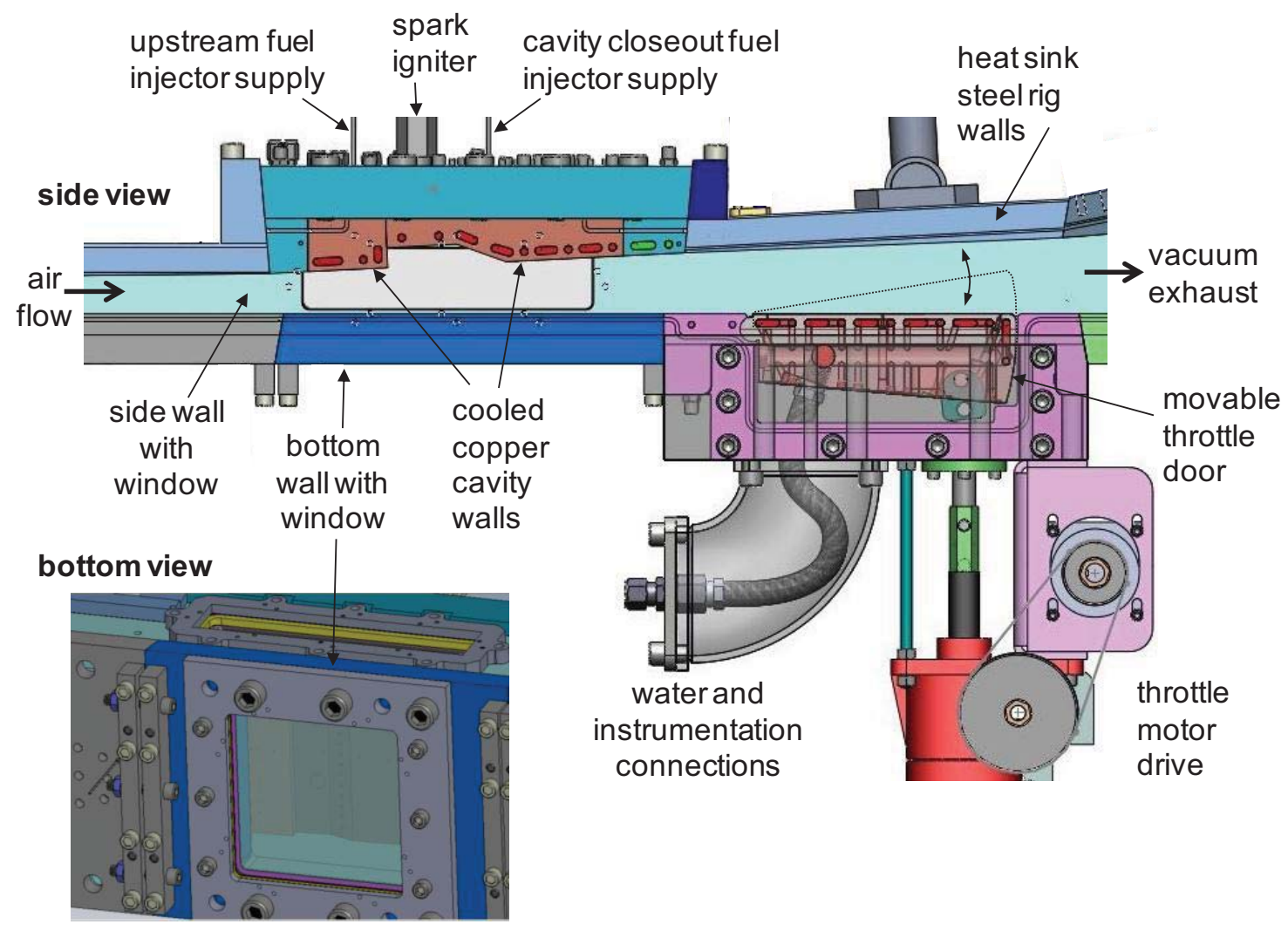

Figure 2.1 UTRC test rig design

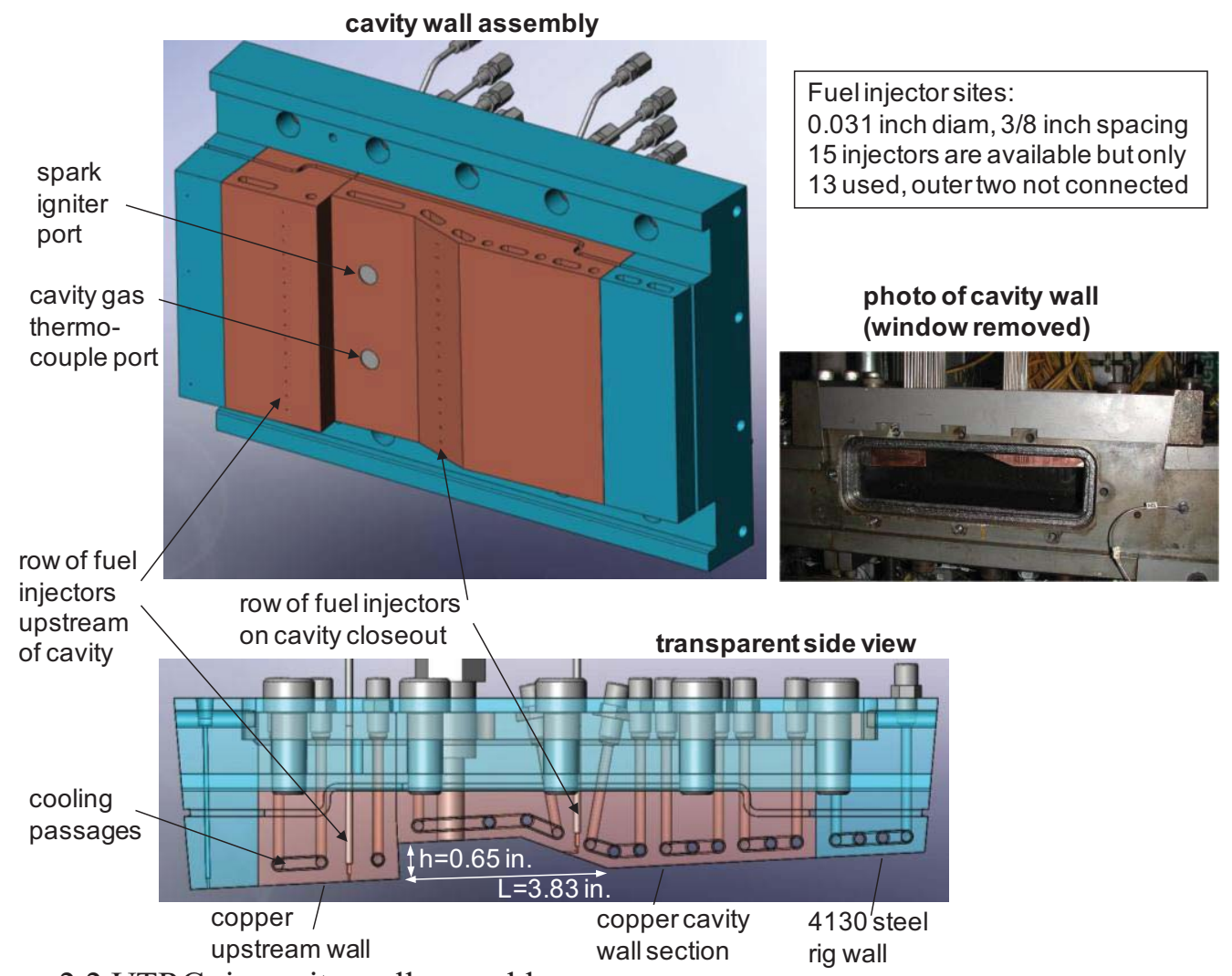

Figure 2.2 UTRC rig cavity wall assembly 


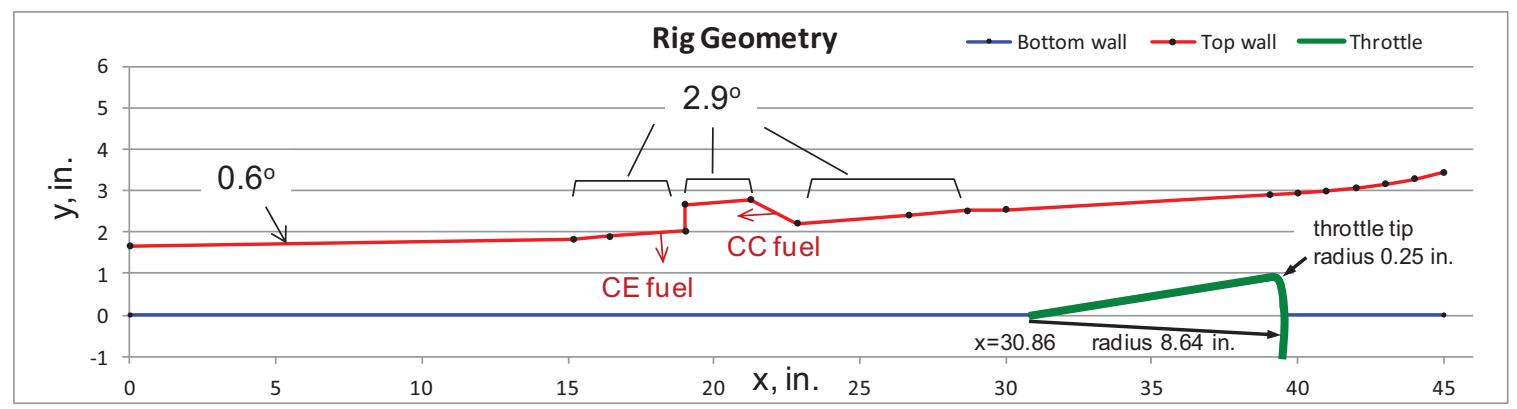

\begin{tabular}{|c|c|c|c|c|}
\hline \multirow{19}{*}{$\begin{array}{l}\text { Flowpath width } \\
\text { (out of the page) } \\
\text { is constant } 6.000 \mathrm{in} \text {. } \\
\text { for entire rig }\end{array}$} & \multicolumn{3}{|c|}{ Top wall coordinates, inches } & \multirow{9}{*}{$\begin{array}{l}\text { Fuel injection } \\
\text { CC fuel injectors: } \\
\text { parallel to cavity floor } \\
\text { at } x=22.065 \\
13 \text { injectors } \\
0.375 \text { spacing } \\
0.031 \text { diam sonic injection }\end{array}$} \\
\hline & & $\mathrm{x}$ & $\mathrm{y}$ & \\
\hline & start of isolator & 0.000 & 1.666 & \\
\hline & start of cavity wall frame & 15.195 & 1.825 & \\
\hline & start of copper block & 16.435 & 1.888 & \\
\hline & lip of cavity & 19.035 & 2.020 & \\
\hline & start of cavity floor & 19.010 & 2.669 & \\
\hline & end of cavity floor & 21.265 & 2.783 & \\
\hline & end of cavity closeout & 22.865 & 2.213 & \\
\hline & downstream end of copper block & 26.685 & 2.407 & CE fuel injectors: \\
\hline & downstream end of frame & 28.685 & 2.508 & normal to wall \\
\hline & air throttle wall & 30.009 & 2.546 & at $x=18.125$ \\
\hline & above throttle throat & 39.050 & 2.900 & 13 injectors \\
\hline & expansion to exit & 40.006 & 2.938 & 0.375 spacing \\
\hline & & 40.975 & 2.987 & 0.031 diam sonic injection \\
\hline & & 42.006 & 3.064 & \\
\hline & & 43.006 & 3.163 & \\
\hline & & 44.006 & 3.287 & \\
\hline & & 45.006 & 3.435 & \\
\hline
\end{tabular}

Figure 2.3 UTRC rig geometry

\begin{tabular}{|l|c|c|c|c|c|c|c|c|c|c|c|}
\hline \multirow{2}{*}{} & \multicolumn{1}{|l|}{ Isolator Inlet - station 2 } & \multicolumn{3}{|l|}{ Isolator exit - station 3 } \\
\hline & Ma 2 & Ps 2 & Tt 2 & V 2 & W & Ps 3 & Ps3/Ps2 & Ma 3 & Cd & V 3 \\
\hline Case $:$ & & psia & R & ft/s & pps & psia & & & & ft/s \\
\hline Ma 2.2 inlet, Pratio = 4 & 2.2 & 6.00 & 1500 & 3061 & 4.11 & 24.0 & 4.0 & 0.69 & 0.86 & 1253 \\
\hline Ma 2.2 inlet, Pratio = 3.5 & 2.2 & 6.00 & 1500 & 3061 & 4.11 & 21.0 & 3.5 & 0.86 & 0.76 & 1538 \\
\hline Ma 2.2 inlet, Pratio = 2.5 & 2.2 & 6.00 & 1500 & 3061 & 4.11 & 15.0 & 2.5 & 1.26 & 0.69 & 2107 \\
\hline Ma 2.2 inlet, Pratio = 1.5 & 2.2 & 6.00 & 1500 & 3061 & 4.11 & 9.0 & 1.5 & 1.75 & 0.74 & 2677 \\
\hline Ma 2.2 higher flowrate & 2.2 & 12.00 & 1500 & 3061 & 8.22 & 42.0 & 3.5 & 0.86 & 0.76 & 1538 \\
\hline Ma 3.3 inlet, Pratio = 5 & 3.31 & 2.38 & 1500 & 3631 & 3.127 & 11.9 & 5.0 & 1.49 & 0.54 & 2393 \\
\hline Ma 3.3 inlet, Pratio = 3.5 & 3.31 & 2.38 & 1500 & 3631 & 3.127 & 8.3 & 3.5 & 1.92 & 0.54 & 2838 \\
\hline Ma 3.3 inlet, Pratio = 2.5 & 3.31 & 2.38 & 1500 & 3631 & 3.127 & 5.9 & 2.5 & 2.30 & 0.58 & 3134 \\
\hline Ma 3.3 inlet, Pratio = 1.5 & 3.31 & 2.38 & 1500 & 3631 & 3.127 & 3.6 & 1.5 & 2.82 & 0.70 & 3432 \\
\hline
\end{tabular}

Figure 2.4 Table of typical calculated test conditions into and out of the isolator showing a distortion coefficient $(\mathrm{Cd})$ less than one is needed at the exit if a 1-D analysis is used. 


\section{Results}

\section{Tare Results}

Non-combustion runs were initially performed to gain experience with the test set-up and to provide baseline unfueled (i.e. tare) runs for future simulations. Pressure profiles were obtained with a fixed inlet condition and various throttle positions as showed in Figure 3.1. Throttle height, $h$, is shown on the right side of the figure and is defined as the vertical distance from the flat wall opposite the cavity to the point of the throttle furthest into the flow. The shock train location was found to be quite sensitive to throttle position. When the area blockage due to the throttle was varied from $30 \%$ to $43 \%$ the shock train moved from downstream of the cavity through the isolator and into the facility nozzle.

\section{Development of the testing approach}

A variety of test procedures to measure flameholding limits were tested initially. These included backpressure ramping, fuel ramping and air temperature ramping. The air temperature ramping approach was selected primarily because it allowed the shock train to be set at locations of interest during the blowout test run. The effect of the shock train is considered a first order effect and is of primary interest in the present program. Holding the flow conditions fixed while ramping the throttle resulted in runs where the shock train moved significantly, sometimes into the facility nozzle making the test run unrepresentative. Figure 3.2 shows an example of a test where the throttle is ramped till blowout; notice the large movement of the shock and the erratic behavior of the combustor pressures when the shock is pushed into the nozzle. Figure 3.3 shows a test where air conditions and throttle position is held fixed while fuel flowrate is decreased until blowout. Again, significant movement of the shock train was observed.

For scramjet engine applications, flameholders will be fueled at close to stoichiometric levels to maximize flameholding, flame propagation and combustion efficiency performance. Lean blowout limits, which are often measured for turbine engine applications where lower combustor gas temperatures are desirable, are not of significant interest for scramjet applications. The blowout temperature limit measurement approach as of great interest to scramjet engine designers because it gives an indication of the minimum flight Mach number that an engine can be operated. Inlet air total temperature is a direct function of the flight Mach number, and is a weak function of altitude and other vehicle parameters at the high altitudes where scramjets normally operate.

Figure 3.4 shows typical axial pressure profiles through the combustor as the flameholder is operating. Top wall data points are black and a limited number of sidewall data points are yellow. The pressure distributions were taken just before blowout during runs 14.7, 15.1 and 15.12. Additional data for these and other blowout temperature test runs is shown in the tables of Appendix A. The cavity is located near the $\mathrm{x}=20$ inch location between the dashed lines. Three different mechanical throttle positions allow three different back-pressure levels, three Pratio values, and three different shock train positions in the upstream duct. Images collected during the same three runs (extracted from the standard $15 \mathrm{fps}$ video) are shown in Figure 3.5. The side window views show significant propagation of the flame upstream of the 
cavity. For these cases the fuel is injected from the $\mathrm{CC}$ site, therefore some of the fuel must be traveling upstream into the isolator through separated flows near the walls. The bottom wall view, collected simultaneously shows there is significant flame along the sidewalls. These single frames do not capture the high level of flame movement for the Pratio 2.5 and 3.5 cases seen in the video. In the Pratio 2.5 case the flame erratically moves upstream of the cavity along the center as well as up the side walls. In the Pratio 3.5 case the flame often, but not always, is seen to move from sidewall to sidewall in successive frames. This is illustrated in Figure 3.6 where several successive frames from the $15 \mathrm{fps}$ video are presented. In the figure $t_{\text {blowout }}$ represents the time that blowout occurs. Three images collected through the side window from the high speed video camera set at 50,000 fps during a run where the shock train position is changed by moving the throttle are shown in Figure 3.7. There appears to be a tendency for less upstream flame propagation to occur at higher Pratio levels. This is because the separated flow zones in the isolator tend to occur further upstream when the shock train strength is high.

\section{Results showing parametric sensitivities}

Results of flameholding measurements made by ramping inlet air temperature down until the blowout temperature is reached are shown and discussed in the section below. Tables of flowfield conditions just prior to blowout are presented in Appendix A for the results plotted in this section. The baseline case (shown as black circles in the figures below) uses the Mach 2.2 inlet nozzle, ethylene fuel from the CC site, the lower inlet air flowrate of about $4 \mathrm{lbm} / \mathrm{sec}$ and a Pratio level of 3.5. To provide more detailed information on the flowfield environment and data collected, additional information on the inlet nozzles is provided in Appendix B, and detailed information about baseline run 14.7 is presented in Appendix C. This run data can be used as a validation test for future simulations and analysis. Sensitivity to a variety of parameters off the baseline were also determined.

Sensitivity to pressure by varying shock train strength

Figure 3.8 shows the effect of Pratio (and therefore shock train location) on the blowout temperature. The plot on the top left presents the overall equivalence ratio on the vertical axis and the inlet air total temperature when blowout occurs on the horizontal axis. Note that in these tests the cavity pressure has different values for each Pratio condition but the inlet pressure and inlet flowrates were nominally the same. The position of the shock train has a significant effect on the inlet conditions into the flameholder and, therefore, the local flowfield over and in the flameholder. Rough trend lines are drawn through the data in the plot but there is significant run to run variation and spread in the plots. The estimated uncertainty of the individual $\mathrm{Tt}$ air measurements is about $3 \%\left(+/-45^{\circ} \mathrm{R}\right)$, so the $+/-150{ }^{\circ} \mathrm{R}$ spread in the data is because of the stochastic nature of the blowout process and not due to the uncertainty of the Tt air measurement itself. The measurements near an overall equivalence ratio of 0.1 were averaged and plotted in the column chart on the bottom right side of the figure to better quantify the results. The bars on each column represent the uncertainty of the mean value using the available measurement samples. The uncertainty of the Pratio 2.5 case is higher than the Pratio 3.5 case because only 3 versus 9 measurement samples were available. The two higher Pratio cases, 2.5 and 3.5, produced similar mean blowout temperatures of $1472{ }^{\circ} \mathrm{R}$ and $1502^{\circ} \mathrm{R}$, respectively. The difference in the means is not significant based on the data available. The Pratio $=1.5$ case, where the flameholder is operating in a scram-type operating mode, produced a significantly higher mean blowout temperature of $1746^{\circ} \mathrm{R}$ compared to the Pratio 3.5 case where the flameholder is operating as in a dual-mode engine. This is consistent with the expected trend that higher Pratio produces lower velocities, high pressure and higher static temperatures in and around the flameholder making it easier to hold a flame at lower inlet air temperatures. 
Sensitivity to fuel injection location

Changes in fuel injection location have the potential to significantly modify local equivalence ratio distributions and temperature distributions and subsequently effect the flameholding mechanism and limits. A comparison of blowout temperature measurements with two fueling approaches is shown in Figure 3.9. The black data points and corresponding trend line are the same baseline condition data shown in the previous figure that utilized the CC fuel site located on the cavity closeout surface. The purple data points and corresponding trend line are the results when using the CE fuel site located upstream of the cavity. Both data sets used the same nominal inlet conditions and Pratio $=3.5$ condition. The trends are quite different with flameholding improving significantly with the CE site as fuel equivalence ratio increases. The "best" lowest blowout temperature was not determined because at the highest fueling levels blowout did not occur by the end of the run (see the data points inside the dashed circle). Video showed that the flame had an even greater tendency to hold on the sidewall, particularly at the highest fueling rates. Figures 3.10 and 3.11 show frames taken with the $15 \mathrm{fps}$ video which illustrate this.

Sensitivity to pressure due to varying flowrate

By increasing flowrate and maintaining a fixed Pratio level the operating pressure can be increased while not significantly changing other flowfield characteristics such as velocity or temperature distributions. Because all inlet flows are choked and at the same Mach number and temperature as the flowrate is increased, flowfield velocities are not expected to change significantly. Fuel/air momentum flux ratios also stay the same so fuel/air mixing is expected to not change significantly. Note that Reynolds numbers are higher in the high pressure case, but the Reynolds number are high enough that all flows are turbulent and mixing is not a strong function of Reynolds number (Reynolds number of the inflow based on duct height is 460,000, Reynolds number of the ethylene fuel jet based on injector diameter is about 170,000). This assumption of Reynolds number independent mixing should be studied further. So if the fuel/air mixing does not change significantly, increasing flowrate allows the effect of pressure on kinetics which effects flameholding to be accessed more directly than if back-pressurization is used. This also better simulates the sensitivity to vehicle altitude. At high altitude, where inlet flowrates are low and combustor pressure is low, flameholding is a concern. The results for ethylene fueling with the baseline condition (in black) and with twice the flowrate (in blue) are shown in Figure 3.12. Doubling the air flowrate causes flameholder pressure to double, causing the mean blowout temperature to decrease by $111^{\circ} \mathrm{R}$, about $7 \%$. There is a $+/-110^{\circ} \mathrm{R}$ to $165^{\circ} \mathrm{R}$ spread in the blowout temperature measurements for the low flowrate and high flowrate case, respectively. This large spread makes the differences in the mean values statistically insignificant for the limited number of measurement samples available. Note that a $111^{\circ} \mathrm{R}$ change in inlet air total temperature corresponds to a relatively small change in flight Mach number, about Mach 3.6 versus Mach 3.8 for the mean Tt inlet values of $1391{ }^{\circ} \mathrm{R}$ and $1502{ }^{\circ} \mathrm{R}$ measured here.

\section{Sensitivity to higher inlet Mach number}

Higher inlet Mach number corresponds to higher simulated flight Mach numbers and can significantly change the flow around the flameholder. The calculated test conditions presented in Figure 2.4 shows that with the Mach 3.3 inlet the 1-D Mach number at the exit of the isolator stays above 1, even at a high Pratio of 5. The low Cd value of 0.54 indicates there is significant non-uniformity and mixed supersonic/ subsonic flowfield over the flameholder region. In the regions of the flow where the velocity is high, 2393 $\mathrm{ft} / \mathrm{sec}$ shown in the table, flameholding will be difficult to maintain. In regions where the velocities are low, recirculation zones can be present and flameholding can be enhanced. The results presented in Figure 3.13 show that the blowout temperature was quite insensitive to the inlet Mach number for the Pratio $=3.5$ case, comparing blue to black data points. Note that there are significant differences in operating pressure, static temperature distributions and velocity distributions between the two cases that 
complicate the comparison. Inlet flowrate was 18\% lower using the Mach 3.31 inlet versus the Mach 2.2 inlet, $3.3 \mathrm{lbm} / \mathrm{s}$ versus $4.0 \mathrm{lbm} / \mathrm{s}$, respectively, but the cavity pressure was significantly lower when using the higher Mach number inlet, about 9 psia versus 21 psia with the low Mach nozzle. The sensitivity to Pratio is stronger with a Mach 3.31 inlet (seen in Figure 3.13) than with a Mach 2.2 inlet (seen in Figure 3.8). Comparing blue to red data points shows blowout temperature is about $420^{\circ} \mathrm{R}$ higher with Pratio 2.5 versus with 3.5. The Pratio 5 case shows a significantly lower blowout temperature of about $1250^{\circ} \mathrm{R}$.

\section{JP-7 blowout temperature measurements}

A limited number of tests with JP-7 fuel were performed because jet fuel is more likely to be used in a flight system due to the higher storage density available with liquid fuels. The JP-7 was heated and injected in a vapor state at $900 \mathrm{~F}$ to simulate the effect of using the fuel as both a coolant and a combustor fuel in a fuel-cooled flight engine design. Reaction rates of kerosene type jet fuels are lower than ethylene so that blowout temperature is expected to be higher with JP-7. The results shown in Figure 3.14 agree with this. The blowout temperatures measured near optimal equivalence ratios is approximately $1650{ }^{\circ} \mathrm{R}$, about $150{ }^{\circ} \mathrm{R}$ higher than the baseline ethylene results seen in Figure 3.8. The JP-7 testing was performed early in the test program before automated control of the Pratio condition was implemented so there is more scatter in the Pratio values during JP-7 testing than during the ethylene testing, the tables presented in Appendix A shows Pratio varied from 2.8 to 4.0 during the JP-7 testing. A weak sensitivity of blowout temperature to operating pressure is seen in the JP-7 fueled tests as it was with the ethylene tests. Figure 3.8 shows a second data series for cases where the inlet flowrate was doubled so that cavity flameholder pressure was increased. No significant change in the blowout temperature was observed. Data points taken at overall equivalence ratio of about 0.1 indicate $\mathrm{a}+/-100^{\circ} \mathrm{R}$ spread in the data.

Sensitivity to air vitiation- measurements from the UVa facility

Measurements made in the UVa scramjet combustor facility with a back-pressured cavity flameholder showed no significant effect of steam addition on the blowout temperature. Results are shown in Figure 3.15 where overall equivalence ratio versus blowout temperature is plotted. For each data point the fuel and air flowrate are held constant and the inlet air temperature is ramped down until blowout of the flame in the cavity occurs. All tests were performed with the same nominal inlet air flowrate. The red squares represent cases where no steam was added and the green triangles represent cases where $6.7 \%$ mole fraction of steam was added to the inlet air. Several equivalence ratios were tested near an overall level of 0.1 where it is expected that the cavity flameholder will be close to local stoichiometric condition that optimize the ability to flamehold. A lean case was also tested with an overall equivalence ratio of 0.02 . The clean versus vitiated air blowout temperatures are the same within the scatter of the data. More details on these UVa facility tests are shown in the report in Appendix D. Note that the UVa facility blowout temperatures where as low as $1000{ }^{\circ} \mathrm{R}$, significantly lower than the UTRC facility results for similar ethylene fueled runs where min blowout was closer to $1400{ }^{\circ} \mathrm{R}$. Figure 3.15 shows a plot of data from both facilities. The lower blowout temperature was not expected while using a smaller cavity, 0.356 inches deep in the UVa facility versus a 0.65 inch deep cavity used in the UTRC facility. There are some significant differences between the two tests so the comparison is not straightforward, features of the two data sets are listed here:

UVa facility:

Mach 2 inlet

1.0 inch high by 1.5 inch wide flowpath at the entrance

Constant area isolator

0.356 inch deep cavity

5 CC injectors 
Pratio 4.3

Pcavity pressure of 24 psia

Steam mole fraction $6.7 \%$.

UTRC facility:

Mach 2.2 inlet

$13 \mathrm{CC}$ injectors

1.666 inch high by 6.0 inch wide flowpath at the entrance

0.6 degree divergence in the isolator

Pratio 3.5

Pcavity psia

Steam mole fraction $6.7 \%$ at $1400{ }^{\circ} \mathrm{R}$ to $10.9 \%$ at $1950{ }^{\circ} \mathrm{R}$

\section{Summary of sensitivity tests}

The sensitivity of flameholding limits to a variety of flowfield conditions that are relevant to the operation of a dual mode scramjet combustor was measured by performing combustor tests where inlet air temperature was ramped down till blowout occurs. Flameholding was most sensitive to the fuel injection location. The measurements showed it was possible to hold a flame to a significantly lower inlet air temperature when using the CE fuel injectors at high fuel flowrates. The flameholding limit was not strongly sensitive to the position of the shock train upstream of the cavity flameholder until the shock was positioned very close to the leading edge of the cavity where the blowout temperature increased. The blowout temperature was not strongly sensitive to flameholder pressure using either ethylene or JP-7 fuel. The mean blowout temperature when using heated vaporized JP-7 was about $150{ }^{\circ} \mathrm{R}$ higher than when using room temperature ethylene. The blowout temperature was also not sensitive to steam addition at levels of $6.7 \%$ mole fraction, a vitiation level that is consistent with facilities that use hydrogen combustion heated air.

\section{High speed measurements to capture flowfield dynamics}

Dynamics of the flowfield was studied using high speed video and high speed pressure measurements in the cavity region. The measurements presented in the previous section provide average flow properties near the flameholding limit, but the mechanisms that limit flameholding are associated with unsteady phenomena such as turbulence levels, unsteady shock boundary layer interactions, mixing, reactions and flame dynamics. The goal of collecting video of the flame and time resolved pressures was to better understand the unsteadiness of the flowfield to help identify processes that limit the flameholding. Significant unsteadiness and asymmetry of the flame was observed in the video. The role of the sidewalls appears to be very important in the flameholding process for the rectangular shaped flowpath tested. Separated recirculating flows that propagate the flame upstream of the cavity flameholder were observed. These recirculation zones can increase aerodynamic size of the flameholder and improve the capability of the flameholder, e.g. allow flameholding at lower inlet air temperatures and lower vehicle flight Mach numbers. Another goal of the high speed measurements was to indentify flow features or measurements that could be used in an engine control system to indicate blowout was eminent, but no significant indicators were found.

High speed video was collected using a Phantom v12 digital high speed camera. Frame rates from 50,000 to 20,000 fps were used and exposure time was typically set at $10 \mu \mathrm{s}$. No filtering of the flame emission was implemented. Views through both the side and the bottom windows were collected simultaneously using a 45 degree mirror below the test rig, as was done with standard video presented previously. The 
view through the side window is across the 6 inch wide flowpath so integrated emission intensities are collected. The bottom view allows lateral movement of the flame to be seen and looks directly up into the cavity. This view also includes a portion of the isolator upstream of the cavity so that movement of the flame can be seen in that region. Figure 3.17 shows four frames taken from the high speed video during run 14.16 (that used a baseline condition with ethylene fueling from the $\mathrm{CC}$ site, Ma inlet $=2.2$, Pratio of 2.5 , Pinlet $=7$ psia). The camera was set-up to collect 20,000 frames per second, with a $10 \mu$ s exposure time. The images shown are not successive frames, they are spaced 40 frames $(2 \mathrm{msec})$ apart and are typical of the rapidly changing flame structures seen in the high speed video collected during many runs. The flame is highly unsteady. In almost all frames some portion of the flame has propagated upstream of the cavity, a phenomena that can have a significant effect of the flameholding capability. Combustion upstream of the cavity makes the effective length and volume of the flameholder larger than if combustion was limited to occurring only inside the cavity. Emission from the shear layer above the cavity and upstream of the cavity is most intense indicating this is where combustion reactions are occurring. Emission inside the cavity is far from uniform so a perfectly stirred reactor environment is not present. In many instances there is no emission on one side of the cavity. The impact of the $13 \mathrm{CC}$ injector jets is not clearly visible, although at times there are observable "holes" in the emission distribution as seen in the bottom two images. Although at some times the flame propagates up the sidewalls and corners of the rectangular duct, where the boundary layer momentum is expected to be weakest, this is not always the case. Often the flame is in the center as well indicating the recirculation flow zones at the back of the isolator are moving laterally. Another important feature is that at almost no time has the flame spread across the entire lateral width of the duct, so a 2-D approach to modeling the phenomena is not practical.

High speed pressure measurements were made using a Kulite model XTE-190-100SG piezoelectric pressure transducer. The transducer has a high frequency response of about $100 \mathrm{kHz}$. The transducer is connected to a pressure tap in the floor of the cavity at the center of the cavity floor at the $X=19.18$ inch location using 1/16 inch stainless steel hypo tubing so that the transducer is located 2 inches from the flowpath. Data is collected at $8 \mathrm{kHz}$ with a $4 \mathrm{kHz}$ low pass filter. An example of high speed pressure measurements from run 14.16 is shown in Figure 3.18. Cavity pressure versus time is plotted over a $4 \mathrm{sec}$ period of time to show the level of pressure variations seen, mean pressure was 16.3 psia and RMS pressure was $0.82 \mathrm{psi}, 5 \%$ of the mean. Figure 3.18 shows frequency content of the signal. The power spectrum plot, shown at the bottom of the figure, is taken about $2 \mathrm{sec}$ before blowout occurs and is typical of spectra of the pressure signal from other runs as the combustor is running. The spectra is broad band with no narrow band peaks. The highest spectral power occurs at the low frequency end. There is a very broad feature near $800 \mathrm{~Hz}$ and almost no frequency content above about $1400 \mathrm{~Hz}$. A spectrogram of the data is shown at the top of the figure, and is typical of the results seen in the other runs. The spectrogram shows how the power spectra changes with time as the inlet air temperature is ramped down about $20{ }^{\circ} \mathrm{R}$ per second. Blowout occurs at 11.5 seconds in the plot. One of the objectives of taking high speed pressure measurements was to see if there are acoustic modes present in the flowfield that could be affecting flame stability and flameholding capability. No frequency modes were detected. If narrow band peaks occur in the power spectra they would appear as vertical bars in the spectrogram, but none are visible. The spectra does not appear to change when blowout is eminent, the colors in the spectrogram suddenly change at 11.5 seconds indicating less spectral energy when the blowout occurs. 

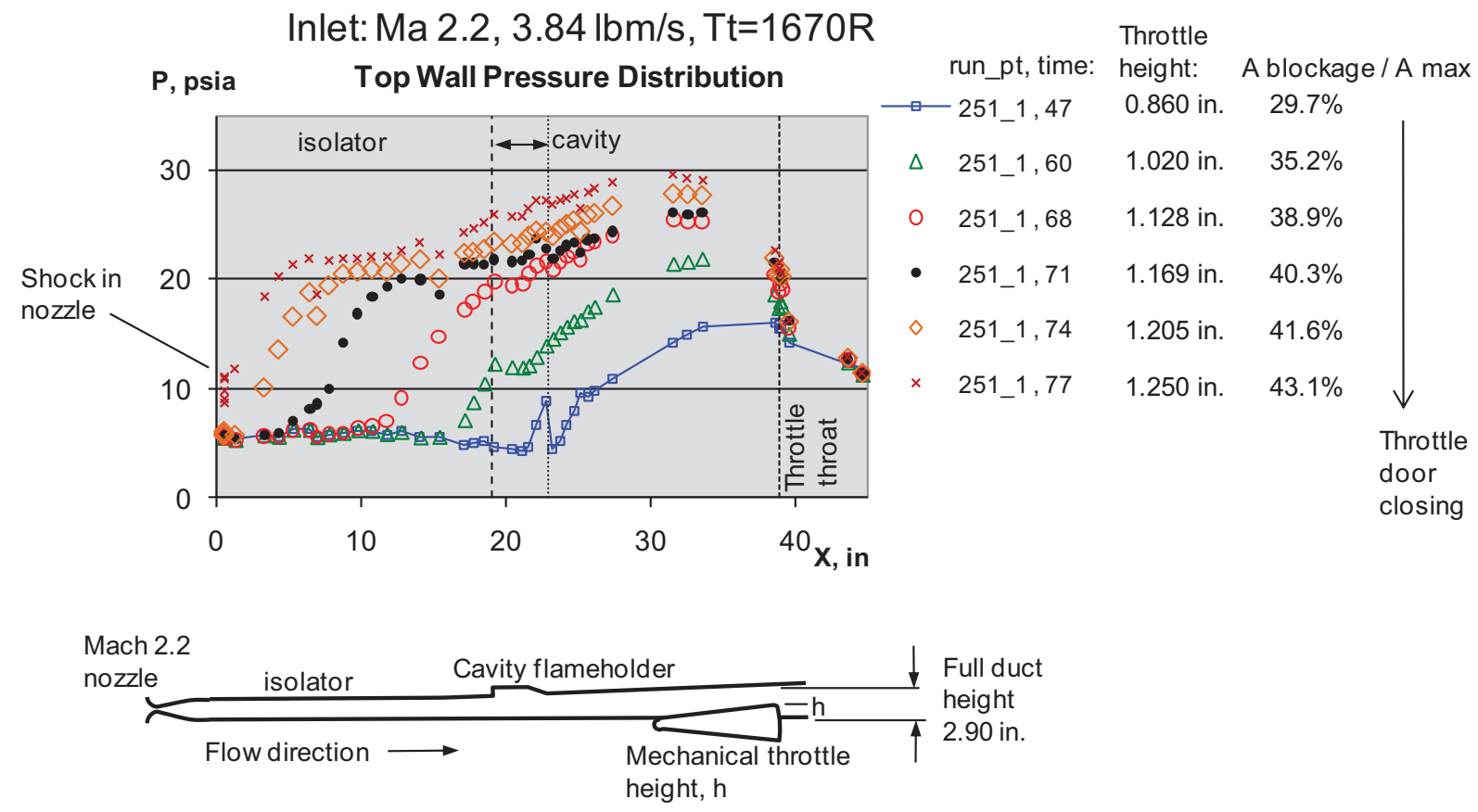

Figure 3.1. Non-combustion Tare run showing pressure distribution variation as throttle position changes. 
Rig pressures as throttle ramped closed

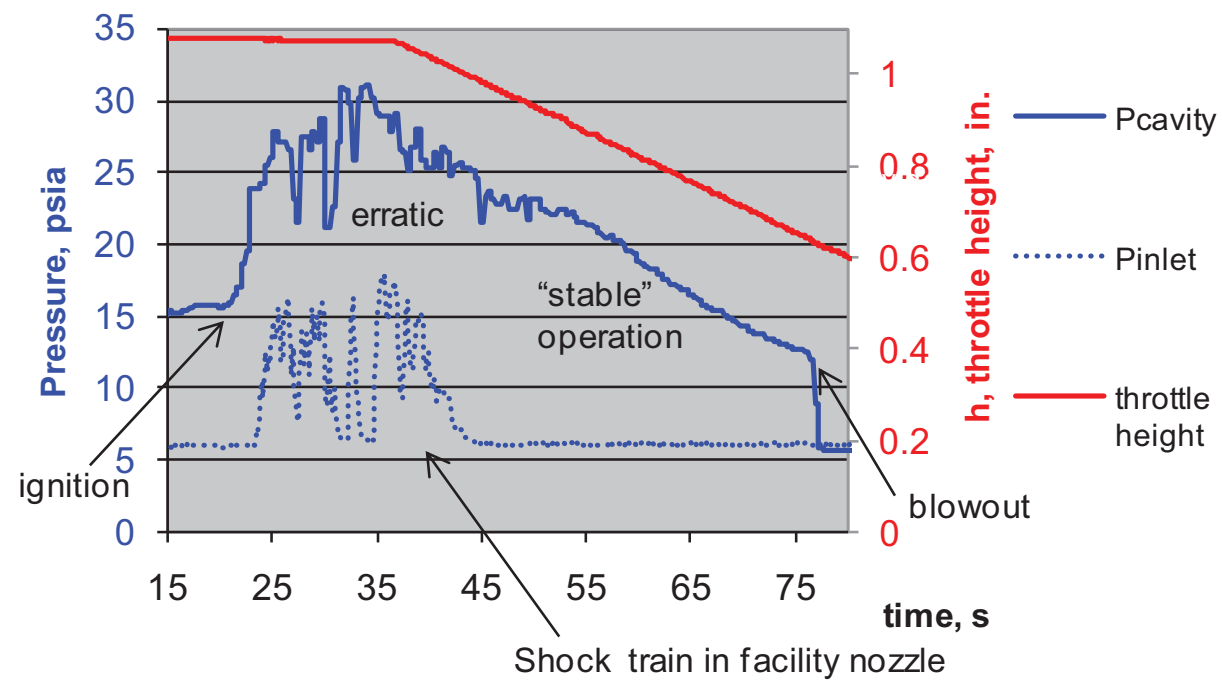

Inlet: Ma 2.2, $3.85 \mathrm{lbm} / \mathrm{s}, \mathrm{Tt}=1670 \mathrm{R}, \Phi=0.1$

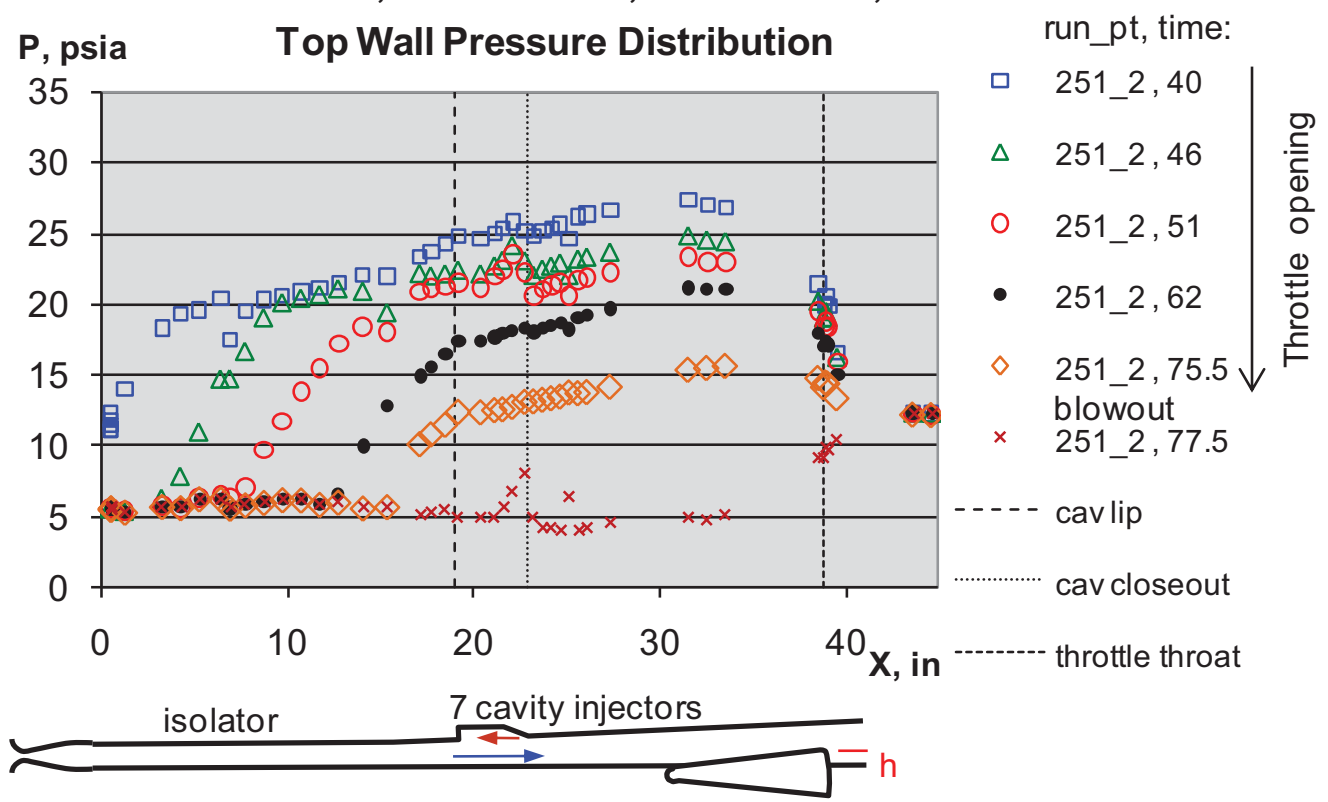

Figure 3.2. Throttle position opened moving shock train back till blowout occurs. 


\section{Rig pressures as fuel flow ramped down}

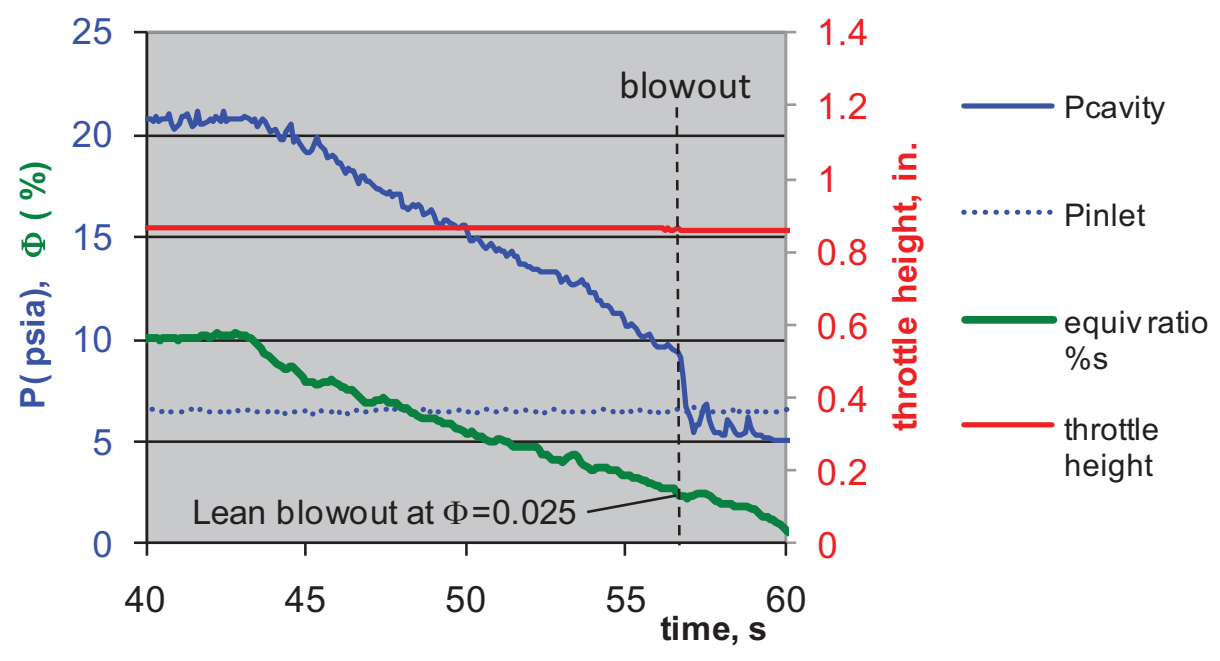

Inlet: Ma 2.2, $3.85 \mathrm{lbm} / \mathrm{s}, \mathrm{Tt}=1730 \mathrm{R}$

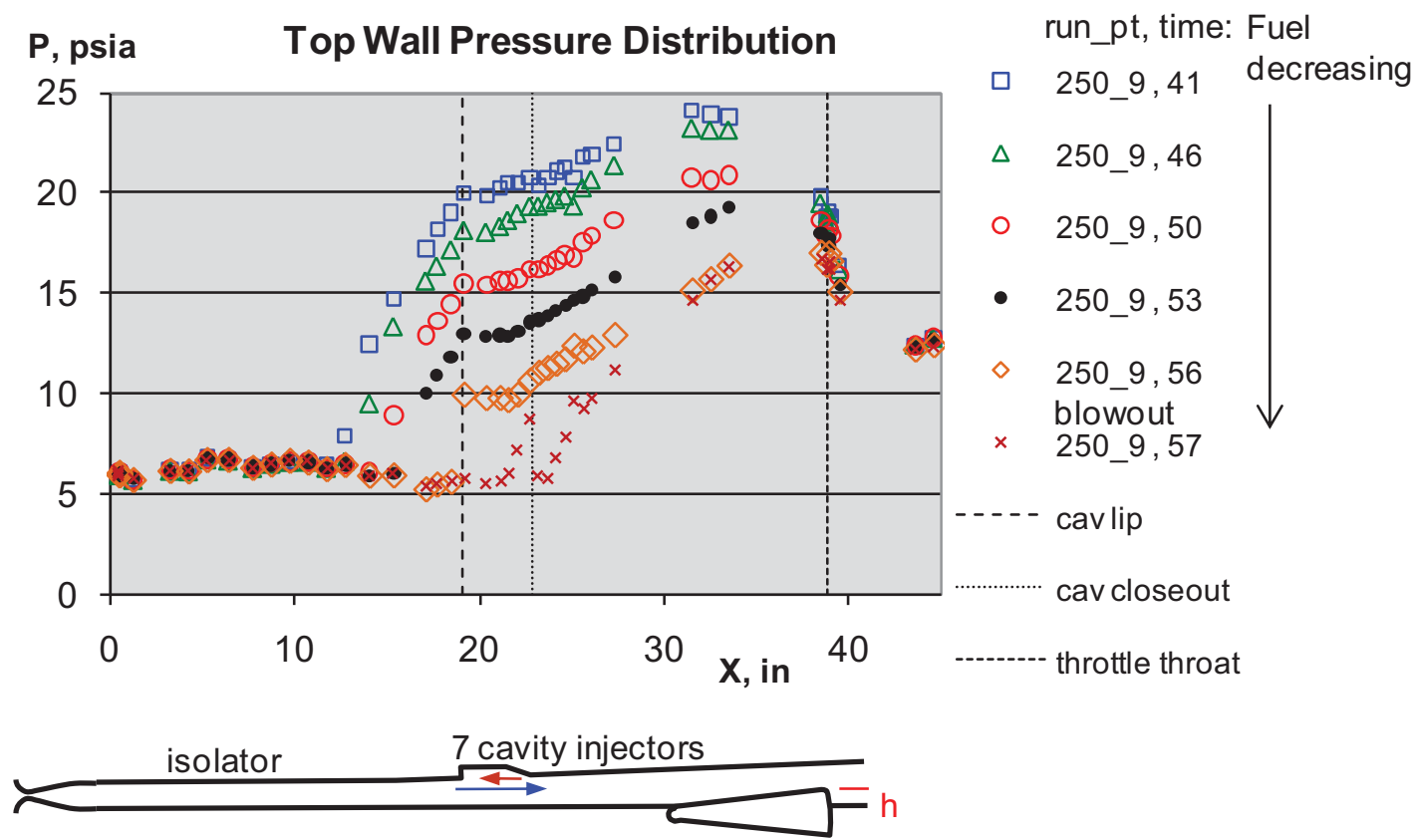

Figure 3.3 Fuel ramped down till blowout, throttle held fixed, but shock train position moves significantly. 

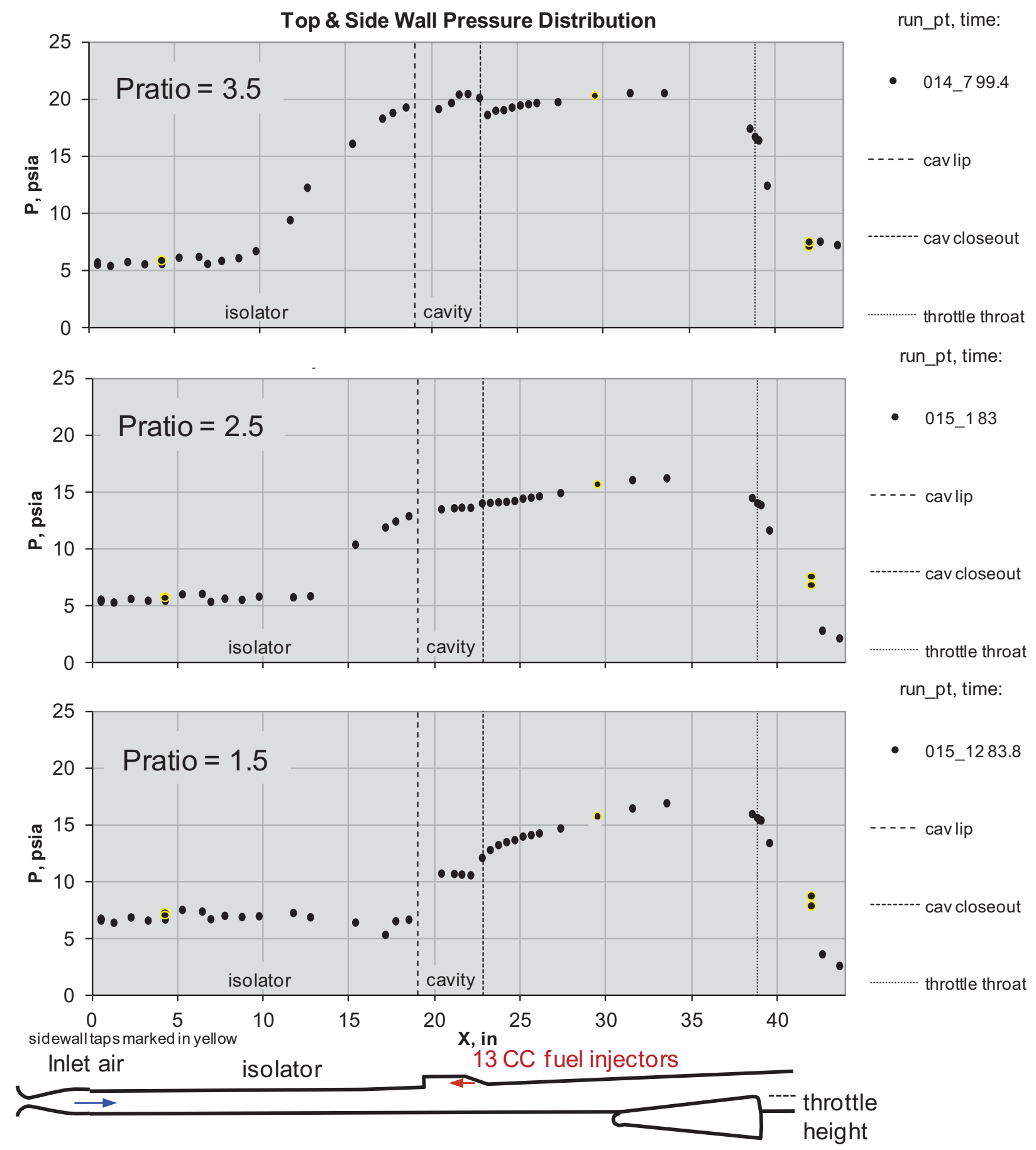

Figure 3.4 Pressure profiles through the flowfield with combustion for three different pressure ratios across the shock train during runs 14.7, 15.1, and 15.12. Each runs used a Mach 2.2 inlet and an ethylene equivalence ratio of 0.1 . 

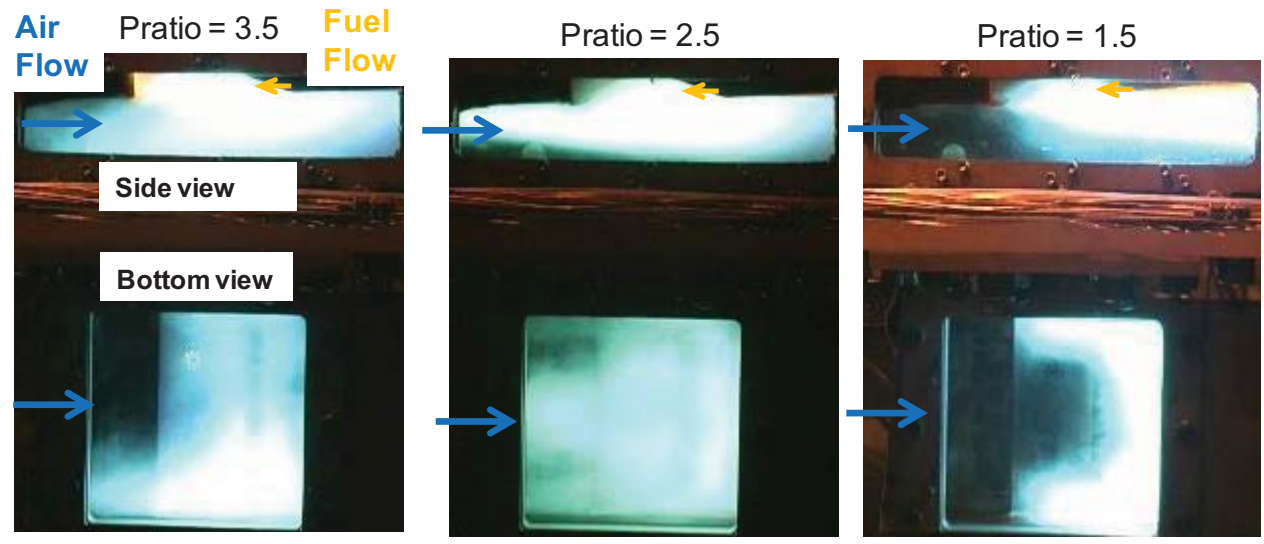

Figure 3.5. Frames extracted from the standard video camera (15 frames per second) showing side and bottom views of the flame structure for runs $14.7,15.1$, and 15.12 .

CC fueling, run $13.2, \Phi=0.11 \mathrm{Tt}$ air $=1455 \mathrm{R}$ at blowout
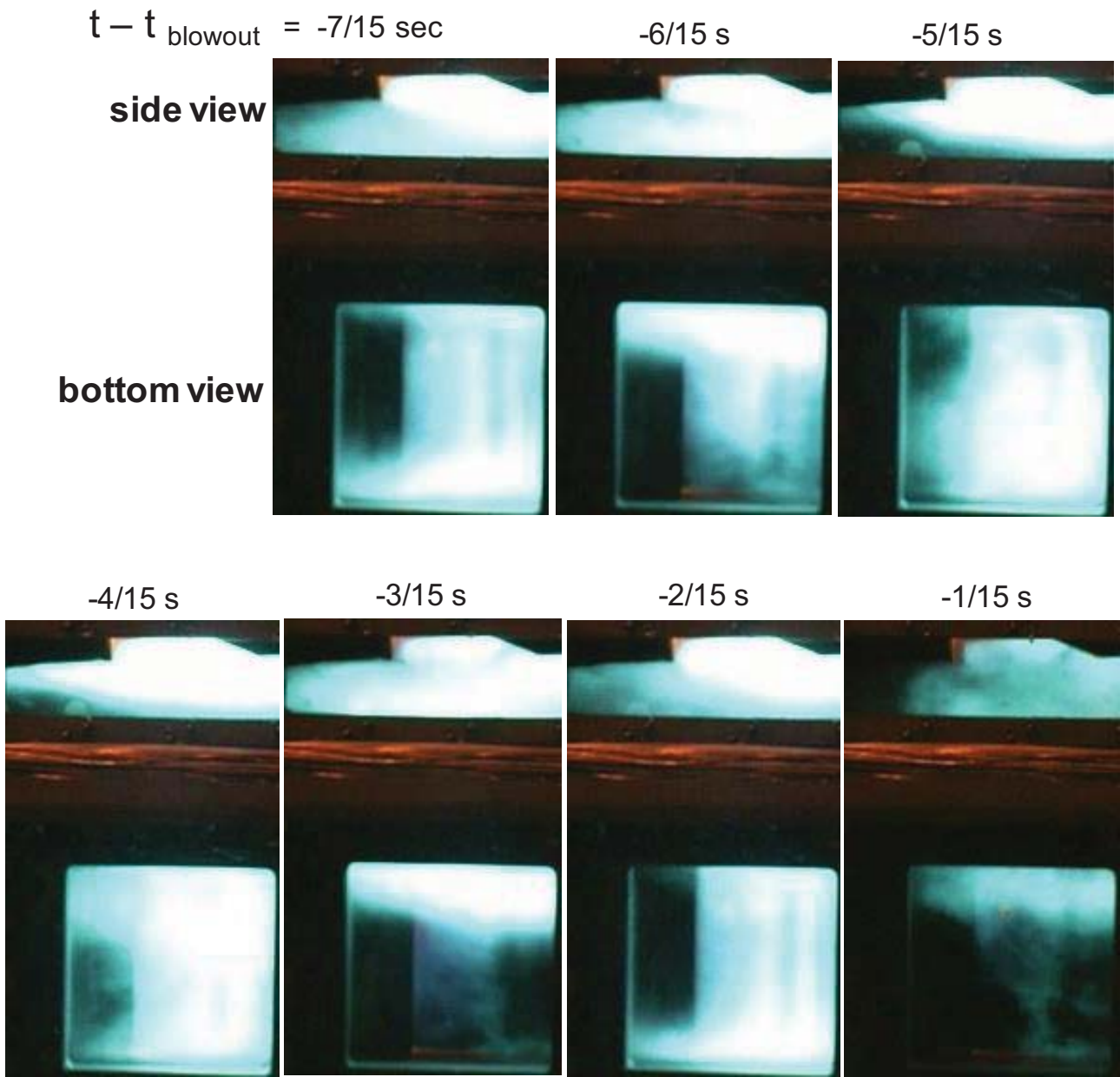

Figure 3.6 Successive images taken from the standard 15 frame per second video showing movement of the flame. Run 13.2, Mach 2.2 inlet, Pratio=3.5, ethylene fuel. 


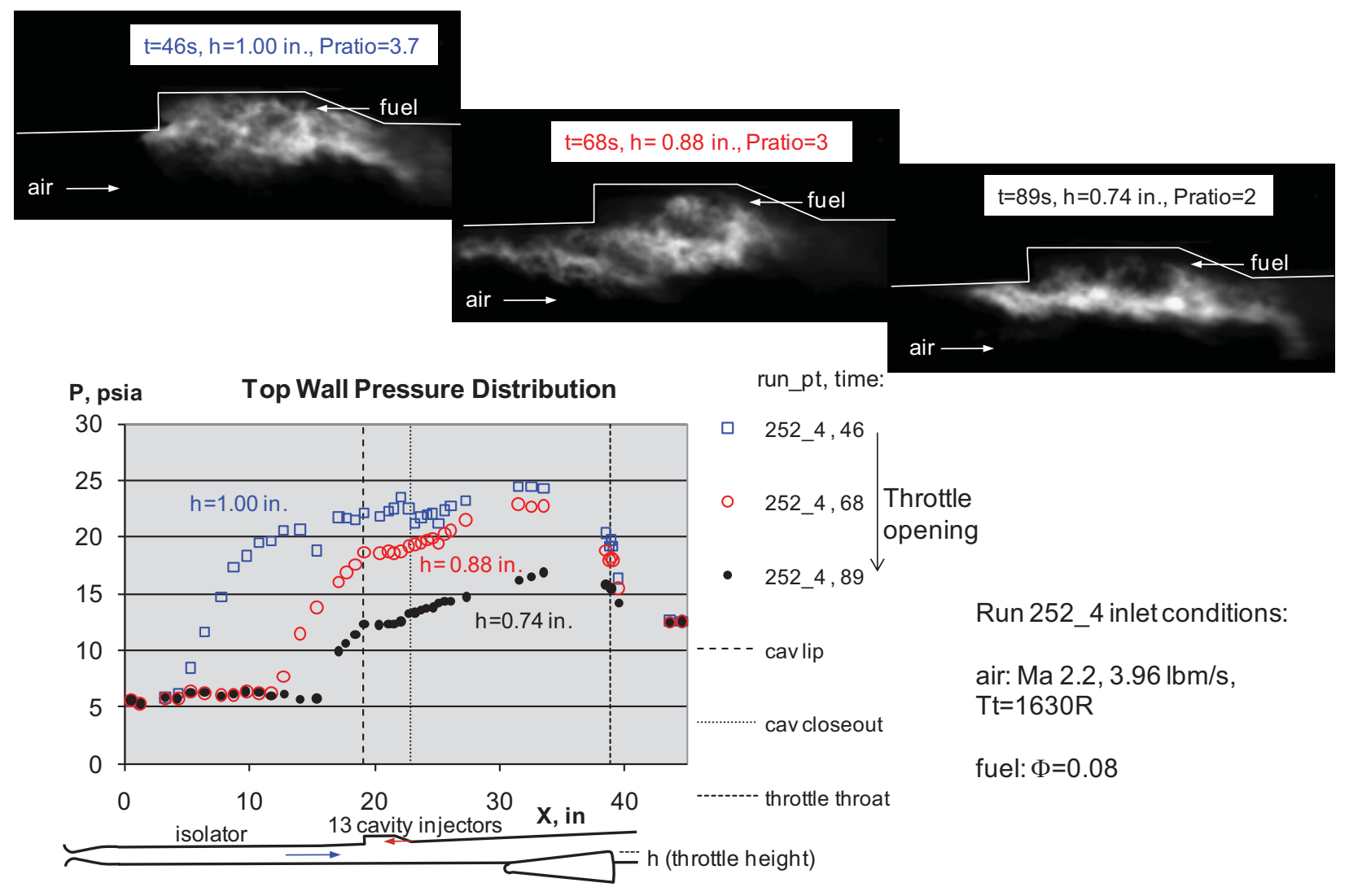

Figure 3.7 Flame images extracted from the 50,000 frame per second high speed video as the throttle is opened during run 252.4. The images indicate broadband flame emission intensity without any filtering with a $20 \mu$ s exposure time. 


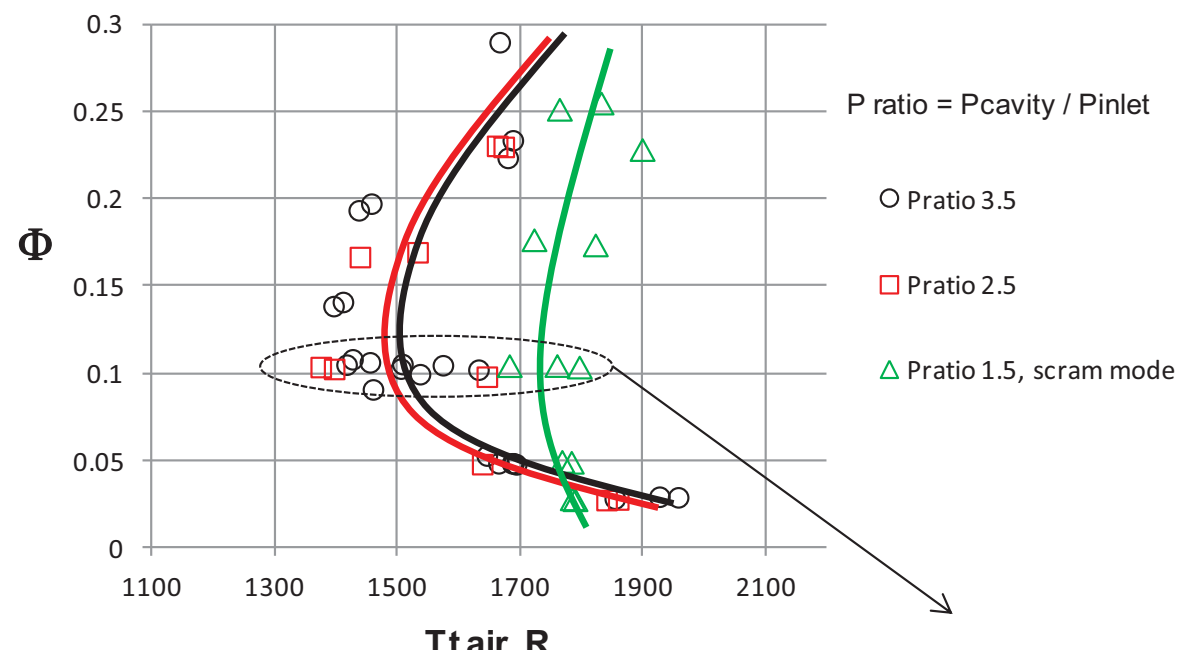

Tt air, $\mathbf{R}$

Mean Ethylene Blowout Temperature

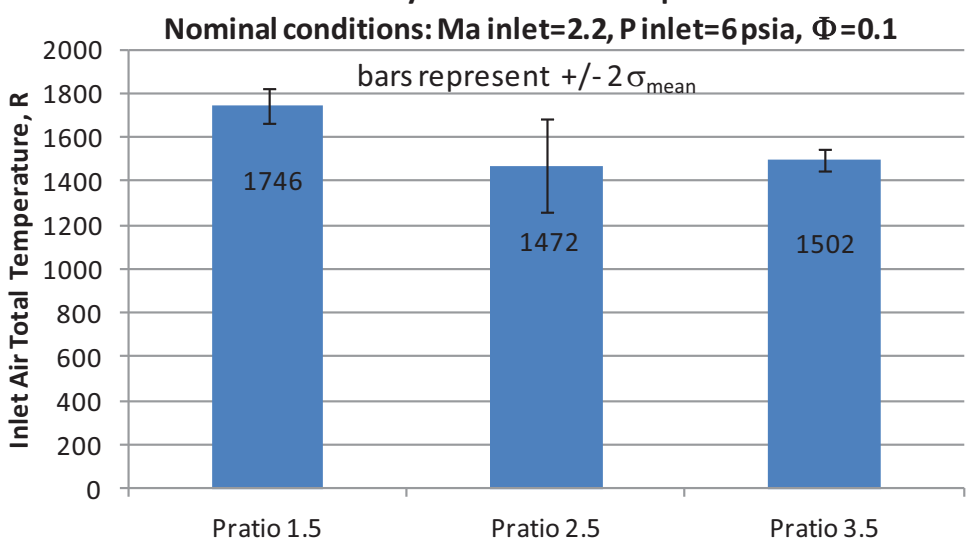

Figure 3.8. Blowout temperature measurements versus overall equivalence ratio for three different Pratio settings. All runs used a Mach 2.2 inlet, 6 psia nominal inlet pressure, 4 lbm/s inlet flowrate and ethylene fueling from the $\mathrm{CC}$ fuel site. 

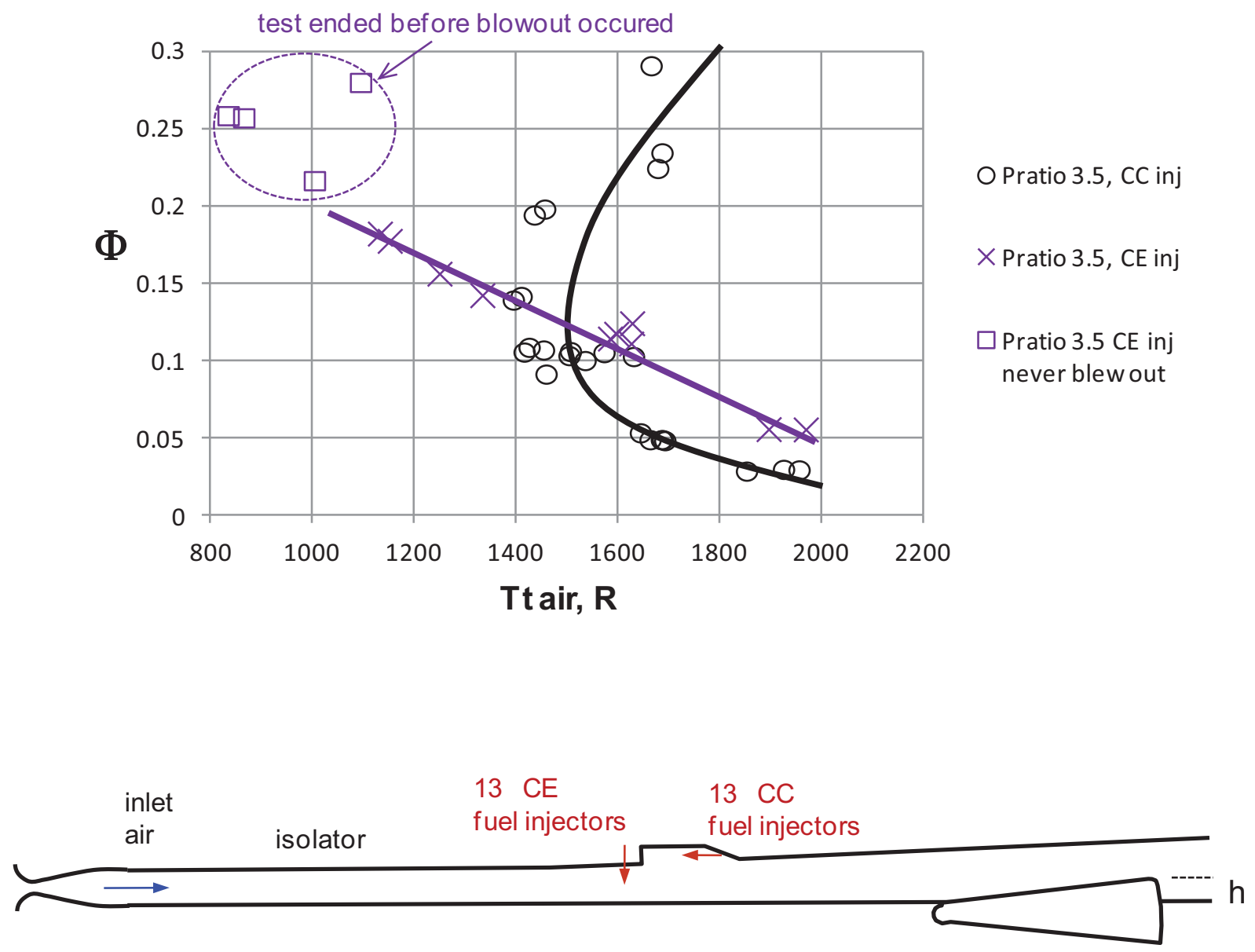

Figure 3.9 Blowout temperature measurements versus overall equivalence ratio and fuel injection location. All runs used a Mach 2.2 inlet, 6 psia nominal inlet pressure, $4 \mathrm{lbm} / \mathrm{s}$ nominal inlet flowrate and ethylene fueling from the $\mathrm{CC}$ or the $\mathrm{CE}$ fuel site. 


\section{CE fueling, run $17.2, \Phi=0.11 \mathrm{Tt}$ air $=1586 \mathrm{R}$ at blowout}
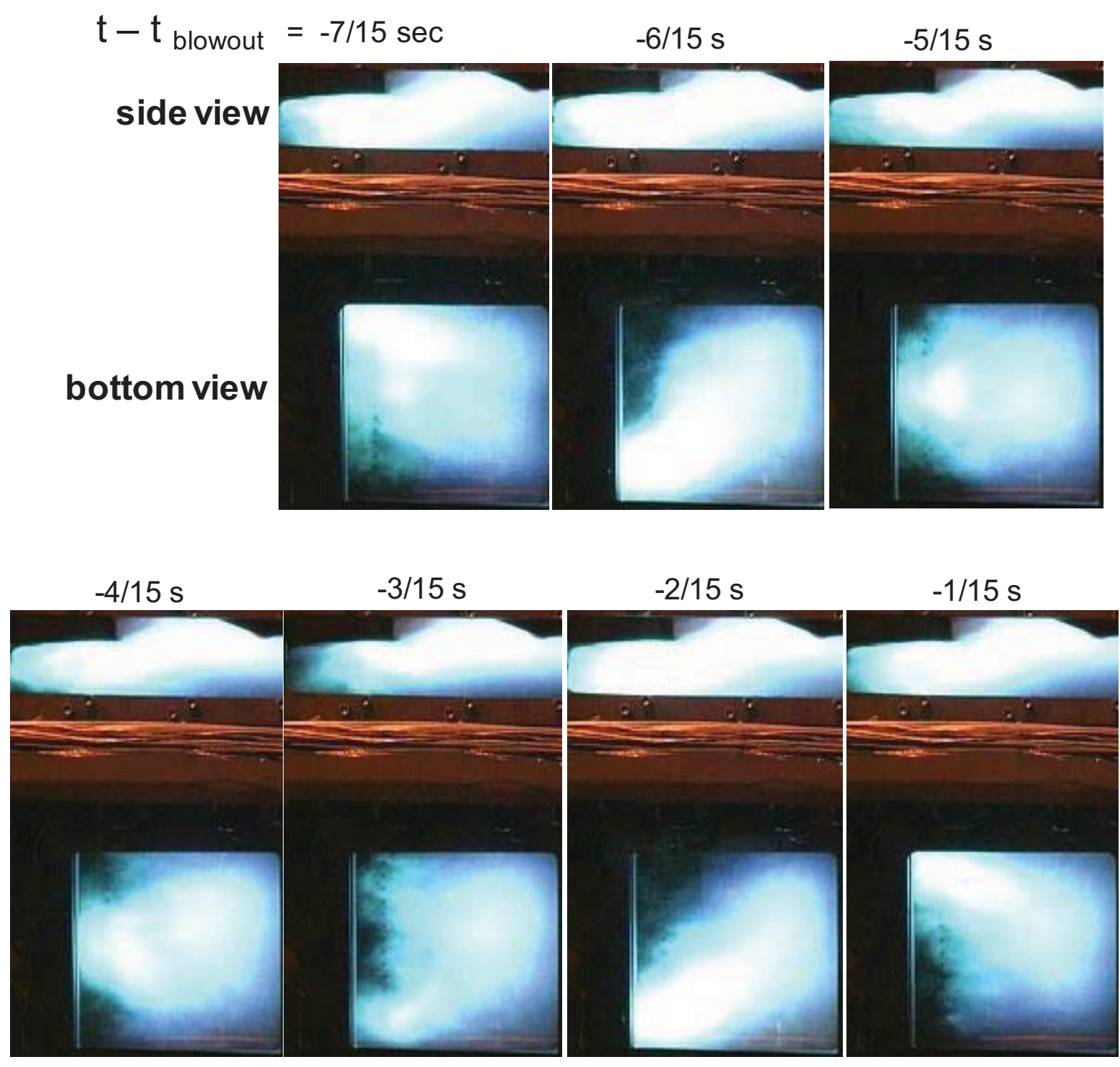

Figure 3.10 Images extracted from 15 frame per second standard video just before blowout occurs showing flame movement when CE fueling is used with a ethylene overall equivalence ratio of 0.11 . Blowout occurs just after the last image when $\mathrm{t}-$ tblowout $=0 \mathrm{sec}$. 


\section{CE fueling, run 17.11, $\Phi=0.26 \mathrm{Tt}$ air $=835 \mathrm{R}$ at blowout}
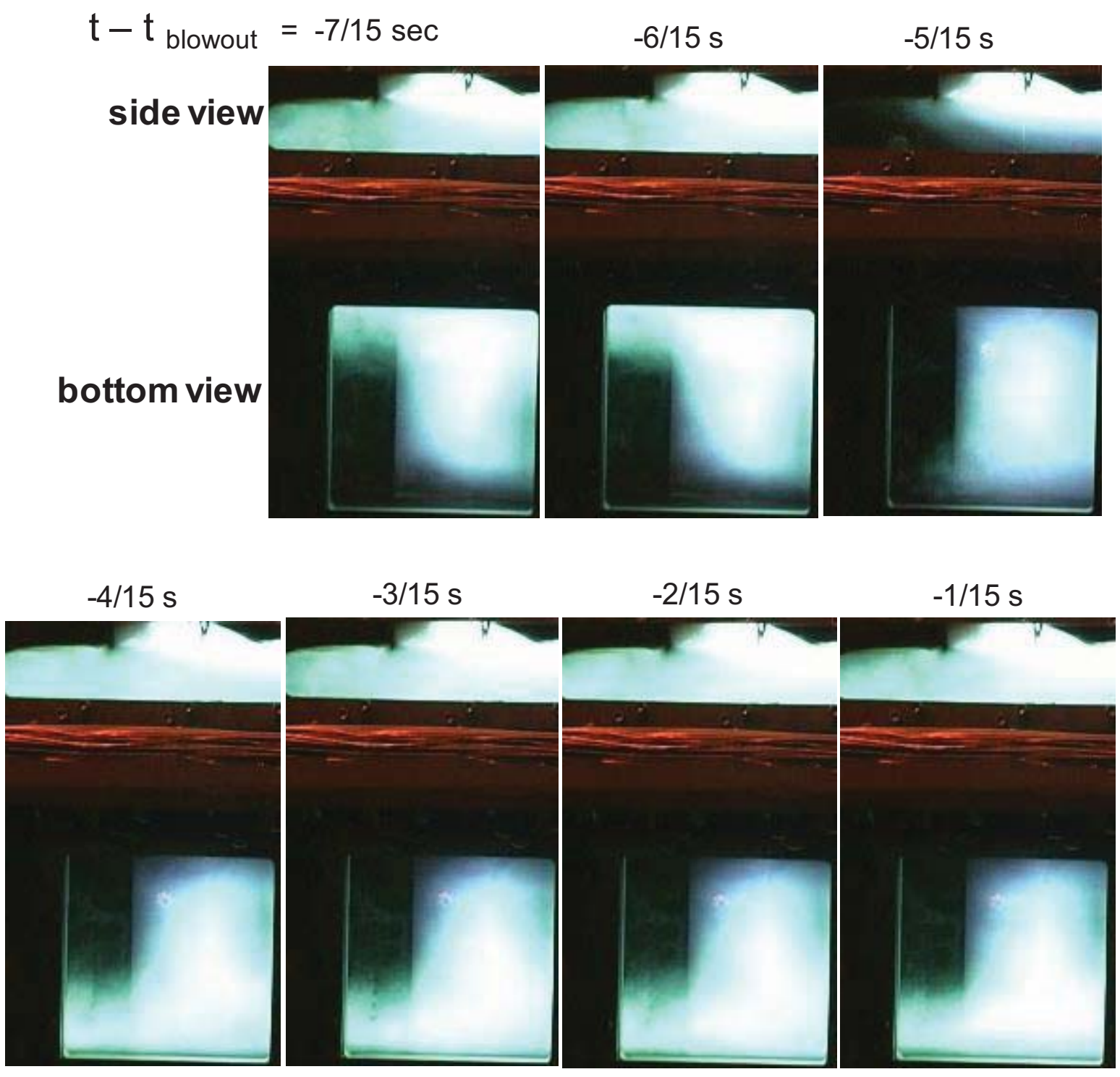

Figure 3.11 Images extracted from 15 frame per second standard video showing flame movement when $\mathrm{CE}$ fueling is used with a higher ethylene overall equivalence ratio of 0.26 . Blowout occurs just after the last image when $\mathrm{t}-$ tblowout $=0$ sec. 


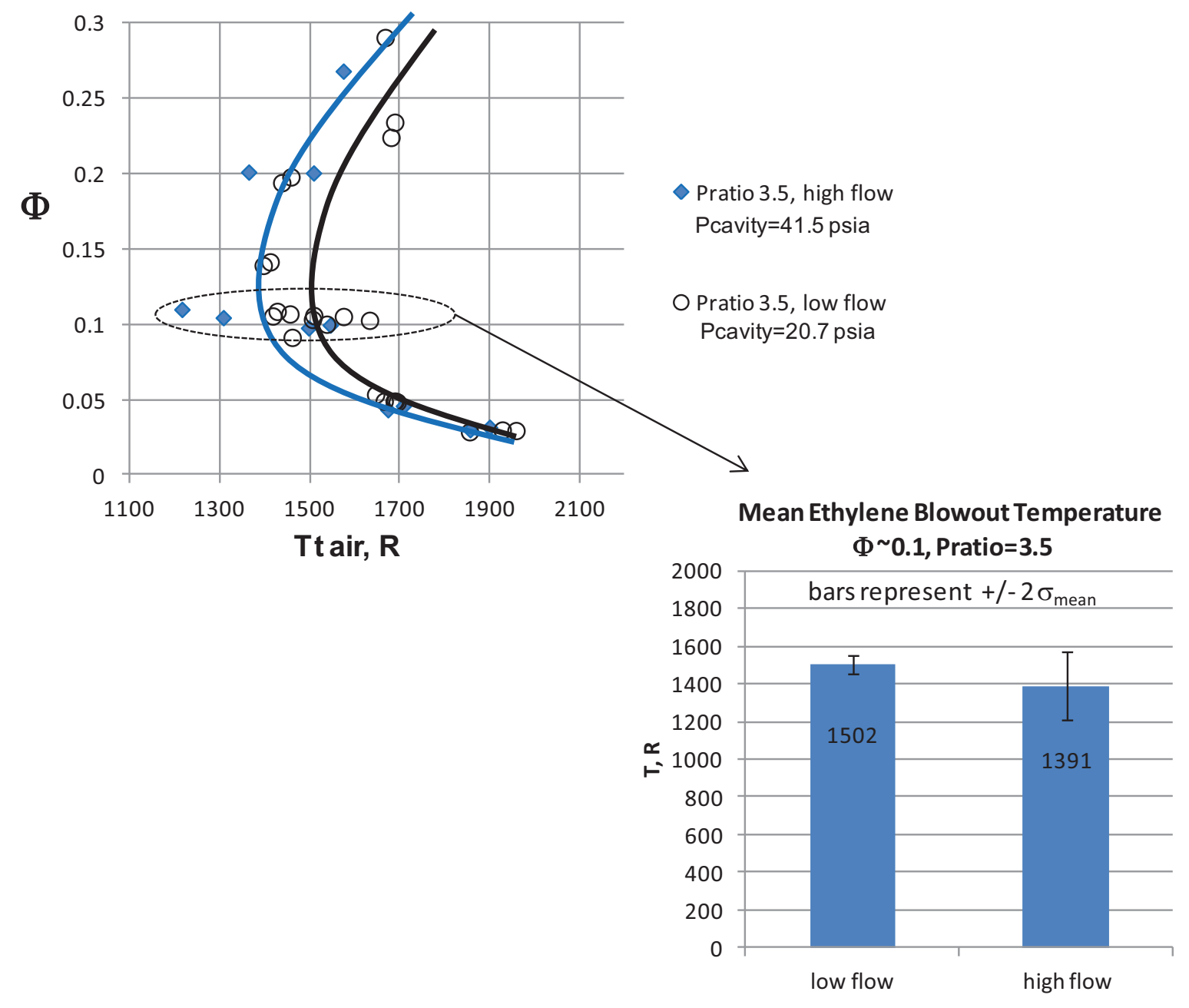

Figure 3.12 Blowout temperature measurements versus overall equivalence ratio and operating pressure by varying the nominal inlet flowrate, $4 \mathrm{lbm} / \mathrm{s}$ or $8 \mathrm{lbm} / \mathrm{s}$. All runs used a Mach 2.2 inlet and ethylene fueling from the $\mathrm{CC}$ fuel site. 


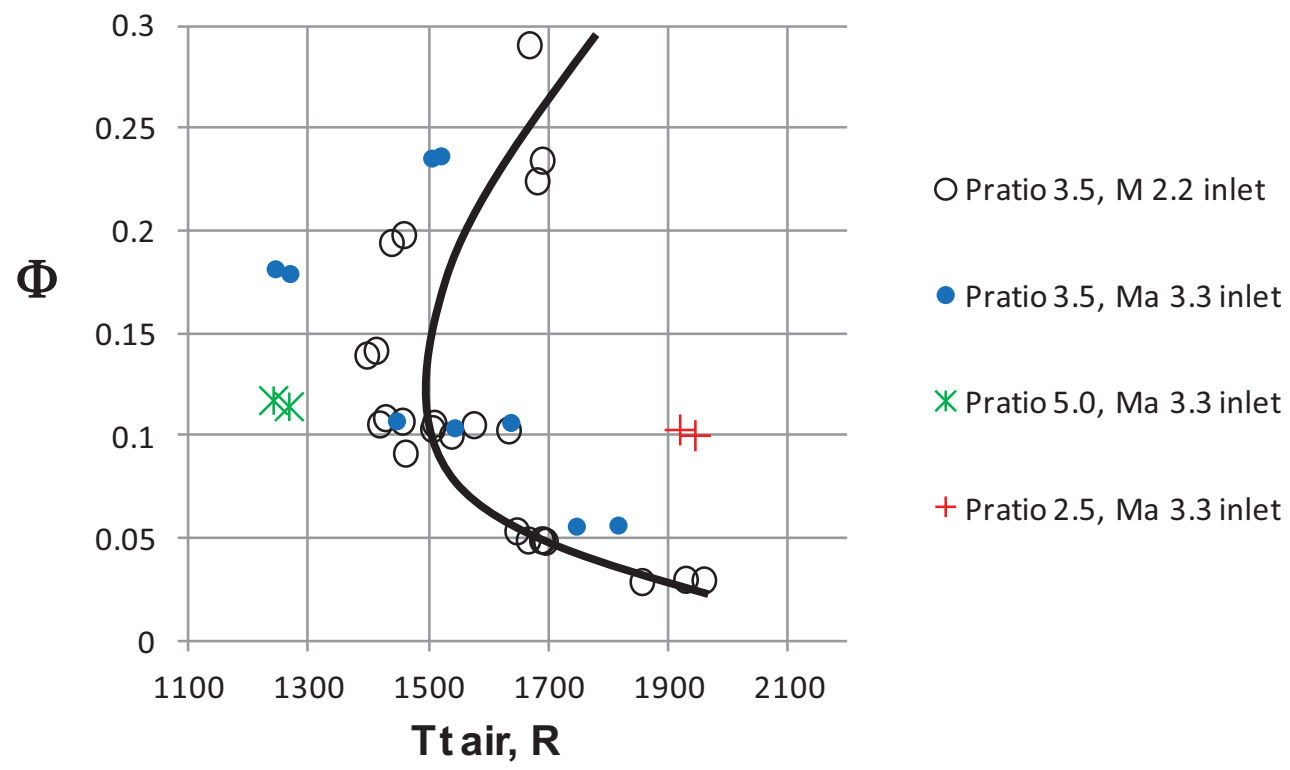

Figure 3.13 Blowout temperature measurements versus overall equivalence ratio, inlet Mach number and Pratio. All test runs used ethylene fueling from the $\mathrm{CC}$ fuel site. The Mach 3.3 inlet runs used a nominal inlet flowrate of $3.2 \mathrm{lbm} / \mathrm{s}$, the Mach 2.2 inlet runs used an inlet flowrate of $4 \mathrm{lbm} / \mathrm{s}$.

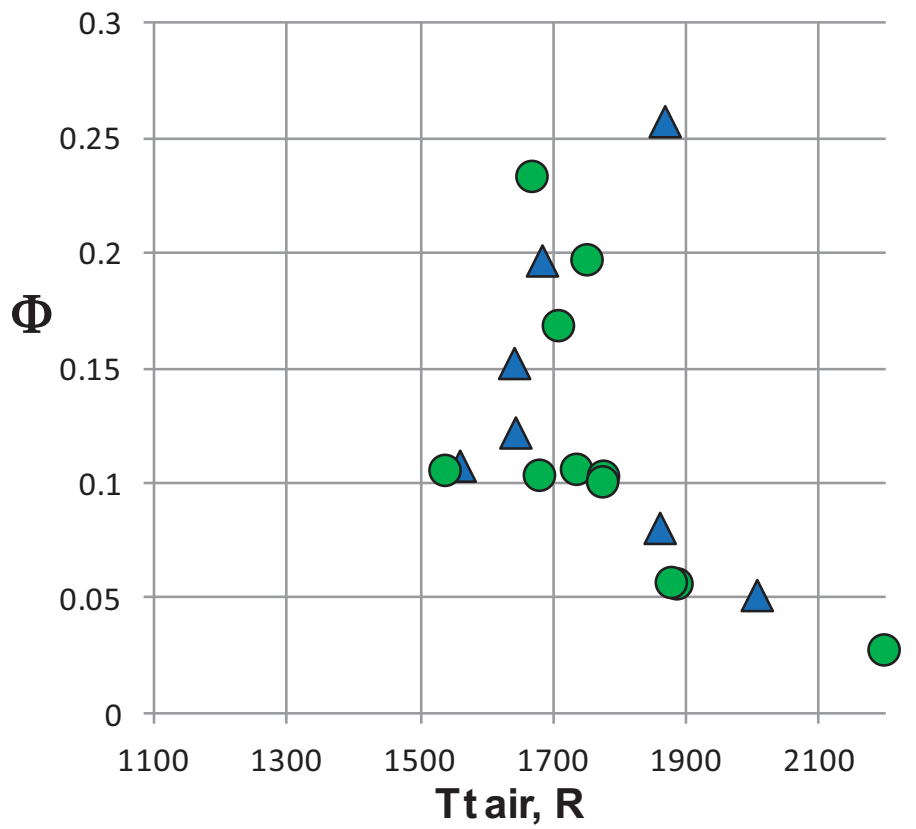

$\triangle \mathrm{JP}-7$ at $900 \mathrm{~F}$, Pcavity 23psia, Wair $4 \mathrm{lbm} / \mathrm{s}$

JP-7 at 900F, Pcavity 51 psi, Wair $8 \mathrm{lbm} / \mathrm{s}$

Figure 3.14. Blowout temperature versus overall equivalence ratio at two different operating pressures due to two different inlet flowrates with heated JP-7 fuel injected from the CC site with a Mach 2.2 inlet and Pratio=3.5. 


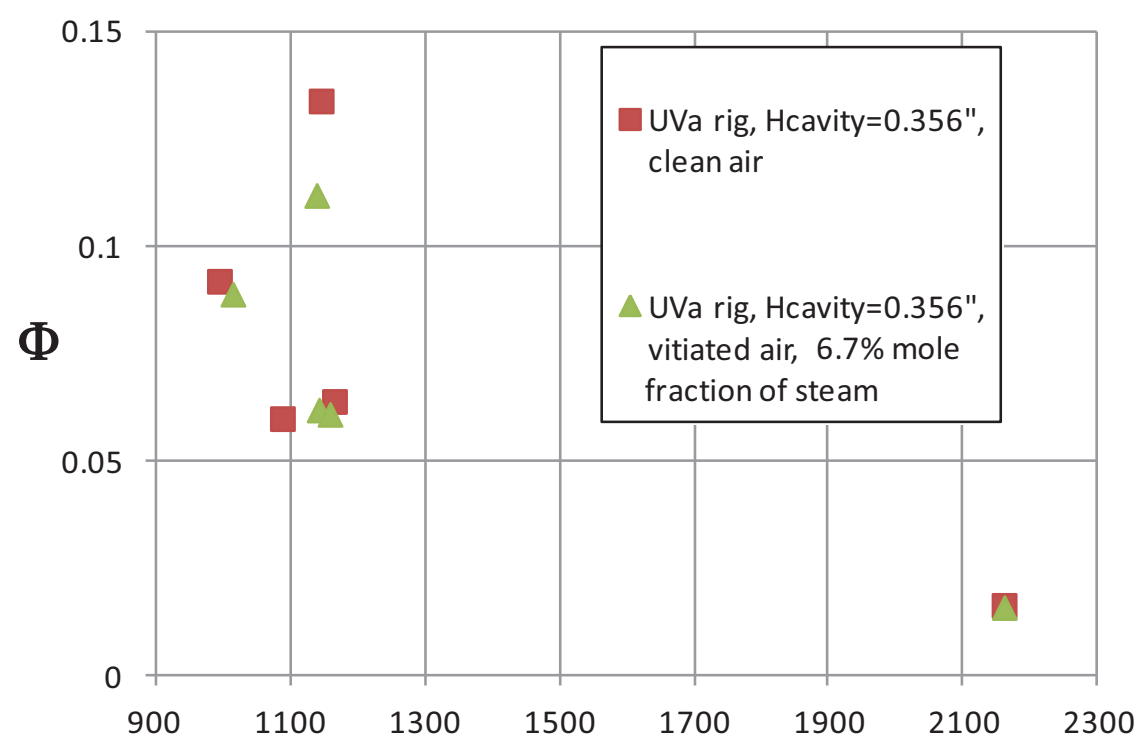

\section{Tt air, $R$}

Figure 3.15. Ethylene blowout temperature measured in the UVa test facility with clean air versus with $6.7 \%$ mole fraction of steam added to the inlet air. The results show the flameholding limit is not sensitive to vitiation.

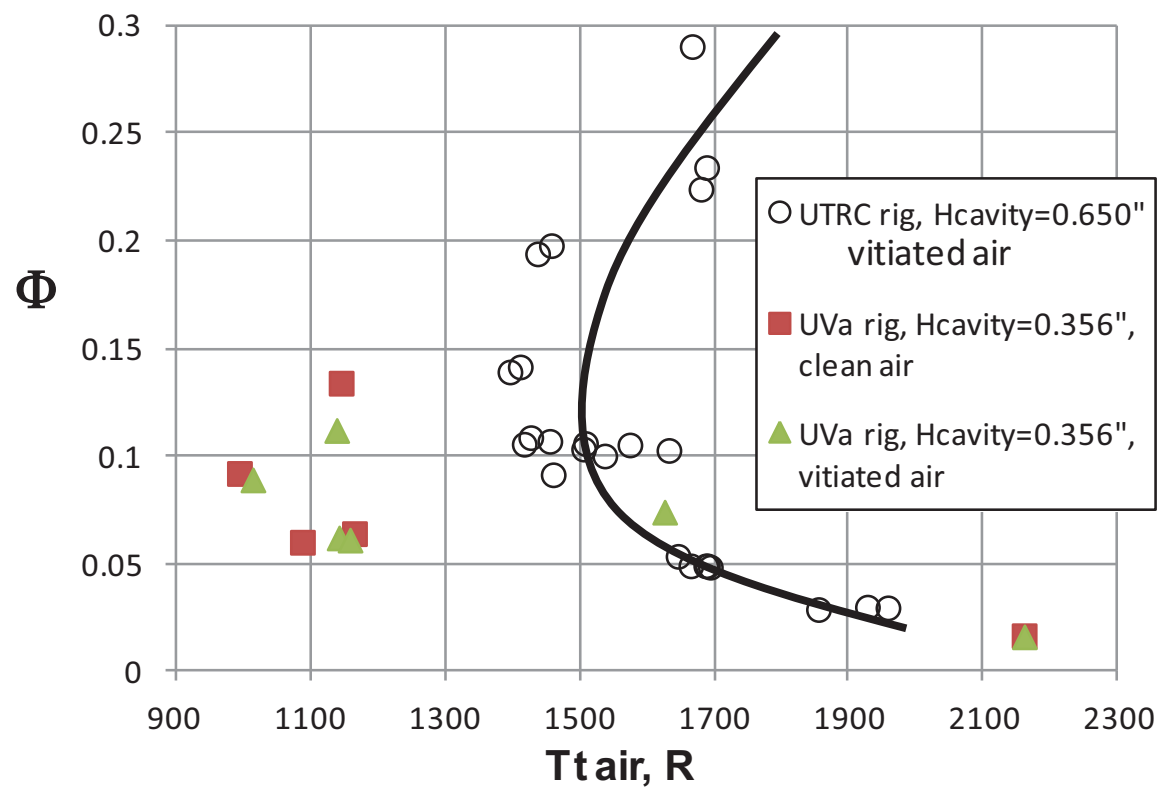

Figure 3.16. Ethylene blowout temperature measured in the UVa test facility compared to UTRC facility measurements. Note, conditions and flowpath geometry in the two facilities are not the same. 

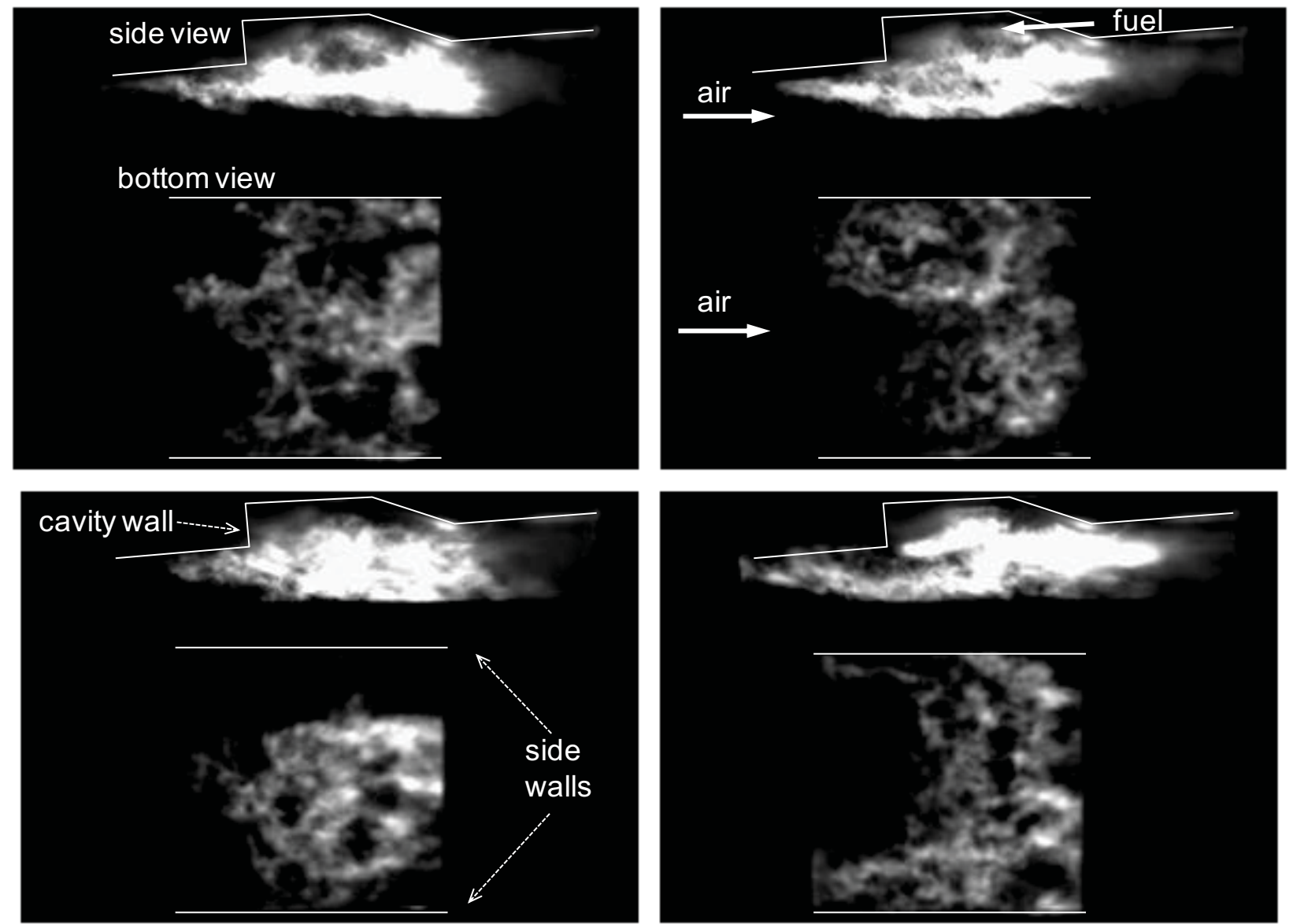

Figure 3.17. Four typical images (not successive) extracted from high speed video showing complexity and asymmetry of the flame dynamics. Video collected at 20,000 frames per second with a $10 \mu \mathrm{s}$ exposure time during Run 14.16 (nominal conditions: Ma inlet $=2.2$, Pinlet $=7$ psia, Pratio=2.5, ethylene fuel). 


\section{$P$ avg $=16.3$ psia, \\ $\mathrm{P}$ RMS $=0.82 \mathrm{psi}$ \\ $8 \mathrm{kHz}$ data rate}

Pcavity vs. time before blowout, run 14-16

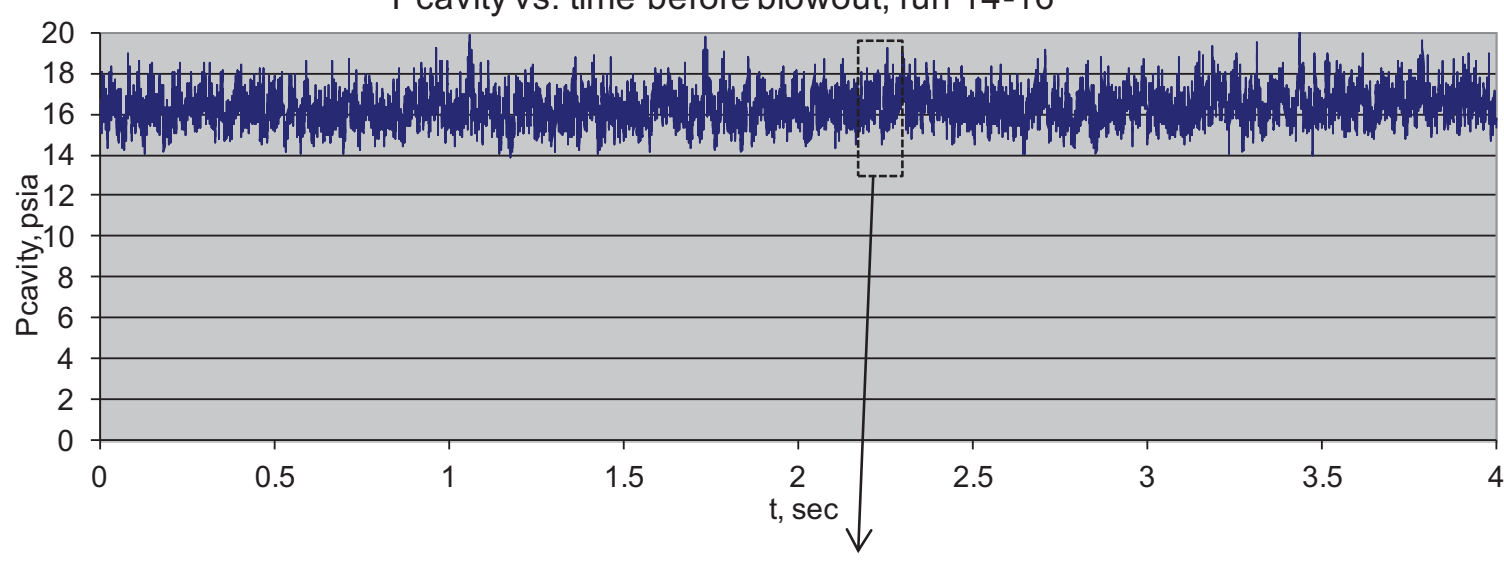

closeup of Pcavity vs. time about 2 sec before blowout, run 14-16

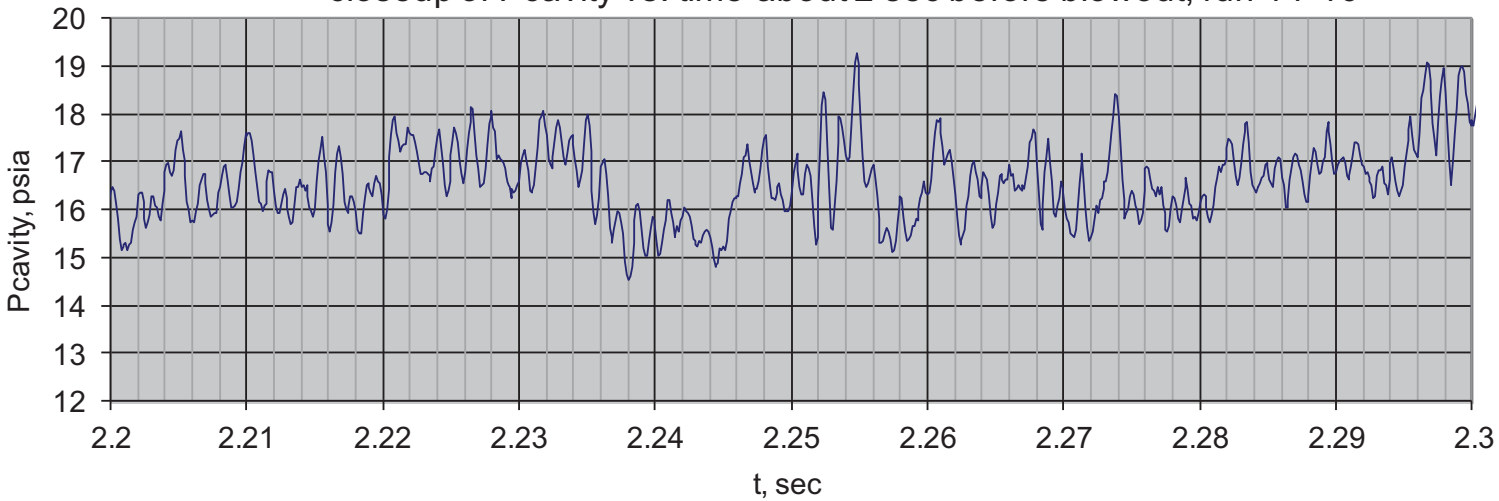

Figure 3.18. Example of high speed pressure measurements taken during run 14.16 from a pressure tap on the floor of the cavity. 


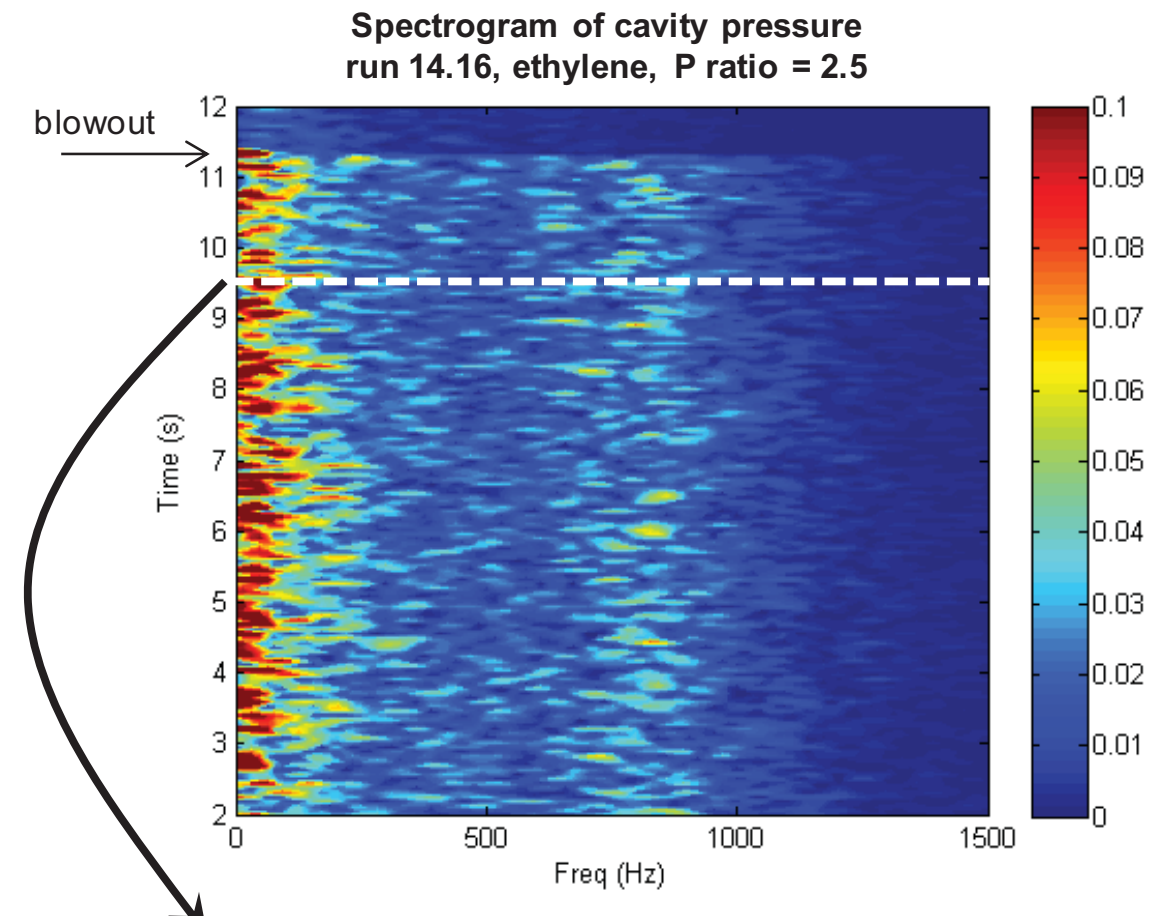

Power Spectrum 2 sec before blowout

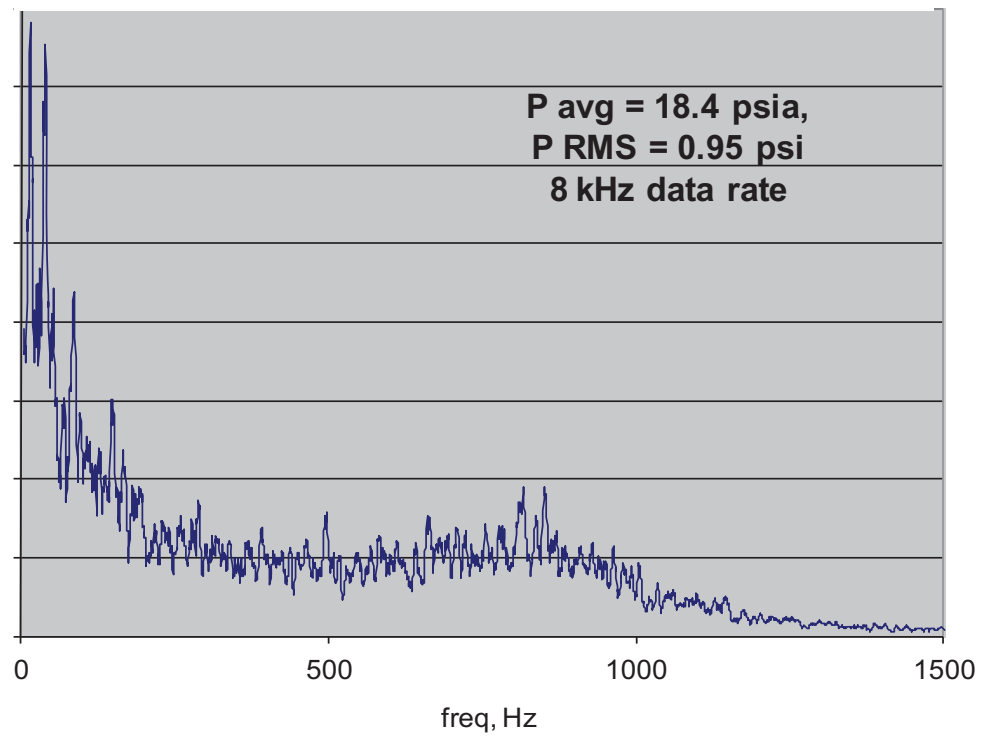

Figure 3.19 High speed pressure measurements, spectrogram showing spectra of cavity pressure versus time till blowout. 


\section{Discussion and Analysis}

This section provides additional discussion and interpretation of the results presented in the previous section. While the content is mostly qualitative because detailed measurements and simulations are not available, an acknowledgment of some of the unexpected results and explanation of the flowfield phenomena is warranted. These include the observation of the highly unsteady flame in the UTRC rig, the weak pressure sensitivity of the temperature blowout limit and a comparison of the UVa to UTRC test results.

Unsteady Flame Dynamics

The large scale unsteadiness of the flame observed during UTRC rig tests is a point of concern since it can have a significant impact on the flameholding limit measurements. Examples are shown with images extracted from the video collected in Figures 3.5, 3.6, 3.10, and 3.17. The cause of the flow unsteadiness seen in the UTRC rig, and subsequently a determination of whether this is a characteristic expected in flight engines is therefore an important consideration. Potential causes due to test facility problems were investigated but dismissed, including leakage at rig wall joints, air heater unsteadiness, and asymmetry in the facility nozzle. Shock train pressure rise was limited to 3.5 for the majority of the tests to ensure that the shocktrain was not pushed into the supersonic inlet nozzle which would disturb the inlet flow. See for example Figure 3.2 where the flameholder repeatedly ignited and blew out when the shock train was pushed into the nozzle. Shocks and separated flow in the inlet nozzle would not be representative of a flight engine.

The flow unsteadiness and upstream burning observed is due to the presence of the shock train. In previous studies with all subsonic flow and all supersonic core flow [3-9] this level of unsteadiness at the flameholder was not reported. Shock trains contain separated flows and recirculation zones due the strong shock boundary layer interactions. These are unsteady flow phenomena that interact with turbulence in the inflow boundary layers. If hot combustion products and fuel are entrained into the upstream shock train and react with the incoming air, as observed in the video, the unsteadiness of the separated flow zones are likely to be amplified by local ignition and blowout events. Figure 4.1 presents a schematic of the flow in an isolator and where the shock train and recirculation zone is formed for different back pressure levels. When the Pratio is low, the shock train leading edge is closer to the combustor region, and recirculation zones are more likely to carry combustion products and fuel upstream causing burning in the isolator. When the pressure ratio is high, the shock train leading edge pushes upstream and the separation zone is thinner near the combustor so upstream flame propagation is less likely. This is consistent with the calculated distortion coefficient, $\mathrm{Cd}$, at the end of the isolator shown in Figure 2.5. Cd is smaller indicating more distortion for small Pratio levels, causing a larger separated zone near the combustor flameholder. This description of how the distortion level, represented by $\mathrm{Cd}$, varies with the pressure ratio across the isolator is consistent with the description presented by Heiser \& Pratt [11].

The rectangular cross section isolator utilized in this study is relevant to flight type 2-D scramjet engine designs[2]. In a study of non-reacting flow in isolator flowfields with shock trains and separated flows by Penzin [12] he shows how shock train length and pressure rise in the duct is sensitive to the aspect ratio of duct cross section. The length of the isolator duct required to hold a particular pressure rise was shown to have two significantly different values, depending on the aspect ratio of the duct. The two different results are a function of where the shock train leading edge is formed and how the shock system reflects through the duct: side to side, top to bottom, or some combination of both. The aspect ratio of the duct used in the present program is also likely to effect the flow through the isolator, and therefore the inlet flow to the combustor and flameholder and possibly the unsteadiness of the flowfield. High levels of unsteadiness 
were observed in the larger aspect ratio UTRC rig but were not observed in the UVa rig where the aspect ratio is significantly smaller. In an isolator flow where burning is occurring, as observed in the present tests, the sensitivity to aspect ratio may be amplified. For example, if the shock is initially launched off one sidewall and combustion begins to occur in the separated flow behind this shock, the flame and shock may become "locked" to one sidewall and then switch to the other sidewall as was seen in the video in Figure 3.11. Downstream pressure perturbations caused by combustion generated backpressure could cause the sudden movements in the quasi-steady shock train positions. The effect of burning in the isolator may be even more relevant in the cases where CE fuel injectors are used. The CE injectors are located in the back of the isolator allowing more fuel to be entrained in the isolator and more combustion heat release to occur in the isolator. Burning in the isolator is generally not desired because of it negative effect on isolator pressure rise performance. This particularly important during low flight Mach number operation where unstart is more likely to occur.

Weak sensitivity to operating pressure

The relatively weak sensitivity to operating pressure observed with both ethylene and JP-7 in Figures 3.12 and 3.14 is contrary to previous test results [6] that show flameholding is negatively impacted by low pressure operation. For example, augmentor flameholding becomes a concern during operation at high altitudes because combustor operating pressures and flowrates are low. It is important to point out that in this study is that gaseous fuel was injected. Most airbreathing engines utilize fuel injected in the liquid state. These engines require atomization, a process that is sensitive to Reynolds number and the operating pressure conditions. A fuel cooled scramjet engine operates for most of its flight with heated vaporized fuel injection so it may be less sensitive to operating pressure.

Flameholding limit models are often based on a ratio of the flowfield time scale to chemical reaction time scale known as the Damkohler number [7]. Two choices for the flow time scale are presented in Figure 4.2. A residence time of the flow over the cavity is estimated to be $200 \mu \mathrm{s}$ using the ratio of the cavity length to velocity over the cavity. The $2000 \mathrm{ft} / \mathrm{sec}$ velocity used is a rough estimate taken from the station 3 conditions presented in Figure 2.5. The width of a flameholder, or depth of the cavity for the case here, is often used for the length scale when calculating the flow time scale and for predicting flame stability [6]. Using the depth of the cavity as the relevant length scale reduces the flow time scale to $25 \mu \mathrm{s}$.

To estimate chemical time scales ethylene kinetics calculations using Chemkin [13] to predict Perfectly Stirred Reactor (PSR) extinction time and of ignition delay time are shown in figures 4.3 and 4.4, respectively. The USC Mechanism, ver.II [14] is used for the analysis with stoichiometric fuel/air ratio. The calculations show the sensitivity of the chemical time scale to the operating pressure and temperature to see if the trends agree with the blowout measurements made and the flow time scales. For a $1500{ }^{\circ} \mathrm{R}$ inlet air temperature and 20 psia operating pressure, which is where blowout was measured for the baseline case, extinction time is predicted in Figure 4.3 to be about $12 \mu \mathrm{s}$, of the same order of magnitude as the $25 \mu$ s flow time calculated above. While this reasonable agreement at one point may indicate that a PSR extinction model could be used to estimate flameholding limits, the model does not capture the weak sensitivity to pressure seen in the measurements. The PSR calculation indicates that doubling the pressure would change the blowout temperature significantly, from $1500{ }^{\circ} \mathrm{R}$ to $1000{ }^{\circ} \mathrm{R}$. The test results saw only a $100^{\circ} \mathrm{R}$ decrease in blowout temperature when the operating pressure was doubled, see Figure 3.12. The ignition delay calculations show significantly higher time scales near $0.1 \mathrm{sec}$, versus the 25 to $200 \mu \mathrm{s}$ flow time scales estimated here, so auto-ignition of the fuel does not appear to be a phenomena that controls flameholding. 
The Ozawa stability correlation parameter, Pbo, has been used to correlate flameholding data for premixed flows of propane and kerosene [6]. The JP-7 blowout data collected in this program at both low and high pressure is plotted in Figure 4.5 on an Ozawa type plot. The definition of Pbo, shown on the horizontal axis of the plot, is inversely proportional to pressure, indicating the flameholding limit predicted with this correlation is sensitive to pressure. The black curve is a rough fit of the results presented in the Ozawa report. The data points from this study do not collapsed to a single curve, indicating the Pbo correlation does not capture the sensitivity to pressure or to equivalence ratio for the present flowfield. The difference in sensitivity to equivalence ratio can be explained because the present study uses direct fuel injection into the cavity versus the premixed flow cases used to generate the Ozawa correlation. Using the Pbo correlation that scales with the product of $(1 / \mathrm{P})$ and $\left(1 / \mathrm{T}^{1.5}\right)$, doubling the pressure should change the blowout temperature from about $1700^{\circ} \mathrm{R}$, as measured for the low pressure JP-7 fueled case, to $1080^{\circ} \mathrm{R}$ for the high pressure case, but the data showed a negligible change. In summary, the flameholding limit measurements made in this study, which are relevant for dual mode scramjet engines, do not exhibit the sensitivity to pressure predicted by the Ozawa correlation or by PSR extinction time calculations.

$\underline{\text { UVa versus UTRC results }}$

Another unexpected result was that the smaller 0.356 inch deep cavity in the UVa facility was able to flamehold to a lower inlet air temperature than the larger 0.65 inch deep cavity in the UTRC test rig, 1100 ${ }^{\circ} \mathrm{R}$ versus $1500{ }^{\circ} \mathrm{R}$ respectively. The comparison is shown in Figure 3.16. It is widely accepted that a larger flameholder will operate at more difficult conditions, such as lower temperatures and higher velocities, than a smaller flameholder [6]. Other differences in the experimental conditions and operation of the flameholder must be the cause of the results found. A comparison of the two facilities and test conditions is shown in the results section. Inlet Mach numbers and cavity pressures are similar. The vitiation level tested in the UVa facility agrees closely with the level in the UTRC facility. The fuel injection configurations are closely matched. Three other difference are more likely to contribute to the difference seen: the UVa isolator duct height is about $60 \%$ of the UTRC duct, the aspect ratio of the UVa duct is significantly smaller, and the back-pressurization methods where different, air throttle versus a mechanical throttle. Another important difference, that may be a result of the facility differences just listed, is that the UTRC flowfield experienced significant unsteadiness of the flame. This would expect to negatively affect flameholding capability, similar to the Ozawa reported measurements that showed higher turbulence levels negatively impact flameholding capability [6]. 

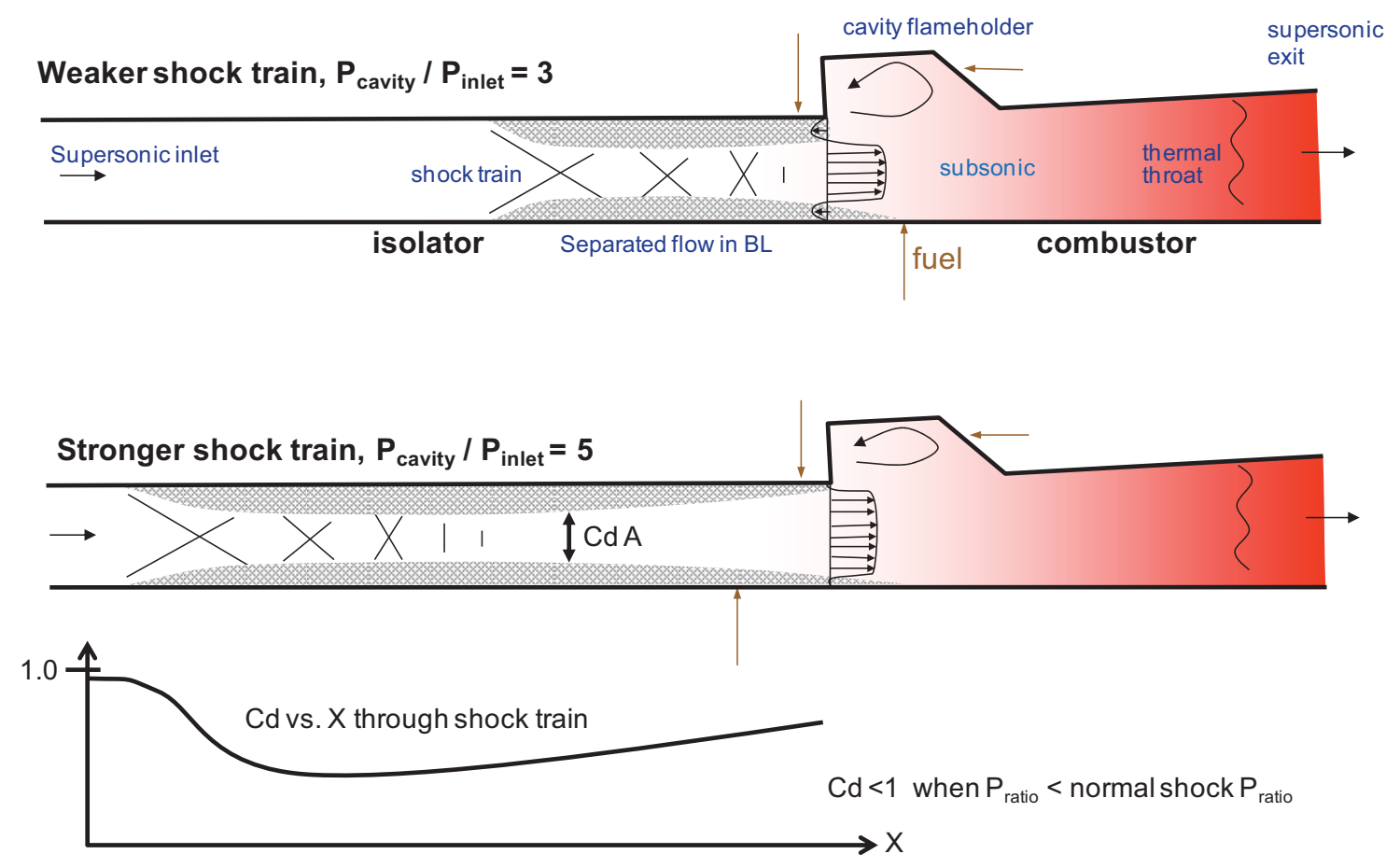

Figure 4.1 Schematic of the flowfield approaching the flameholder showing how $\mathrm{Cd}$ and recirculation zone locations vary with shock train location.

\section{Flow times:}

$$
\begin{aligned}
& \bullet \tau \sim \text { Lcavity } / \mathrm{V}=4 \mathrm{in} / 2000 \mathrm{ft} / \mathrm{s} \sim 200 \mu \mathrm{s} \\
& \bullet \tau \sim \text { Hcavity } / \mathrm{V}=0.65 \mathrm{in} / 2000 \mathrm{ft} / \mathrm{s}=25 \mu \mathrm{s}
\end{aligned}
$$

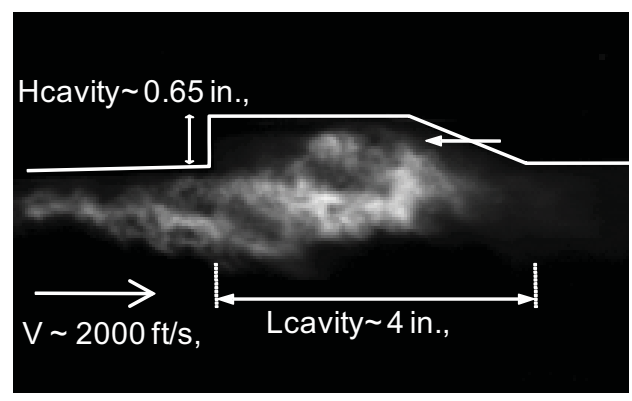

Figure 4.2 Estimate of relevant flowfield time scales. 


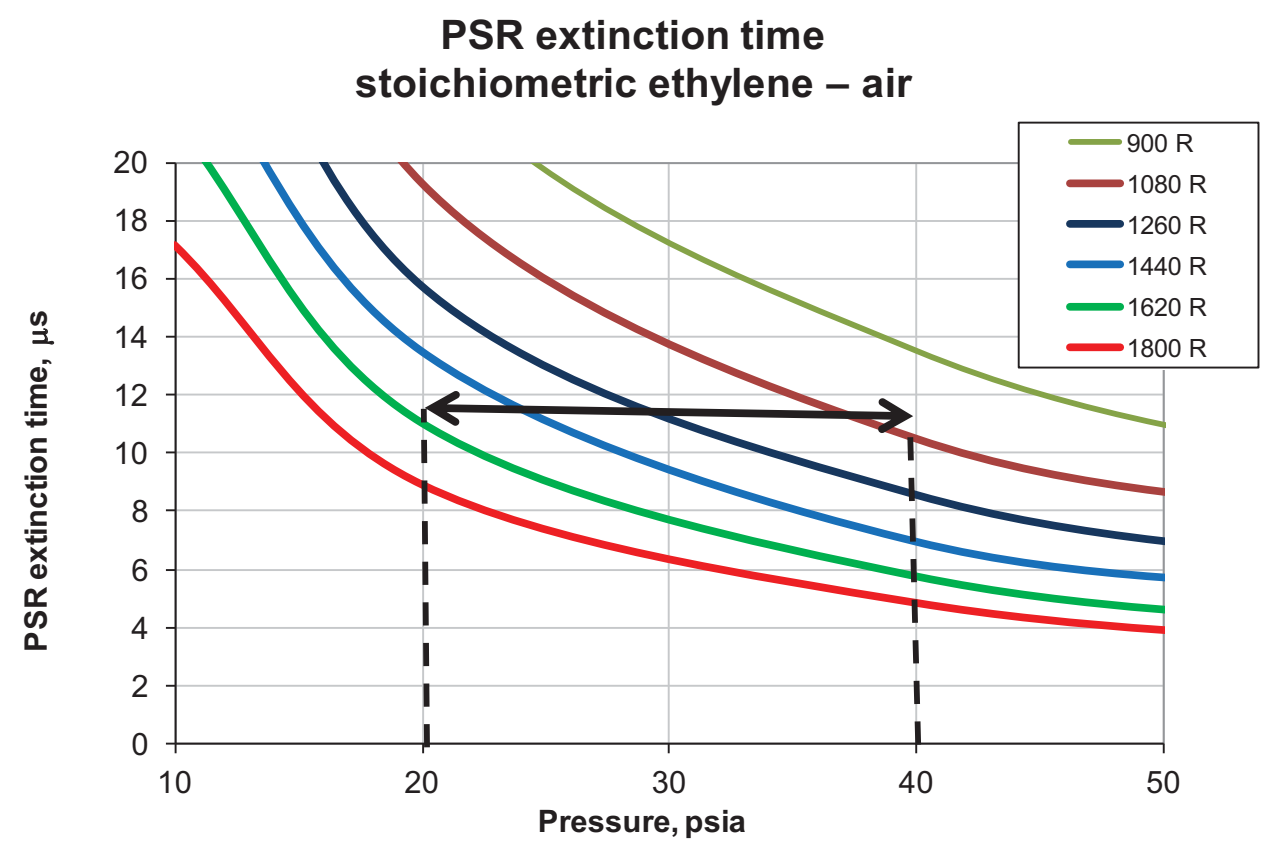

Figure 4.3 Sensitivity of extinction time to pressure and temperature 


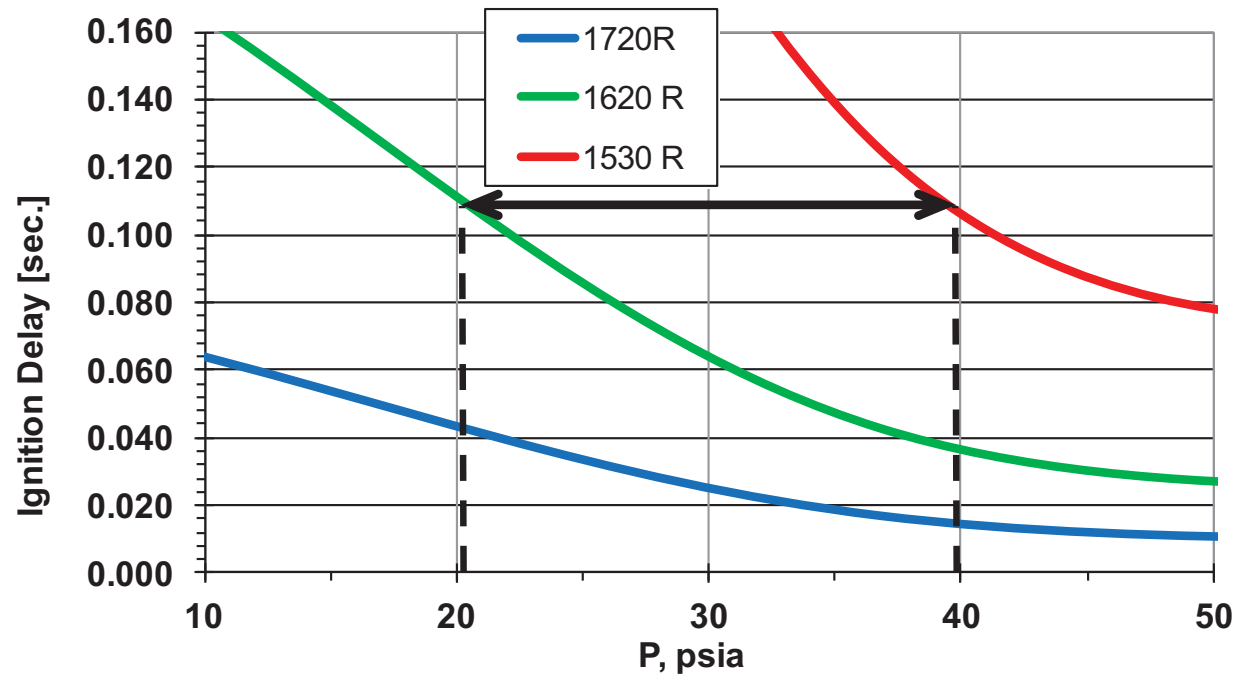

Figure 4.4 Sensitivity of ignition delay time to pressure and temperature

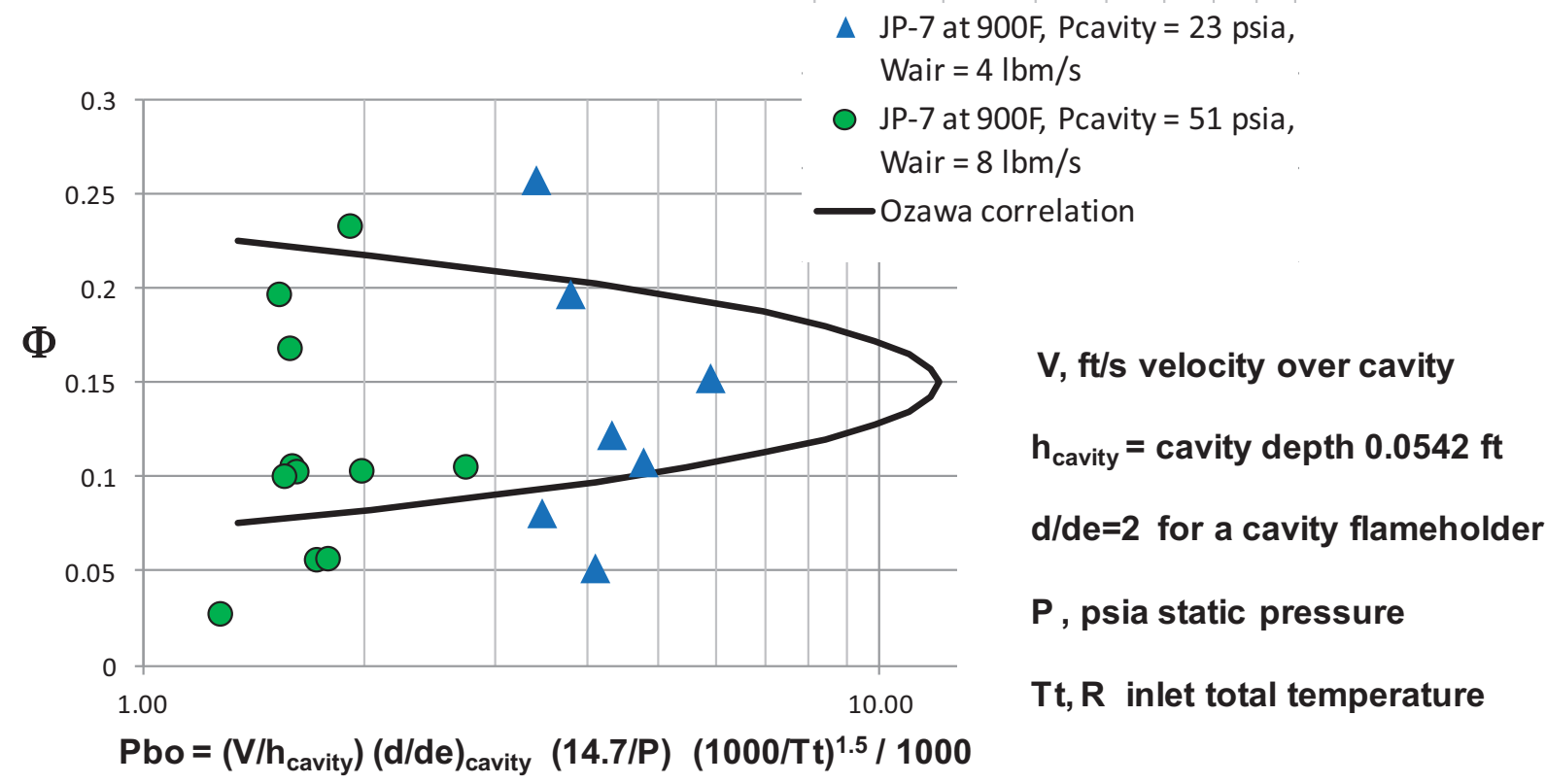

Figure 4.5 JP-7 blowout conditions data presented using the Ozawa correlation 


\section{Suggestions for Future Work}

The results of this study leave many open questions unanswered so this section presents additional work that would help improve the understanding of flameholding limits in a dual mode combustor environment.

1. Test a smaller and larger size cavity to measure the effect of scale.

2. Instrument the rig with more lateral pressures to better measure the asymmetric flow behavior observed.

3. Perform similar tests in another facility with a high aspect ratio isolator to show repeatability.

4. Compare isolator pressure profiles during tare cases versus combustion cases to see if burning in the isolator has a significant effect of isolator pressure rise performance.

5. Analysis of high speed video to understand flame dynamics.

6. Test with modified isolator geometries to see if they effect the unsteady flame dynamics.

7. Ignition visualization testing using the two views available. Ignition process and criteria to design ignition systems is less developed than flameholding.

8. Add additional optical access to make schlieren or shadowgraph visualization of the shock train location and dynamics.

9. PIV and/or flame Image analysis to estimate velocities and better quantify the flowfield and flow time scales in the very non-uniform flowfield

10. High speed pressure measurements at multiple lateral \& axial locations to identify spatial variations and correlations of the pressure signals.

11. High fidelity and unsteady modeling to understand the important physics/chemistry not captured with RANS simulations.

12. Reduced order modeling to predict flameholding limits

\section{Conclusions}

Two dual mode scramjet combustor facilities were modified to add back pressure devices that allow a shock train to be located upstream of a cavity flameholder, independent of core flow heat release and thermal choking, so that blowout tests could be performed in a cavity flameholder that is relevant to dual mode scramjet engine flowfields. The tests were performed by reducing inlet air temperature till blowout of the cavity flame was observed, both using video and cavity pressure data.

Sensitivity of the blowout temperature to several flowfield parameters was measured. The nominal baseline condition used ethylene fueling from the cavity closeout injection site, a pressure ratio across the shock train of 3.5, inlet air flowrate of $4 \mathrm{lbm} / \mathrm{s}$, a cavity pressure of 21 psia.

1. The blowout temperature limit was most sensitive to the fuel injection location. The measurements showed it was possible to hold a flame to a significantly lower inlet air temperature when using the $\mathrm{CE}$ fuel injectors at high fuel flowrates. With the CC injector site an optimal fueling rate was observed but with the $\mathrm{CE}$ site the blowout temperature continued to decrease as fueling was increased.

2. The blowout temperature limit was not strongly sensitive to the position of the shock train upstream of the cavity flameholder using Pratio levels from 3.5 to 2.5. When Pratio was decreased to 1.5 so that the leading edge shock was positioned very close to the upstream edge of the cavity (as the 
combustor would operate when in a pure scramjet mode) the mean blowout temperature increased from $1502{ }^{\circ} \mathrm{R}$ to $1746{ }^{\circ} \mathrm{R}$.

3. The blowout temperature was not strongly sensitive to flameholder pressure using either ethylene or JP-7 fuel. With ethylene fuel the blowout temperature decreased from $1502{ }^{\circ} \mathrm{R}$ to $1392{ }^{\circ} \mathrm{R}$ when pressure and flowrate were doubled. This weak pressure sensitivity is not in agreement with PSR calculations or with the flame stability correlation from Ozawa [6].

4. Data with a higher inlet Mach number of 3.31 was collected and showed the blowout temperature was similar to the lower Mach 2.2 inlet results when the Pratio level was 3.5. The high Mach inlet case was sensitive to Pratio with blowout temperatures from $1250{ }^{\circ} \mathrm{R}$ to $1950{ }^{\circ} \mathrm{R}$ for Pratio levels from 5.0 to 2.5 , respectively.

5. The mean blowout temperature when using heated vaporized JP-7 was about $150{ }^{\circ} \mathrm{R}$ higher than when using room temperature ethylene.

6. Test performed in the UVa facility showed that blowout temperature was not sensitive to steam addition at levels of $6.7 \%$ mole fraction, a vitiation level that is consistent with facilities that use hydrogen combustion heated air.

7. The placement of windows on both the side and the bottom of the test rig provided a view of the cavity flame dynamics not previously available. In both low speed and high speed video the flame was seen to propagate upstream of the cavity through recirculation zones that are generated by the shock train. The upstream flame propagation occurred more consistently when the shock train was shorter, Pratio is smaller, and the leading edge of the shock train where a large recirculation zone occurs is close to the cavity. The bottom view showed that the upstream flame propagation was often, but not always occurs on the sidewalls. The flame location was also observed to be very unsteady both inside the cavity and when it propagates upstream. The phenomenon of combustion occurring upstream of the flameholder should be accounted for in a flameholding model since it can modify the effective aerodynamic size of the flameholder. The presence of significant unsteadiness observed in the flame should also be accounted for in a model or correlation.

8. Test Frequency analysis of high speed pressure measurements was performed, but no significant frequency modes were observed.

The measurements of flameholding limits in terms of blowout temperatures made in this study are expected to be useful to designers of dual mode scramjet combustors. The data collected can be used to assess the flameholding operability limits of flameholder designs and the sensitivity to operating parameters flight conditions. The data can also be used for the development of reduced order models of flameholding and as validation test cases. 


\section{References}

[1] Kay, I , Peschke, W., Guile, R., "Hydrocarbon-Fueled Scramjet Combustor Investigations", AIAA Paper 90-2337, July 1990.

[2] Andreadis, D., Beckel, S., Kay, I., Lehrach, R., Peschke, W., Zumpano, F., Donohue, J., "Development of Alternate Piloting Concepts for a Hydrocarbon Fueled Scramjet Engine," Presented at the JANNAF Airbreathing Propulsion Subcommittee, Meeting, Monterey, CA Nov. 2000.

[3] Khosla, S., Leach, T.T., Smith, C.E., "Flame Stabilization and the Role of von Karman Vortex Shedding Behind Bluff Body Flameholders,” AIAA Paper 2007-5653.

[4] Winterfeld, G.: On Processes of Turbulent Exchange Behind Flameholders, Tenth Symposium (International) on Combustion, pp. 1265-1275, The Combustion Institute, 1965.

[5] Huellmantel, L.W., Ziemer, R.W., Cambel, A.B., "Stabilization of Premixed Propane-Air Flames in Recessed Ducts," Jet Propulsion, pp. 31-43, Jan 1957.

[6] Ozawa, R. I., "Survey of Basic Data on Flame Stabilization and Propagation for High Speed Combustion Systems", AFAPL-TR-70-81, Marquardt Company, Van Nuy, California, 1970.

[7] Driscoll, J.E. and Rasmussen, C.C., "Correlation and Analysis of Blowout Limits of Flames in HighSpeed Airflows," Journal of Propulsion and Power, Vol, 21, No. 6, 2005.

[8] Gruber, M.R., "Mixing and Combustion Studies Using cavity-based Flameholders in a Supersonic Flow, "Journal of Propulsion and Power, Vol. 20, No. 5, 2004.

[9] Gruber, M.R. Baurle, R.A, Mathur, T., Hsu, K.Y., "Fundamental Studies of Cavity-Based Flameholder Concepts for Supersonic Combustors," Journal of Propulsion and Power, Vol. 17, No. 1, 2001.

[10] Lin, K.C., et., al., "Flame Characteristics and Fuel Entrainment Inside a Cavity Flae Holder in a Scramjet Combustor," AIAA Paper 2007-5381, 2007.

[11] Heiser, W.H., and Pratt, D.T. Hypersonic Airbreathing Propulsion, Chapter 6, AIAA Education Series, J.S. Przemieniecki, editor, 1994.

[12] Penzin, V.I. "Experimental Investigation of Supersonic Flows with Separated Regions in Ducts", AFRL-PR-WP-TR-1998-2140, August 1998.

[13] Kee, R.J, Rupley, F.M. and Miller, J.A., "Chemkin II: A Fortran Chemical Kinetics Package for the Analysis of Gas Phase Chemical Kinetics," Sandia Report SAND89-8009, Sandia National laboratories, 1989.

[14] Hai Wang, Xiaoqing You, Ameya V. Joshi, Scott G. Davis, Alexander Laskin, Fokion Egolfopoulos \& Chung K. Law, USC Mech Version II. High-Temperature Combustion Reaction Model of H2/CO/C1C4 Compounds. 


\section{Appendix A: Table of test conditions just before blowout during flameholding limit experiments.}

This appendix provides tables that summarize the test conditions for the temperature blowout plots presented in the main text of the report. A description of each of the parameters presented in the tables is listed here:

run, is the test run number

$\mathbf{t}, \mathrm{s}$, is the time slice where blowout occurs and data was taken as the blowout condition, approximately $0.5 \mathrm{sec}$ before the cavity pressure drops.

$\mathbf{W} / \mathbf{A}, 1 \mathrm{bm} / \mathrm{s} / \mathrm{in}^{2},+/-3 \%$, is the flow per area at the rig inlet and is calculated from measured flowrates into the air heater and the cross sectional area at the rig inlet

$=(\mathrm{Wair}+\mathrm{WO} 2+\mathrm{WH} 2) / 9.984 \mathrm{in}^{2}$

Pt air heater, psia, $+/-2 \%$, Inlet stagnation pressure in heater measured from a pressure tap inside the air heater

Tt inlet, ${ }^{\circ} \mathrm{R}+/-3 \%$, is the air total temperature at the inlet to the test rig calculated using thermodynamic equilibrium from the measured flowrates into the air heater and the measured heat loss to water cooled components.

ER ethylene, $+/-4 \%$, is the overall equivalence ratio and is calculated from the measured inlet flowrates. $=$ Wethylene / (Wair + WO2 + WH2) / F/A stoic

Pcavity, psia, $+/-2 \%$, is measured from a pressure tap on the floor of the cavity at the $x=20.38$ inch location

Pinlet, $\mathrm{psia},+/-2 \%$, is measured from a pressure tap centered on the top wall of the test rig at the $\mathrm{x}=0.5$ inch location.

$P$ ratio, psia, $+/-3 \%$ is calculated from the measured cavity and inlet pressure

$=$ Pcavity $/$ Pinlet

h throttle, in. +/-0.010 in. measured height of the throttle above the flat bottom wall of the rig using a potentiometer

Twall B12, F +/-20F, is a calculated inner wall temperature in the isolator at $\mathrm{X}=12$ inch just upstream of the cavity walls. It is extrapolated from two thermocouple measurements, $\mathrm{Ti}$ is located 0.125 inches from the inner wall, Tmid is located 0.563 from the inner wall (at the center of the heat sink wall).

$=\mathrm{Ti}+0.285 *(\mathrm{Ti}-\mathrm{Tmid})$ 
Table A.1. Test conditions for results shown in Figure 3.8

Pratio 3.5, CC fuel inj., low air flow, ethylene fuel, Ma 2.2

inflow

\begin{tabular}{|c|c|c|c|c|c|c|c|c|c|c|}
\hline run & $\mathrm{t}, \mathrm{s}$ & $\begin{array}{l}\text { W/A, } \\
\text { pps/in2 }\end{array}$ & $\begin{array}{l}\text { Pt air } \\
\text { heater }\end{array}$ & Tt inlet, $\mathrm{R}$ & $\begin{array}{l}\text { ER } \\
\text { ethylene }\end{array}$ & P ratio & P cavity & Pinlet & $\begin{array}{l}\text { h throttle, } \\
\text { in }\end{array}$ & $\begin{array}{l}\text { Twall } \\
\text { B12, F }\end{array}$ \\
\hline $012 \_6$ & 79 & 0.379 & 59.1 & 1417 & 0.106 & 3.56 & 19.57 & 5.50 & 0.836 & 404 \\
\hline $012 \_7$ & 75 & 0.386 & 62.2 & 1505 & 0.103 & 3.83 & 22.42 & 5.85 & 0.943 & 407 \\
\hline $013 \_2$ & 74.6 & 0.379 & 59.1 & 1455 & 0.107 & 3.49 & 18.37 & 5.29 & 0.842 & 410 \\
\hline $013 \_3$ & 63 & 0.397 & 66.6 & 1632 & 0.103 & 3.53 & 21.35 & 6.04 & 0.903 & 355 \\
\hline $013 \_4$ & 69.8 & 0.390 & 62.7 & 1508 & 0.106 & 3.49 & 19.76 & 5.70 & 0.881 & 387 \\
\hline $013 \_5$ & 73.6 & 0.381 & 59.6 & 1427 & 0.109 & 3.66 & 19.90 & 5.43 & 0.853 & 416 \\
\hline 013_6 & 68.4 & 0.389 & 64.2 & 1574 & 0.105 & 3.53 & 20.49 & 5.81 & 0.892 & 389 \\
\hline $013 \_7$ & 68.4 & 0.397 & 67.7 & 1689 & 0.049 & 3.43 & 21.10 & 6.15 & 1.031 & 356 \\
\hline $013 \_8$ & 76.4 & 0.393 & 66.7 & 1665 & 0.049 & 3.51 & 21.14 & 6.04 & 1.028 & 394 \\
\hline 013_9 & 70 & 0.394 & 67.5 & 1687 & 0.049 & 3.78 & 22.95 & 6.10 & 1.042 & 364 \\
\hline 013_10 & 62 & 0.400 & 68.2 & 1694 & 0.048 & 3.49 & 21.77 & 6.24 & 1.031 & 357 \\
\hline $014 \_2$ & 71.6 & 0.385 & 65.0 & 1646 & 0.053 & 3.66 & 21.75 & 5.93 & 1.010 & 467 \\
\hline 014_3 & 57 & 0.401 & 74.2 & 1958 & 0.029 & 3.67 & 25.03 & 6.81 & 1.138 & 419 \\
\hline $014 \_4$ & 56 & 0.402 & 72.9 & 1854 & 0.029 & 3.33 & 22.07 & 6.65 & 1.073 & 380 \\
\hline 014_5 & 56 & 0.388 & 72.0 & 1927 & 0.030 & 3.23 & 21.22 & 6.58 & 1.074 & 383 \\
\hline $014 \_7$ & 99.4 & 0.383 & 60.3 & 1428 & 0.091 & 3.53 & 19.04 & 5.41 & 0.892 & 491 \\
\hline 014_8 & 72 & 0.381 & 59.8 & 1411 & 0.142 & 3.53 & 18.76 & 5.35 & 0.752 & 392 \\
\hline 014_9 & 65.8 & 0.386 & 59.8 & 1396 & 0.139 & 3.52 & 18.98 & 5.40 & 0.766 & 378 \\
\hline $014 \_10$ & 62.6 & 0.380 & 60.4 & 1457 & 0.198 & 3.48 & 18.75 & 5.40 & 0.631 & 396 \\
\hline $014 \_11$ & 78.6 & 0.373 & 58.9 & 1437 & 0.194 & 3.65 & 19.34 & 5.31 & 0.635 & 461 \\
\hline $014 \_12$ & 50 & 0.382 & 65.9 & 1688 & 0.234 & 3.52 & 20.98 & 5.95 & 0.635 & 325 \\
\hline $014 \_13$ & 51.6 & 0.390 & 66.9 & 1680 & 0.224 & 3.60 & 21.84 & 6.02 & 0.648 & 337 \\
\hline 014_14 & 58.4 & 0.399 & 68.0 & 1667 & 0.291 & 3.52 & 21.63 & 6.16 & 0.516 & 372 \\
\hline $018 \_2$ & 75.2 & 0.394 & 63.3 & 1537 & 0.100 & 3.66 & 20.38 & 5.58 & 0.867 & 376 \\
\hline
\end{tabular}


Pratio 2.5, CC fuel inj., low air flow, ethylene fuel, Ma 2.2

inflow

\begin{tabular}{|c|c|c|c|c|c|c|c|c|c|c|}
\hline run & $t, s$ & $\begin{array}{l}\text { W/A, } \\
\text { pps/in2 }\end{array}$ & $\begin{array}{l}\text { Pt air } \\
\text { heater }\end{array}$ & Tt inlet, $\mathrm{R}$ & \begin{tabular}{|l|} 
ER \\
ethylene
\end{tabular} & P ratio & P cavity & Pinlet & $\begin{array}{l}\text { h throttle, } \\
\text { in }\end{array}$ & $\begin{array}{l}\text { Twall } \\
\text { B12, F }\end{array}$ \\
\hline 014_15 & 74.4 & 0.390 & 60.4 & 1397 & 0.103 & 2.58 & 14.05 & 5.45 & 0.687 & 376 \\
\hline 014_16 & 62.6 & 0.401 & 67.3 & 1646 & 0.099 & 2.62 & 16.00 & 6.12 & 0.758 & 348 \\
\hline 015_1 & 83 & 0.384 & 59.2 & 1375 & 0.104 & 2.54 & 13.38 & 5.27 & 0.672 & 382 \\
\hline $015 \_2$ & 75 & 0.388 & 63.2 & 1533 & 0.170 & 2.67 & 15.19 & 5.71 & 0.529 & 419 \\
\hline 015_3 & 71.6 & 0.388 & 60.9 & 1439 & 0.167 & 2.65 & 14.50 & 5.48 & 0.504 & 363 \\
\hline $015 \_5$ & 67.2 & 0.385 & 65.9 & 1662 & 0.231 & 2.59 & 15.38 & 5.96 & 0.435 & 401 \\
\hline 015 6 & 66.4 & 0.390 & 66.3 & 1673 & 0.231 & 2.61 & 15.66 & 6.03 & 0.440 & 433 \\
\hline 015_9 & 58.2 & 0.391 & 65.8 & 1638 & 0.049 & 2.54 & 15.06 & 5.97 & 0.911 & 359 \\
\hline 015_10 & 63 & 0.395 & 71.3 & 1841 & 0.028 & 2.41 & 15.62 & 6.48 & 0.988 & 385 \\
\hline 015_11 & 53 & 0.395 & 71.4 & 1860 & 0.028 & 2.57 & 16.70 & 6.53 & 0.991 & 359 \\
\hline
\end{tabular}

Pratio 1.5, scram mode case. CC fuel inj, low air flow, ethylene fuel, Ma 2.2 inflow

\begin{tabular}{|l|l|l|l|l|l|l|l|l|l|l|}
\hline run & t, s & $\begin{array}{l}\text { W/A, } \\
\text { pps/in2 }\end{array}$ & $\begin{array}{l}\text { Pt air } \\
\text { heater }\end{array}$ & Tt inlet, R & $\begin{array}{l}\text { ER } \\
\text { ethylene }\end{array}$ & P ratio & P cavity & Pinlet & $\begin{array}{l}\text { h throttle, } \\
\text { in }\end{array}$ & $\begin{array}{l}\text { Twall } \\
\text { B12, F }\end{array}$ \\
\hline $015 \_12$ & 83.8 & 0.401 & 71.1 & 1796 & 0.104 & 1.64 & 10.62 & 6.50 & 0.657 & 511 \\
\hline $015 \_13$ & 60 & 0.390 & 66.6 & 1682 & 0.105 & 1.55 & 9.36 & 6.06 & 0.620 & 413 \\
\hline $015 \_14$ & 68.4 & 0.395 & 69.1 & 1760 & 0.105 & 1.57 & 9.91 & 6.35 & 0.637 & 402 \\
\hline $015 \_15$ & 59.8 & 0.386 & 68.9 & 1822 & 0.174 & 1.61 & 10.14 & 6.29 & 0.466 & 379 \\
\hline $015 \_16$ & 64.6 & 0.387 & 66.9 & 1723 & 0.177 & 1.58 & 9.64 & 6.12 & 0.436 & 420 \\
\hline $015 \_17$ & 56 & 0.395 & 72.4 & 1899 & 0.229 & 1.62 & 10.67 & 6.59 & 0.349 & 386 \\
\hline $015 \_18$ & 66.4 & 0.391 & 69.4 & 1783 & 0.050 & 1.55 & 9.82 & 6.33 & 0.813 & 390 \\
\hline $016 \_2$ & 63 & 0.385 & 67.3 & 1768 & 0.050 & 1.55 & 9.44 & 6.09 & 0.810 & 384 \\
\hline $016 \_3$ & 67.6 & 0.394 & 68.8 & 1785 & 0.029 & 1.49 & 9.33 & 6.28 & 0.876 & 431 \\
\hline $016 \_4$ & 58.6 & 0.391 & 68.6 & 1789 & 0.028 & 1.55 & 9.62 & 6.23 & 0.882 & 386 \\
\hline $016 \_5$ & 62.6 & 0.394 & 69.0 & 1764 & 0.252 & 1.62 & 10.14 & 6.24 & 0.238 & 427 \\
\hline $016 \_7$ & 63.4 & 0.394 & 70.4 & 1832 & 0.256 & 1.65 & 10.49 & 6.38 & 0.264 & 411 \\
\hline
\end{tabular}


Table A.2. Test conditions for results shown in Figure 3.9.

Pratio 3.5, CE fuel inj, low air flow, ethylene fuel, Ma 2.2

inflow

\begin{tabular}{|c|c|c|c|c|c|c|c|c|c|c|}
\hline run & $\mathrm{t}, \mathrm{s}$ & $\begin{array}{l}\text { W/A, } \\
\text { pps/in2 }\end{array}$ & $\begin{array}{l}\text { Pt air } \\
\text { heater }\end{array}$ & Tt inlet, $\mathrm{R}$ & $\begin{array}{l}\text { ER } \\
\text { ethylene }\end{array}$ & P ratio & P cavity & Pinlet & $\begin{array}{l}\text { h throttle, } \\
\text { in }\end{array}$ & $\begin{array}{l}\text { Twall } \\
\text { B12, F }\end{array}$ \\
\hline $017 \quad 1$ & 69 & 0.386 & 63.5 & 1598 & 0.117 & 3.40 & 20.07 & 5.90 & 0.873 & 353 \\
\hline 017 2 & 62 & 0.384 & 63.1 & 1586 & 0.114 & 3.53 & 20.03 & 5.65 & 0.875 & 362 \\
\hline 017_3 & 59.6 & 0.395 & 65.8 & 1627 & 0.111 & 3.43 & 20.14 & 5.88 & 0.885 & 354 \\
\hline 017 5 & 84.4 & 0.381 & 53.4 & 1153 & 0.177 & 3.56 & 16.89 & 4.76 & 0.649 & 365 \\
\hline $017 \_6$ & 76.8 & 0.371 & 51.7 & 1133 & 0.182 & 3.62 & 16.53 & 4.59 & 0.629 & 355 \\
\hline $017 \quad 7$ & 80 & 0.372 & 54.3 & 1250 & 0.156 & 3.58 & 17.21 & 4.81 & 0.724 & 380 \\
\hline $017 \_8$ & 67.2 & 0.374 & 56.5 & 1335 & 0.142 & 3.60 & 18.04 & 5.03 & 0.774 & 358 \\
\hline 017_9 & 57.6 & 0.386 & 64.4 & 1629 & 0.124 & 3.66 & 21.12 & 5.78 & 0.862 & 360 \\
\hline $017 \_14$ & 53 & 0.408 & 74.5 & 1898 & 0.056 & 3.45 & 23.23 & 6.74 & 1.061 & 391 \\
\hline \begin{tabular}{|l|}
$017 \_15$ \\
\end{tabular} & 63 & 0.407 & 75.9 & 1971 & 0.056 & 3.51 & 24.11 & 6.91 & 1.052 & 502 \\
\hline
\end{tabular}

Run stopped due to heat sink max wal temperature reached, not due to

blowout

\begin{tabular}{|l|l|l|l|l|l|l|l|l|l|l|}
\hline $017 \_4$ & 92 & 0.370 & 48.9 & 1004 & 0.216 & 3.61 & 15.56 & 4.32 & 0.489 & 436 \\
\hline $017 \_10$ & 81 & 0.381 & 52.5 & 1095 & 0.280 & 3.70 & 16.99 & 4.62 & 0.324 & 390 \\
\hline $017 \_11$ & 75 & 0.366 & 44.3 & 835 & 0.258 & 3.44 & 14.12 & 4.08 & 0.359 & 305 \\
\hline $017 \_12$ & 76.6 & 0.375 & 46.3 & 865 & 0.257 & 3.46 & 14.75 & 4.20 & 0.369 & 318 \\
\hline
\end{tabular}

Table A.3. Test conditions for results in Figure 3.12.

Pratio 3.5, CC fuel inj., high air flow, ethylene fuel, Ma 2.2

inflow

\begin{tabular}{|c|c|c|c|c|c|c|c|c|c|c|}
\hline run & $t, s$ & $\begin{array}{l}\text { W/A, } \\
\text { pps/in2 }\end{array}$ & $\begin{array}{l}\text { Pt air } \\
\text { heater }\end{array}$ & Tt inlet, $\mathrm{R}$ & $\begin{array}{l}\text { ER } \\
\text { ethylene }\end{array}$ & P ratio & $\begin{array}{l}\text { P cavity, } \\
\text { psia }\end{array}$ & $\begin{array}{l}\text { Pinlet, } \\
\text { psia }\end{array}$ & $\begin{array}{l}\text { h throttle, } \\
\text { in }\end{array}$ & $\begin{array}{l}\text { Twall } \\
\text { B12, F }\end{array}$ \\
\hline $018 \_3$ & 54 & 0.781 & 127.3 & 1545 & 0.100 & 3.62 & 41.06 & 11.40 & 0.893 & 401 \\
\hline $018 \_4$ & 67.2 & 0.761 & 109.2 & 1215 & 0.110 & 3.60 & 35.20 & 9.91 & 0.836 & 458 \\
\hline $018 \_5$ & 61.8 & 0.763 & 114.1 & 1307 & 0.104 & 3.54 & 36.19 & 10.23 & 0.861 & 451 \\
\hline $018 \_6$ & 55.2 & 0.775 & 124.4 & 1496 & 0.098 & 3.64 & 40.60 & 11.19 & 0.891 & 455 \\
\hline $018 \_7$ & 62.6 & 0.771 & 123.9 & 1508 & 0.201 & 3.65 & 40.59 & 11.14 & 0.680 & 484 \\
\hline $018 \_8$ & 62.4 & 0.757 & 116.2 & 1363 & 0.201 & 3.65 & 38.70 & 10.50 & 0.663 & 468 \\
\hline $018 \_9$ & 46.6 & 0.790 & 130.2 & 1574 & 0.268 & 3.55 & 41.42 & 11.66 & 0.573 & 433 \\
\hline $018 \_10$ & 47 & 0.796 & 135.6 & 1673 & 0.043 & 3.59 & 43.53 & 12.17 & 1.052 & 415 \\
\hline 018_11 & 46 & 0.779 & 134.0 & 1707 & 0.046 & 3.73 & 44.88 & 12.09 & 1.053 & 427 \\
\hline $018 \_12$ & 46 & 0.806 & 144.6 & 1855 & 0.030 & 3.62 & 47.48 & 13.14 & 1.109 & 488 \\
\hline $018 \_13$ & 38 & 0.800 & 146.0 & 1899 & 0.032 & 3.58 & 46.94 & 13.18 & 1.106 & 416 \\
\hline
\end{tabular}


Table A.4. Test conditions for results shown in Figure 3.13.

Pratio 3.5, CC fuel inj., low air flow, ethylene fuel, Ma 3.3

inflow

\begin{tabular}{|l|l|l|l|l|l|l|l|l|l|l|}
\hline run & t, s & $\begin{array}{l}\text { W/A, } \\
\text { pps/in2 }\end{array}$ & $\begin{array}{l}\text { Pt air } \\
\text { heater }\end{array}$ & Tt inlet, R & $\begin{array}{l}\text { ER } \\
\text { ethylene }\end{array}$ & P ratio & $\begin{array}{l}\text { P cavity, } \\
\text { psia }\end{array}$ & $\begin{array}{l}\text { Pinlet, } \\
\text { psia }\end{array}$ & $\begin{array}{l}\text { h throttle, } \\
\text { in }\end{array}$ & $\begin{array}{l}\text { Twall } \\
\text { B12, F }\end{array}$ \\
\hline $021 \_5$ & 63.4 & 0.321 & 197.8 & 1544 & 0.103 & 3.80 & 8.55 & 2.25 & 0.918 & 354 \\
\hline $021 \_6$ & 72.6 & 0.316 & 188.3 & 1447 & 0.106 & 3.13 & 6.85 & 2.19 & 0.887 & 388 \\
\hline $021 \_7$ & 62.4 & 0.316 & 201.3 & 1638 & 0.106 & 3.53 & 7.97 & 2.26 & 0.932 & 358 \\
\hline $021 \_8$ & 66.6 & 0.324 & 197.8 & 1506 & 0.235 & 3.55 & 7.84 & 2.22 & 0.600 & 459 \\
\hline $021 \_9$ & 64 & 0.318 & 195.2 & 1521 & 0.236 & 4.74 & 10.45 & 2.19 & 0.585 & 393 \\
\hline $021 \_10$ & 74 & 0.310 & 171.5 & 1245 & 0.181 & 3.37 & 7.07 & 2.09 & 0.680 & 404 \\
\hline $021 \_11$ & 71.8 & 0.311 & 174.6 & 1270 & 0.178 & 3.17 & 6.74 & 2.10 & 0.682 & 405 \\
\hline $021 \_12$ & 86 & 0.333 & 224.2 & 1817 & 0.056 & 3.89 & 9.68 & 2.48 & 1.087 & 522 \\
\hline $021 \_13$ & 49 & 0.336 & 223.7 & 1747 & 0.055 & 3.73 & 9.31 & 2.51 & 1.081 & 465 \\
\hline
\end{tabular}

Pratio 5, CC fuel inj., low air flow, ethylene fuel, Ma 3.3

inflow

\begin{tabular}{|l|l|l|l|l|l|l|l|l|l|l|}
\hline run & t, s & $\begin{array}{l}\text { W/A, } \\
\text { pps/in2 }\end{array}$ & $\begin{array}{l}\text { Pt air } \\
\text { heater }\end{array}$ & Tt inlet, $R$ & $\begin{array}{l}\text { ER } \\
\text { ethylene }\end{array}$ & P ratio & $\begin{array}{l}\text { P cavity, } \\
\text { psia }\end{array}$ & $\begin{array}{l}\text { Pinlet, } \\
\text { psia }\end{array}$ & $\begin{array}{l}\text { h throttle, } \\
\text { in }\end{array}$ & $\begin{array}{l}\text { Twall } \\
\text { B12, F }\end{array}$ \\
\hline $021 \_14$ & 73 & 0.311 & 173.6 & 1266 & 0.114 & 4.85 & 10.43 & 2.14 & 0.875 & 644 \\
\hline $021 \_15$ & 74 & 0.309 & 171.4 & 1240 & 0.117 & 4.72 & 9.79 & 2.10 & 0.857 & 628 \\
\hline
\end{tabular}

Pratio 2.5, CC fuel inj., low air flow, ethylene fuel, Ma 3.3

inflow

\begin{tabular}{|l|l|l|l|l|l|l|l|l|l|l|}
\hline run & $\mathrm{t}, \mathrm{s}$ & $\begin{array}{l}\text { W/A, } \\
\mathrm{pps} / \mathrm{in} 2\end{array}$ & $\begin{array}{l}\text { Pt air } \\
\text { heater }\end{array}$ & Tt inlet, $\mathrm{R}$ & $\begin{array}{l}\text { ER } \\
\text { ethylene }\end{array}$ & P ratio & $\begin{array}{l}\text { P cavity, } \\
\text { psia }\end{array}$ & $\begin{array}{l}\text { Pinlet, } \\
\text { psia }\end{array}$ & $\begin{array}{l}\text { h throttle, } \\
\text { in }\end{array}$ & $\begin{array}{l}\text { Twall } \\
\text { B12, F }\end{array}$ \\
\hline $021 \_17$ & 46.4 & 0.332 & 232.0 & 1917 & 0.103 & 2.48 & 6.41 & 2.57 & 0.895 & 349 \\
\hline $021 \_18$ & 52 & 0.343 & 239.7 & 1943 & 0.100 & 2.55 & 6.63 & 2.63 & 0.904 & 383 \\
\hline
\end{tabular}


Table A.5. Condition from results presented in Figure 3.14

JP-7 at 900F, Pcavity 50 psi, Wair $81 \mathrm{bm} / \mathrm{s}$

\begin{tabular}{|c|c|c|c|c|c|c|c|c|c|}
\hline run & $t, s$ & $\begin{array}{l}\mathrm{W} / \mathrm{A}, \\
\mathrm{pps} / \mathrm{in} 2\end{array}$ & $\begin{array}{l}\text { Pt air } \\
\text { heater }\end{array}$ & Tt inlet, $\mathrm{R}$ & ER JP-7 & P ratio & $\begin{array}{l}\text { P cavity, } \\
\text { psia }\end{array}$ & Pinlet, psia & $\begin{array}{l}\text { h throttle, } \\
\text { in }\end{array}$ \\
\hline $257 \_1$ & 59.5 & 0.784 & 128.9 & 1537 & 0.106 & 2.78 & 51.32 & 18.48 & 0.992 \\
\hline $257 \_3$ & 47.5 & 0.786 & 138.8 & 1735 & 0.106 & 4.00 & 50.31 & 12.58 & 0.991 \\
\hline $257 \_4$ & 41.5 & 0.801 & 143.6 & 1775 & 0.103 & 3.89 & 50.93 & 13.10 & 0.991 \\
\hline $257 \_5$ & 49.0 & 0.799 & 148.2 & 1886 & 0.056 & 3.65 & 49.57 & 13.56 & 1.072 \\
\hline 257_6 & 56.0 & 0.798 & 147.1 & 1877 & 0.057 & 3.62 & 48.77 & 13.48 & 1.066 \\
\hline $258 \_7$ & 27.6 & 0.785 & 135.2 & 1668 & 0.234 & 3.66 & 50.35 & 13.75 & 0.806 \\
\hline 258_9 & 26.0 & 0.804 & 138.5 & 1679 & 0.104 & 3.73 & 46.91 & 12.57 & 0.974 \\
\hline $260 \_1$ & 27.0 & 0.804 & 143.4 & 1774 & 0.101 & 3.95 & 51.52 & 13.04 & 0.975 \\
\hline $260 \_2$ & 41.0 & 0.795 & 139.0 & 1707 & 0.169 & 3.99 & 51.60 & 12.92 & 0.873 \\
\hline 260_3 & 30.5 & 0.799 & 140.9 & 1751 & 0.197 & 4.01 & 51.62 & 12.86 & 0.823 \\
\hline $260 \_4$ & 31.0 & 0.834 & 166.6 & 2198 & 0.028 & 3.69 & 56.62 & 15.33 & 1.100 \\
\hline
\end{tabular}

JP-7 at 900F, Pcavity 25psia, Wair 4lbm/s

\begin{tabular}{|l|l|l|l|l|l|l|l|l|l|}
\hline run & t, s & $\begin{array}{l}\text { W/A, } \\
\text { pps/in2 }\end{array}$ & $\begin{array}{l}\text { Pt air } \\
\text { heater }\end{array}$ & Tt inlet, R & ER JP-7 & P ratio & $\begin{array}{l}\text { P cavity, } \\
\text { psia }\end{array}$ & $\begin{array}{l}\text { h throttle, } \\
\text { Pinlet, psia }\end{array}$ \\
\hline $260 \_5$ & 61.0 & 0.396 & 68.9 & 1643 & 0.122 & 3.85 & 23.86 & 6.19 & 0.970 \\
\hline $260 \_6$ & 37.5 & 0.417 & 76.8 & 1868 & 0.257 & 3.83 & 26.58 & 6.94 & 0.774 \\
\hline $260 \_7$ & 54.0 & 0.394 & 68.8 & 1684 & 0.197 & 3.56 & 26.49 & 7.45 & 0.884 \\
\hline $260 \_8$ & 39.0 & 0.409 & 78.2 & 2007 & 0.051 & 2.88 & 20.58 & 7.14 & 1.061 \\
\hline $260 \_9$ & 59.0 & 0.393 & 66.2 & 1560 & 0.107 & 3.84 & 22.77 & 5.94 & 0.988 \\
\hline $260 \_10$ & 41.0 & 0.408 & 75.1 & 1861 & 0.080 & 3.86 & 26.21 & 6.80 & 1.023 \\
\hline $260 \_11$ & 55.0 & 0.394 & 67.4 & 1642 & 0.152 & 2.87 & 17.54 & 6.11 & 0.926 \\
\hline
\end{tabular}




\section{Appendix B: Facility inlet nozzle information}

Descriptions of the Mach 2.2 and the Mach 3.31 supersonic nozzles used to set the test rig inlet conditions is given in this appendix to allow CFD simulations to be performed. The nozzles have a rectangular cross section containing flat sidewalls and contoured top and bottom walls. Photos of the Mach 2.2 nozzle and the Mach 3.31 nozzle are shown in Figures B.1. and B.2., respectively. The photos of the upstream end show the inlet to the nozzle is rounded on the top, bottom as well as the two side walls (a departure from the otherwise two dimensional geometry). The supersonic contour of the nozzle downstream of the throat can be seen in the photos on the right. The contour was defined using a method of characteristics calculation with a boundary layer correction. The geometry of the contours for the two nozzles are given by the lists of $(\mathrm{x}, \mathrm{y})$ coordinates shown below the photos. The top and bottom walls are symmetrical, $\mathrm{y}$ is the height from the centerline of the nozzle to the top wall and $\mathrm{x}$ is the axial distance. The distance between sidewalls for both the nozzle is 6 inches.

Inlet conditions to the test rig can be calculated with a CFD simulation using the nozzle contour geometry, the measured stagnation pressure upstream of the nozzle (named Pt air heater in the data set) and the stagnation temperature upstream of the nozzle, which can be derived from measurements in the data set as follows:

$$
\text { Tt stagnation }=\mathrm{Tt} \text { inlet }+ \text { qloss nozzle } /(\mathrm{Cp} * \text { Winlet })
$$

Tt stagnation $\left[{ }^{\circ} \mathrm{R}\right]+/-35^{\circ} \mathrm{R}$ is the total temperature upstream of the nozzle to be used for the nozzle inlet boundary condition.

Tt inlet $\left[{ }^{\circ} \mathrm{R}\right]$ the total temperature at the exit of the nozzle (inlet to the test rig), is in the data set and is derived from the inlet air, oxygen and hydrogen flowrates, temperatures, and inlet heat losses using a thermodynamic equilibrium calculation.

qloss nozzle [BTU/s] the heat loss to the water cooled nozzle is in the data set and is derived from the measured cooling water flowrate and cooling water temperature rise across the nozzle.

Winlet $[\mathrm{lbm} / \mathrm{s}]$ the vitiated inlet air flowrate is in the data set and is the sum of the measured inlet air, oxygen and hydrogen flowrates.

$\mathrm{Cp}=0.27 \mathrm{BTU} / \mathrm{lbm}-{ }^{\circ} \mathrm{R}$ is an estimate of the vitiated air specific heat for the conditions of interest.

A typical difference between $\mathrm{Tt}$ stagnation and $\mathrm{Tt}$ inlet due to the heat loss to the nozzle is $40^{\circ} \mathrm{R}$ for a baseline test case. 


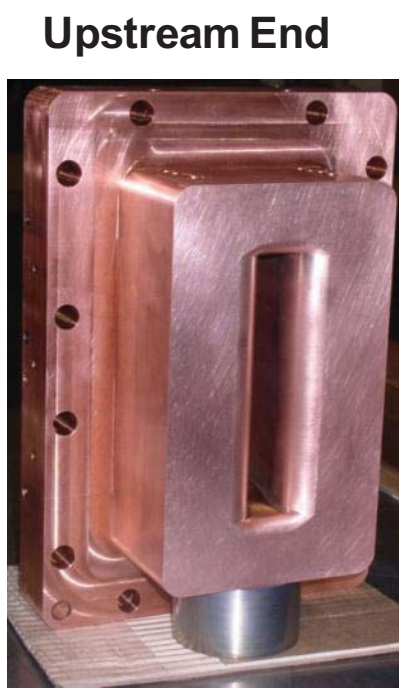

\section{Downstream End}

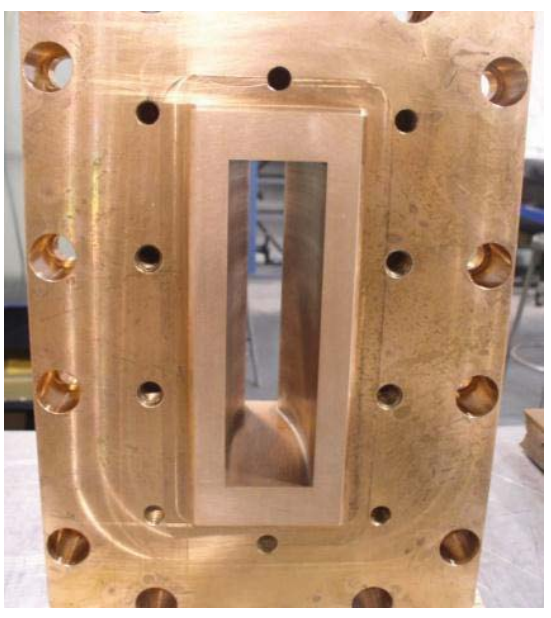

Figure B.1 Photos of the Mach 2.2 facility nozzle

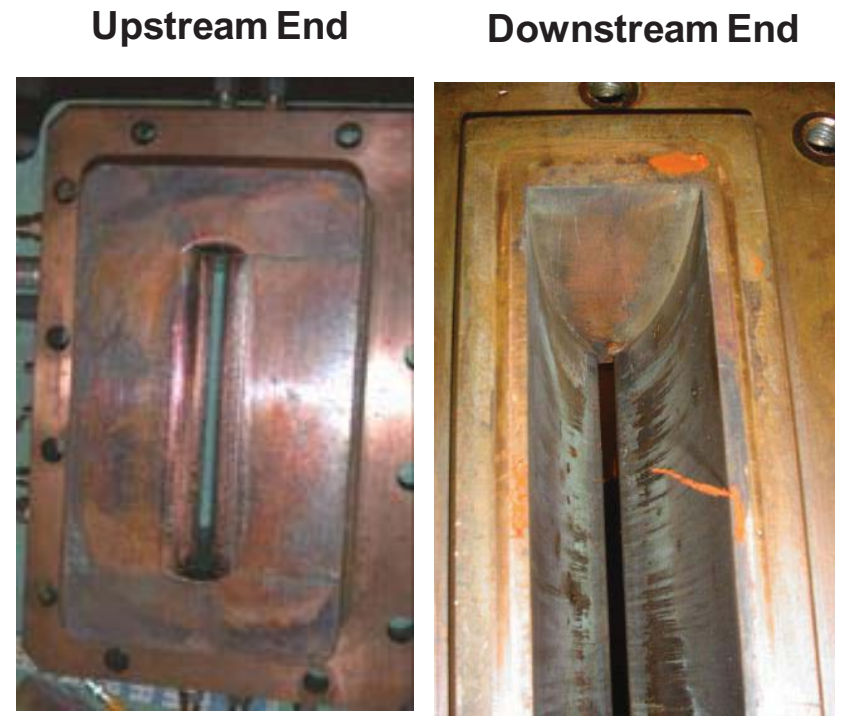

Figure B.2 Photos of the Mach 3.31 facility nozzle 


$\begin{array}{ll}\text { Mach 2.2 Nozzle contour: } \\ \text { X, in } & \text { Y, in } \\ -4.6550 \mathrm{E}+00 & 7.4754 \mathrm{E}-01 \\ -4.6375 \mathrm{E}+00 & 7.2140 \mathrm{E}-01 \\ -4.6194 \mathrm{E}+00 & 6.9654 \mathrm{E}-01 \\ -4.6007 \mathrm{E}+00 & 6.7284 \mathrm{E}-01 \\ -4.5814 \mathrm{E}+00 & 6.5022 \mathrm{E}-01 \\ -4.5615 \mathrm{E}+00 & 6.2868 \mathrm{E}-01 \\ -4.5411 \mathrm{E}+00 & 6.0816 \mathrm{E}-01 \\ -4.5202 \mathrm{E}+00 & 5.8864 \mathrm{E}-01 \\ -4.4989 \mathrm{E}+00 & 5.7014 \mathrm{E}-01 \\ -4.4773 \mathrm{E}+00 & 5.5266 \mathrm{E}-01 \\ -4.4553 \mathrm{E}+00 & 5.3618 \mathrm{E}-01 \\ -4.4330 \mathrm{E}+00 & 5.2071 \mathrm{E}-01 \\ -4.4106 \mathrm{E}+00 & 5.0625 \mathrm{E}-01 \\ -4.3881 \mathrm{E}+00 & 4.9277 \mathrm{E}-01 \\ -4.3656 \mathrm{E}+00 & 4.8027 \mathrm{E}-01 \\ -4.3432 \mathrm{E}+00 & 4.6876 \mathrm{E}-01 \\ -4.3210 \mathrm{E}+00 & 4.5822 \mathrm{E}-01 \\ -4.2990 \mathrm{E}+00 & 4.4865 \mathrm{E}-01 \\ -4.2773 \mathrm{E}+00 & 4.4001 \mathrm{E}-01 \\ -4.2560 \mathrm{E}+00 & 4.3226 \mathrm{E}-01 \\ -4.2353 \mathrm{E}+00 & 4.2536 \mathrm{E}-01 \\ -4.2152 \mathrm{E}+00 & 4.1925 \mathrm{E}-01 \\ -4.1957 \mathrm{E}+00 & 4.1390 \mathrm{E}-01 \\ -4.1769 \mathrm{E}+00 & 4.0925 \mathrm{E}-01 \\ -4.1590 \mathrm{E}+00 & 4.0527 \mathrm{E}-01 \\ -4.1419 \mathrm{E}+00 & 4.0190 \mathrm{E}-01 \\ -4.1257 \mathrm{E}+00 & 3.9907 \mathrm{E}-01 \\ -4.1105 \mathrm{E}+00 & 3.9673 \mathrm{E}-01 \\ -4.0962 \mathrm{E}+00 & 3.9483 \mathrm{E}-01 \\ -4.0830 \mathrm{E}+00 & 3.9330 \mathrm{E}-01 \\ -4.0708 \mathrm{E}+00 & 3.9209 \mathrm{E}-01 \\ -4.0596 \mathrm{E}+00 & 3.9115 \mathrm{E}-01 \\ -4.0494 \mathrm{E}+00 & 3.9044 \mathrm{E}-01 \\ -4.0403 \mathrm{E}+00 & 3.8991 \mathrm{E}-01 \\ -4.0322 \mathrm{E}+00 & 3.8953 \mathrm{E}-01 \\ -4.0251 \mathrm{E}+00 & 3.8926 \mathrm{E}-01 \\ -4.0189 \mathrm{E}+00 & 3.8908 \mathrm{E}-01 \\ -4.0137 \mathrm{E}+00 & 3.8897 \mathrm{E}-01 \\ -4.0095 \mathrm{E}+00 & 3.8890 \mathrm{E}-01 \\ -4.0061 \mathrm{E}+00 & 3.8886 \mathrm{E}-01 \\ -4.0035 \mathrm{E}+00 & 3.8884 \mathrm{E}-01 \\ -4.0017 \mathrm{E}+00 & 3.8883 \mathrm{E}-01 \\ -4.0005 \mathrm{E}+00 & 3.8883 \mathrm{E}-01 \\ -4.0000 \mathrm{E}+00 & 3.8878 \mathrm{E}-01 \\ -3.9995 \mathrm{E}+00 & 3.8878 \mathrm{E}-01\end{array}$

$\begin{array}{ll}-3.9980 \mathrm{E}+00 & 3.8879 \mathrm{E}-01 \\ -3.9948 \mathrm{E}+00 & 3.8882 \mathrm{E}-01 \\ -3.9890 \mathrm{E}+00 & 3.8891 \mathrm{E}-01 \\ -3.9800 \mathrm{E}+00 & 3.8917 \mathrm{E}-01 \\ -3.9672 \mathrm{E}+00 & 3.8967 \mathrm{E}-01 \\ -3.9503 \mathrm{E}+00 & 3.9066 \mathrm{E}-01 \\ -3.9294 \mathrm{E}+00 & 3.9243 \mathrm{E}-01 \\ -3.9049 \mathrm{E}+00 & 3.9518 \mathrm{E}-01 \\ -3.8781 \mathrm{E}+00 & 3.9909 \mathrm{E}-01 \\ -3.8504 \mathrm{E}+00 & 4.0417 \mathrm{E}-01 \\ -3.8236 \mathrm{E}+00 & 4.1010 \mathrm{E}-01 \\ -3.7992 \mathrm{E}+00 & 4.1634 \mathrm{E}-01 \\ -3.7783 \mathrm{E}+00 & 4.2229 \mathrm{E}-01 \\ -3.7615 \mathrm{E}+00 & 4.2737 \mathrm{E}-01 \\ -3.7488 \mathrm{E}+00 & 4.3128 \mathrm{E}-01 \\ -3.7398 \mathrm{E}+00 & 4.3404 \mathrm{E}-01 \\ -3.7340 \mathrm{E}+00 & 4.3580 \mathrm{E}-01 \\ -3.7309 \mathrm{E}+00 & 4.3676 \mathrm{E}-01 \\ -3.7294 \mathrm{E}+00 & 4.3721 \mathrm{E}-01 \\ -3.7290 \mathrm{E}+00 & 4.3736 \mathrm{E}-01 \\ -4.0000 \mathrm{E}+00 & 3.8883 \mathrm{E}-01 \\ -3.9995 \mathrm{E}+00 & 3.8883 \mathrm{E}-01 \\ -3.9980 \mathrm{E}+00 & 3.8884 \mathrm{E}-01 \\ -3.9948 \mathrm{E}+00 & 3.8887 \mathrm{E}-01 \\ -3.9890 \mathrm{E}+00 & 3.8896 \mathrm{E}-01 \\ -3.9800 \mathrm{E}+00 & 3.8922 \mathrm{E}-01 \\ -3.9672 \mathrm{E}+00 & 3.8972 \mathrm{E}-01 \\ -3.9503 \mathrm{E}+00 & 3.9070 \mathrm{E}-01 \\ -3.9294 \mathrm{E}+00 & 3.9248 \mathrm{E}-01 \\ -3.9049 \mathrm{E}+00 & 3.9523 \mathrm{E}-01 \\ -3.8781 \mathrm{E}+00 & 3.9914 \mathrm{E}-01 \\ -3.8504 \mathrm{E}+00 & 4.0422 \mathrm{E}-01 \\ -3.8236 \mathrm{E}+00 & 4.1015 \mathrm{E}-01 \\ -3.7992 \mathrm{E}+00 & 4.1639 \mathrm{E}-01 \\ -3.7783 \mathrm{E}+00 & 4.2234 \mathrm{E}-01 \\ -3.7615 \mathrm{E}+00 & 4.2742 \mathrm{E}-01 \\ -3.7488 \mathrm{E}+00 & 4.3133 \mathrm{E}-01 \\ -3.7398 \mathrm{E}+00 & 4.3409 \mathrm{E}-01 \\ -3.7340 \mathrm{E}+00 & 4.3585 \mathrm{E}-01 \\ -3.7309 \mathrm{E}+00 & 4.3681 \mathrm{E}-01 \\ -3.7294 \mathrm{E}+00 & 4.3726 \mathrm{E}-01 \\ -3.7290 \mathrm{E}+00 & 4.3741 \mathrm{E}-01 \\ -3.7285 \mathrm{E}+00 & 4.3755 \mathrm{E}-01 \\ -3.7274 \mathrm{E}+00 & 4.3787 \mathrm{E}-01 \\ -3.7262 \mathrm{E}+00 & 4.3826 \mathrm{E}-01 \\ -3.7246 \mathrm{E}+00 & 4.3875 \mathrm{E}-01 \\ -3.7226 \mathrm{E}+00 & 4.3934 \mathrm{E}-01\end{array}$

$\begin{array}{ll}-3.7204 \mathrm{E}+00 & 4.4004 \mathrm{E}-01 \\ -3.7178 \mathrm{E}+00 & 4.4084 \mathrm{E}-01 \\ -3.7148 \mathrm{E}+00 & 4.4174 \mathrm{E}-01 \\ -3.7115 \mathrm{E}+00 & 4.4276 \mathrm{E}-01 \\ -3.7078 \mathrm{E}+00 & 4.4389 \mathrm{E}-01 \\ -3.7038 \mathrm{E}+00 & 4.4513 \mathrm{E}-01 \\ -3.6993 \mathrm{E}+00 & 4.4649 \mathrm{E}-01 \\ -3.6945 \mathrm{E}+00 & 4.4796 \mathrm{E}-01 \\ -3.6893 \mathrm{E}+00 & 4.4956 \mathrm{E}-01 \\ -3.6837 \mathrm{E}+00 & 4.5127 \mathrm{E}-01 \\ -3.6777 \mathrm{E}+00 & 4.5311 \mathrm{E}-01 \\ -3.6713 \mathrm{E}+00 & 4.5508 \mathrm{E}-01 \\ -3.6645 \mathrm{E}+00 & 4.5717 \mathrm{E}-01 \\ -3.6572 \mathrm{E}+00 & 4.5940 \mathrm{E}-01 \\ -3.6495 \mathrm{E}+00 & 4.6175 \mathrm{E}-01 \\ -3.6414 \mathrm{E}+00 & 4.6424 \mathrm{E}-01 \\ -3.6328 \mathrm{E}+00 & 4.6686 \mathrm{E}-01 \\ -3.6238 \mathrm{E}+00 & 4.6960 \mathrm{E}-01 \\ -3.6144 \mathrm{E}+00 & 4.7249 \mathrm{E}-01 \\ -3.6045 \mathrm{E}+00 & 4.7550 \mathrm{E}-01 \\ -3.5941 \mathrm{E}+00 & 4.7865 \mathrm{E}-01 \\ -3.5833 \mathrm{E}+00 & 4.8193 \mathrm{E}-01 \\ -3.5720 \mathrm{E}+00 & 4.8534 \mathrm{E}-01 \\ -3.5603 \mathrm{E}+00 & 4.8889 \mathrm{E}-01 \\ -3.5480 \mathrm{E}+00 & 4.9256 \mathrm{E}-01 \\ -3.5353 \mathrm{E}+00 & 4.9637 \mathrm{E}-01 \\ -3.5222 \mathrm{E}+00 & 5.0030 \mathrm{E}-01 \\ -3.5085 \mathrm{E}+00 & 5.0436 \mathrm{E}-01 \\ -3.4944 \mathrm{E}+00 & 5.0855 \mathrm{E}-01 \\ -3.4798 \mathrm{E}+00 & 5.1285 \mathrm{E}-01 \\ -3.4647 \mathrm{E}+00 & 5.1728 \mathrm{E}-01 \\ -3.4491 \mathrm{E}+00 & 5.2182 \mathrm{E}-01 \\ -3.4331 \mathrm{E}+00 & 5.2647 \mathrm{E}-01 \\ -3.4165 \mathrm{E}+00 & 5.3124 \mathrm{E}-01 \\ -3.3995 \mathrm{E}+00 & 5.3610 \mathrm{E}-01 \\ -3.3820 \mathrm{E}+00 & 5.4106 \mathrm{E}-01 \\ -3.3641 \mathrm{E}+00 & 5.4612 \mathrm{E}-01 \\ -3.3456 \mathrm{E}+00 & 5.5127 \mathrm{E}-01 \\ -3.3267 \mathrm{E}+00 & 5.5650 \mathrm{E}-01 \\ -3.3074 \mathrm{E}+00 & 5.6180 \mathrm{E}-01 \\ -3.2875 \mathrm{E}+00 & 5.6718 \mathrm{E}-01 \\ -3.2672 \mathrm{E}+00 & 5.7263 \mathrm{E}-01 \\ -3.2465 \mathrm{E}+00 & 5.7814 \mathrm{E}-01 \\ -3.2253 \mathrm{E}+00 & 5.8371 \mathrm{E}-01 \\ -3.2037 \mathrm{E}+00 & 5.8932 \mathrm{E}-01 \\ -3.1592 \mathrm{E}+00 & 6.0065 \mathrm{E}-01\end{array}$ 


\begin{tabular}{|c|c|c|c|c|c|}
\hline$-3.1363 \mathrm{E}+00$ & $6.0636 \mathrm{E}-01$ & $-1.8045 \mathrm{E}+00$ & $8.0896 \mathrm{E}-01$ & $-8.2137 \mathrm{E}-01$ & $8.3200 \mathrm{E}-01$ \\
\hline$-3.1130 \mathrm{E}+00$ & $6.1209 \mathrm{E}-01$ & $-1.7778 \mathrm{E}+00$ & $8.1073 \mathrm{E}-01$ & $-8.0291 \mathrm{E}-01$ & $8.3200 \mathrm{E}-01$ \\
\hline$-3.0893 \mathrm{E}+00$ & $6.1783 \mathrm{E}-01$ & $-1.7514 \mathrm{E}+00$ & $8.1240 \mathrm{E}-01$ & $-7.8446 \mathrm{E}-01$ & $8.3200 \mathrm{E}-01$ \\
\hline$-3.0652 \mathrm{E}+00$ & $6.2356 \mathrm{E}-01$ & $-1.7253 \mathrm{E}+00$ & $8.1399 \mathrm{E}-01$ & $-7.6600 \mathrm{E}-01$ & $8.3200 \mathrm{E}-01$ \\
\hline$-3.0408 \mathrm{E}+00$ & $6.2930 \mathrm{E}-01$ & $-1.6994 \mathrm{E}+00$ & $8.1550 \mathrm{E}-01$ & $-7.4754 \mathrm{E}-01$ & $8.3200 \mathrm{E}-01$ \\
\hline$-3.0159 \mathrm{E}+00$ & $6.3503 \mathrm{E}-01$ & $-1.6738 \mathrm{E}+00$ & $8.1693 \mathrm{E}-01$ & $-7.2908 \mathrm{E}-01$ & $8.3200 \mathrm{E}-01$ \\
\hline$-2.9908 \mathrm{E}+00$ & $6.4075 \mathrm{E}-01$ & $-1.6485 \mathrm{E}+00$ & $8.1827 \mathrm{E}-01$ & $-7.1062 \mathrm{E}-01$ & $8.3200 \mathrm{E}-01$ \\
\hline$-2.9652 \mathrm{E}+00$ & $6.4645 \mathrm{E}-01$ & $-1.6235 \mathrm{E}+00$ & $8.1953 \mathrm{E}-01$ & $-6.9217 \mathrm{E}-01$ & $8.3200 \mathrm{E}-01$ \\
\hline$-2.9394 \mathrm{E}+00$ & $6.5211 \mathrm{E}-01$ & $-1.5988 \mathrm{E}+00$ & 8.2073E-01 & $-6.7371 \mathrm{E}-01$ & $8.3200 \mathrm{E}-01$ \\
\hline$-2.9132 \mathrm{E}+00$ & $6.5775 \mathrm{E}-01$ & $-1.5744 \mathrm{E}+00$ & $8.2185 \mathrm{E}-01$ & $-6.5525 \mathrm{E}-01$ & $8.3200 \mathrm{E}-01$ \\
\hline$-2.8867 \mathrm{E}+00$ & $6.6335 \mathrm{E}-01$ & $-1.5503 \mathrm{E}+00$ & $8.2290 \mathrm{E}-01$ & $-6.3679 \mathrm{E}-01$ & $8.3200 \mathrm{E}-01$ \\
\hline$-2.8600 \mathrm{E}+00$ & $6.6890 \mathrm{E}-01$ & $-1.5265 \mathrm{E}+00$ & $8.2387 \mathrm{E}-01$ & $-6.1834 \mathrm{E}-01$ & $8.3200 \mathrm{E}-01$ \\
\hline$-2.8329 \mathrm{E}+00$ & $6.7440 \mathrm{E}-01$ & $-1.5030 \mathrm{E}+00$ & $8.2477 \mathrm{E}-01$ & $-5.9988 \mathrm{E}-01$ & $8.3200 \mathrm{E}-01$ \\
\hline$-2.8056 \mathrm{E}+00$ & $6.7984 \mathrm{E}-01$ & $-1.4799 \mathrm{E}+00$ & $8.2561 \mathrm{E}-01$ & $-5.8142 \mathrm{E}-01$ & $8.3200 \mathrm{E}-01$ \\
\hline$-2.7780 \mathrm{E}+00$ & $6.8521 \mathrm{E}-01$ & $-1.4570 \mathrm{E}+00$ & $8.2640 \mathrm{E}-01$ & $-5.6296 \mathrm{E}-01$ & $8.3200 \mathrm{E}-01$ \\
\hline$-2.7502 \mathrm{E}+00$ & $6.9052 \mathrm{E}-01$ & $-1.4345 \mathrm{E}+00$ & $8.2713 \mathrm{E}-01$ & $-5.4450 \mathrm{E}-01$ & $8.3200 \mathrm{E}-01$ \\
\hline$-2.7222 \mathrm{E}+00$ & $6.9575 \mathrm{E}-01$ & $-1.4124 \mathrm{E}+00$ & $8.2779 \mathrm{E}-01$ & $-5.2605 \mathrm{E}-01$ & $8.3200 \mathrm{E}-01$ \\
\hline$-2.6940 \mathrm{E}+00$ & 7.0091E-01 & $-1.3905 \mathrm{E}+00$ & $8.2841 \mathrm{E}-01$ & $-5.0759 \mathrm{E}-01$ & $8.3200 \mathrm{E}-01$ \\
\hline$-2.6656 \mathrm{E}+00$ & $7.0598 \mathrm{E}-01$ & $-1.3690 \mathrm{E}+00$ & 8.2897E-01 & $-4.8913 \mathrm{E}-01$ & $8.3200 \mathrm{E}-01$ \\
\hline$-2.6371 \mathrm{E}+00$ & 7.1096E-01 & $-1.3478 \mathrm{E}+00$ & $8.2948 \mathrm{E}-01$ & $-4.7067 \mathrm{E}-01$ & $8.3200 \mathrm{E}-01$ \\
\hline$-2.6083 \mathrm{E}+00$ & $7.1585 \mathrm{E}-01$ & $-1.3270 \mathrm{E}+00$ & 8.2994E-01 & $-4.5222 \mathrm{E}-01$ & $8.3200 \mathrm{E}-01$ \\
\hline$-2.5795 \mathrm{E}+00$ & $7.2066 \mathrm{E}-01$ & $-1.3065 \mathrm{E}+00$ & $8.3035 \mathrm{E}-01$ & $-4.3376 \mathrm{E}-01$ & $8.3200 \mathrm{E}-01$ \\
\hline$-2.5505 \mathrm{E}+00$ & $7.2536 \mathrm{E}-01$ & $-1.2863 \mathrm{E}+00$ & $8.3072 \mathrm{E}-01$ & $-4.1530 \mathrm{E}-01$ & $8.3200 \mathrm{E}-01$ \\
\hline$-2.5214 \mathrm{E}+00$ & 7.2996E-01 & $-1.2665 \mathrm{E}+00$ & $8.3104 \mathrm{E}-01$ & $-3.9684 \mathrm{E}-01$ & $8.3200 \mathrm{E}-01$ \\
\hline$-2.4922 \mathrm{E}+00$ & 7.3446E-01 & $-1.2470 \mathrm{E}+00$ & $8.3132 \mathrm{E}-01$ & $-3.7838 \mathrm{E}-01$ & $8.3200 \mathrm{E}-01$ \\
\hline$-2.4629 \mathrm{E}+00$ & $7.3885 \mathrm{E}-01$ & $-1.2279 \mathrm{E}+00$ & $8.3155 \mathrm{E}-01$ & $-3.5993 \mathrm{E}-01$ & $8.3200 \mathrm{E}-01$ \\
\hline$-2.4336 \mathrm{E}+00$ & 7.4314E-01 & $-1.2091 \mathrm{E}+00$ & $8.3176 \mathrm{E}-01$ & $-3.4147 \mathrm{E}-01$ & $8.3200 \mathrm{E}-01$ \\
\hline$-2.4043 E+00$ & 7.4731E-01 & $-1.1905 \mathrm{E}+00$ & 8.3193E-01 & $-3.2301 \mathrm{E}-01$ & $8.3200 \mathrm{E}-01$ \\
\hline$-2.3749 \mathrm{E}+00$ & 7.5138E-01 & $-1.1813 \mathrm{E}+00$ & $8.3200 \mathrm{E}-01$ & $-3.0455 \mathrm{E}-01$ & $8.3200 \mathrm{E}-01$ \\
\hline$-2.3455 \mathrm{E}+00$ & 7.5533E-01 & $-1.1721 \mathrm{E}+00$ & $8.3200 \mathrm{E}-01$ & $-2.8610 \mathrm{E}-01$ & $8.3200 \mathrm{E}-01$ \\
\hline$-2.3161 E+00$ & 7.5917E-01 & $-1.1536 \mathrm{E}+00$ & $8.3200 \mathrm{E}-01$ & $-2.6764 \mathrm{E}-01$ & $8.3200 \mathrm{E}-01$ \\
\hline$-2.2867 \mathrm{E}+00$ & $7.6290 \mathrm{E}-01$ & $-1.1352 \mathrm{E}+00$ & $8.3200 \mathrm{E}-01$ & $-2.4918 \mathrm{E}-01$ & $8.3200 \mathrm{E}-01$ \\
\hline$-2.2574 \mathrm{E}+00$ & 7.6651E-01 & $-1.1167 \mathrm{E}+00$ & $8.3200 \mathrm{E}-01$ & $-2.3072 \mathrm{E}-01$ & $8.3200 \mathrm{E}-01$ \\
\hline$-2.2281 \mathrm{E}+00$ & $7.7001 \mathrm{E}-01$ & $-1.0982 \mathrm{E}+00$ & $8.3200 \mathrm{E}-01$ & $-2.1226 \mathrm{E}-01$ & $8.3200 \mathrm{E}-01$ \\
\hline$-2.1989 \mathrm{E}+00$ & $7.7340 \mathrm{E}-01$ & $-1.0798 \mathrm{E}+00$ & $8.3200 \mathrm{E}-01$ & $-1.9381 \mathrm{E}-01$ & $8.3200 \mathrm{E}-01$ \\
\hline$-2.1698 \mathrm{E}+00$ & $7.7666 \mathrm{E}-01$ & $-1.0613 \mathrm{E}+00$ & $8.3200 \mathrm{E}-01$ & $-1.7535 \mathrm{E}-01$ & $8.3200 \mathrm{E}-01$ \\
\hline$-2.1407 E+00$ & $7.7982 \mathrm{E}-01$ & $-1.0429 \mathrm{E}+00$ & $8.3200 \mathrm{E}-01$ & $-1.5689 \mathrm{E}-01$ & $8.3200 \mathrm{E}-01$ \\
\hline$-2.1118 \mathrm{E}+00$ & 7.8287E-01 & $-1.0244 \mathrm{E}+00$ & $8.3200 \mathrm{E}-01$ & $-1.3843 \mathrm{E}-01$ & $8.3200 \mathrm{E}-01$ \\
\hline$-2.0830 \mathrm{E}+00$ & $7.8580 \mathrm{E}-01$ & $-1.0059 \mathrm{E}+00$ & $8.3200 \mathrm{E}-01$ & $-1.1998 \mathrm{E}-01$ & $8.3200 \mathrm{E}-01$ \\
\hline$-2.0543 \mathrm{E}+00$ & $7.8860 \mathrm{E}-01$ & $-9.8749 \mathrm{E}-01$ & $8.3200 \mathrm{E}-01$ & $-1.0152 \mathrm{E}-01$ & $8.3200 \mathrm{E}-01$ \\
\hline$-2.0258 \mathrm{E}+00$ & $7.9129 \mathrm{E}-01$ & $-9.6903 \mathrm{E}-01$ & $8.3200 \mathrm{E}-01$ & $-8.3060 \mathrm{E}-02$ & $8.3200 \mathrm{E}-01$ \\
\hline$-1.9975 \mathrm{E}+00$ & 7.9387E-01 & $-9.5057 \mathrm{E}-01$ & $8.3200 \mathrm{E}-01$ & $-6.4602 \mathrm{E}-02$ & $8.3200 \mathrm{E}-01$ \\
\hline$-1.9693 E+00$ & $7.9634 \mathrm{E}-01$ & $-9.3212 \mathrm{E}-01$ & $8.3200 \mathrm{E}-01$ & $-4.6144 \mathrm{E}-02$ & $8.3200 \mathrm{E}-01$ \\
\hline$-1.9413 E+00$ & $7.9870 \mathrm{E}-01$ & $-9.1366 \mathrm{E}-01$ & $8.3200 \mathrm{E}-01$ & $-2.7687 \mathrm{E}-02$ & $8.3200 \mathrm{E}-($ \\
\hline$-1.9135 E+00$ & $8.0096 \mathrm{E}-01$ & $-8.9520 \mathrm{E}-01$ & $8.3200 \mathrm{E}-01$ & $-9.2287 \mathrm{E}-03$ & $8.3200 \mathrm{E}-01$ \\
\hline$-1.8859 \mathrm{E}+00$ & $8.0311 \mathrm{E}-01$ & $-8.7674 \mathrm{E}-01$ & $8.3200 \mathrm{E}-01$ & $0.0000 \mathrm{E}+00$ & $8.3200 \mathrm{E}-$ \\
\hline$-1.8585 E+00$ & $8.0516 \mathrm{E}-01$ & $-8.5829 \mathrm{E}-01$ & $8.3200 \mathrm{E}-01$ & & \\
\hline$-1.8314 \mathrm{E}+00$ & $8.0711 \mathrm{E}-01$ & $-8.3983 \mathrm{E}-01$ & $8.3200 \mathrm{E}-01$ & & \\
\hline
\end{tabular}


Mach 3.31 nozzle contour

\begin{tabular}{|c|c|c|c|c|c|}
\hline$x$, in. & in. & $x$, in. & $y$, in. & $x$, in. & $v$ in \\
\hline 0.03758 & 0.134813 & 0.314153 & 0.227956 & 0.777865 & 22137 \\
\hline 0.03758 & 0.134813 & 0.316721 & 0.229288 & 0.780529 & 0.423088 \\
\hline 0.03758 & 0.134909 & 0.321764 & 0.231856 & 0.785952 & 0.424991 \\
\hline 0.03758 & 0.134909 & 0.332039 & 0.236899 & 0.788616 & 0.425847 \\
\hline 0.03758 & 0.134909 & 0.337176 & 0.239372 & 0.790043 & 0.426323 \\
\hline 0.048521 & 0.135099 & 0.347452 & 0.244415 & 0.792707 & 0.427274 \\
\hline 0.049949 & 0.135099 & 0.368002 & 0.254405 & 0.798035 & 0.429082 \\
\hline 0.051376 & 0.135194 & 0.388647 & 0.264204 & 0.808881 & 0.432792 \\
\hline 0.052803 & 0.135194 & 0.409293 & 0.273908 & 0.814304 & 0.4346 \\
\hline 0.05423 & 0.135289 & 0.430033 & 0.283517 & 0.82515 & 0.43831 \\
\hline 0.057084 & 0.135384 & 0.440499 & 0.288179 & 0.846842 & 0.445541 \\
\hline 0.059938 & 0.135575 & 0.445636 & 0.290558 & 0.868534 & 0.452581 \\
\hline 0.062792 & 0.135765 & 0.456102 & 0.29522 & 0.890321 & 0.459622 \\
\hline 0.065647 & 0.135955 & 0.461334 & 0.297503 & 0.912108 & 0.466472 \\
\hline 0.068501 & 0.136145 & 0.463903 & 0.29874 & 0.933895 & 0.473322 \\
\hline 0.074114 & 0.136621 & 0.469136 & 0.301023 & 0.955777 & 0.479982 \\
\hline 0.079823 & 0.137287 & 0.479601 & 0.30559 & 0.977659 & 0.486642 \\
\hline 0.085531 & 0.137858 & 0.500532 & 0.314723 & 0.999542 & 0.493111 \\
\hline 0.096757 & 0.139475 & 0.521558 & 0.323667 & 1.021519 & 0.499581 \\
\hline 0.108079 & 0.141283 & 0.532118 & 0,328043 & 1.043401 & 0.50586 \\
\hline 0.119211 & 0.143471 & 0.537351 & 0,330326 & 1.065474 & 0.512139 \\
\hline 0.124824 & 0.144708 & 0.540015 & 0.331468 & 1.087546 & 0.518323 \\
\hline 0.13586 & 0.147467 & 0.541347 & 0.331944 & 1.109619 & 0.524317 \\
\hline 0.141378 & 0.148894 & 0.543916 & 0.333085 & 1.131691 & 0.530311 \\
\hline 0.152414 & 0.152034 & 0.549244 & 0.335274 & 1.153764 & 0.536209 \\
\hline 0.173916 & 0.159169 & 0.551812 & 0.336415 & 1.175836 & 0.542013 \\
\hline 0.184667 & 0.16326 & 0.55714 & 0.338604 & 1.197909 & 0.547721 \\
\hline 0.187331 & 0.164307 & 0.567701 & 0.342885 & 1.220076 & 0.553335 \\
\hline 0.188663 & 0.164878 & 0.588917 & 0.351447 & 1.231113 & 0.556189 \\
\hline 0.191327 & 0.165924 & 0.610133 & 0.36001 & 1.236726 & 0.557521 \\
\hline 0.196464 & 0.168303 & 0.63135 & 0.368287 & 1.247762 & 0.56028 \\
\hline 0.199128 & 0.169349 & 0.652661 & 0.376564 & 1.253375 & 0.561707 \\
\hline 0.20046 & 0.16992 & 0.674067 & 0.384651 & 1.264412 & 0.564371 \\
\hline 0.203029 & 0.171062 & 0.695474 & 0.392643 & 1.286674 & 0.569794 \\
\hline 0.204266 & 0.171728 & 0.716881 & 0.40054 & 1.308842 & 0.575122 \\
\hline 0.20693 & 0.17287 & 0.738477 & 0.408246 & 1.331105 & 0.580354 \\
\hline 0.212067 & 0.175343 & 0.749228 & 0.412052 & 1.353368 & 0.585492 \\
\hline 0.214541 & 0.176675 & 0.754556 & 0.413954 & 1.375726 & 0.59063 \\
\hline 0.215873 & 0.177246 & 0.757315 & 0.415001 & 1.397988 & 0.595577 \\
\hline 0.216444 & 0.177627 & 0.762643 & 0.416809 & 1.420346 & 0.600524 \\
\hline 0.217776 & 0.178293 & 0.765307 & 0.41776 & 1.442704 & 0.605376 \\
\hline 0.220249 & 0.179529 & 0.766734 & 0.418331 & 1,464967 & 0.610228 \\
\hline 0.225292 & 0.182193 & 0.769398 & 0.419282 & 1,48742 & 0.61489 \\
\hline 0.22786 & 0.183525 & 0.77073 & 0.419758 & 1.509778 & 0.619552 \\
\hline 0.232903 & 0.186189 & 0.771396 & 0.419948 & 1.521004 & 0.621836 \\
\hline 0.242988 & 0.191517 & 0.772823 & 0.420424 & 1.526523 & 0.622977 \\
\hline 0.263253 & 0.202078 & 0.773489 & 0.420614 & 1.529377 & 0.623548 \\
\hline 0.283517 & 0.212543 & 0.773774 & 0.420805 & 1.530709 & 0.623834 \\
\hline 0.293697 & 0.217681 & 0.77444 & 0.420995 & 1.533563 & 0.624404 \\
\hline 0.2988355 & 0.220249 & 0.775772 & 0.421471 & 1.534895 & 0.62469 \\
\hline 0.309015 & 0.225387 & 0.776533 & 0.421661 & 1.537749 & 0.625261 \\
\hline
\end{tabular}


Mach 3.31 nozzle contour (continued)

\begin{tabular}{rrrr} 
x, in. & y, in. & x, in. & \multicolumn{1}{c}{$y$, in. } \\
1.543362 & 0.626402 & 2.675529 & 0.781481 \\
1.554589 & 0.628686 & 2.698363 & 0.783383 \\
1.577042 & 0.633062 & 2.721101 & 0.785191 \\
1.599495 & 0.637534 & 2.743935 & 0.786999 \\
1.621948 & 0.641815 & 2.766674 & 0.788806 \\
1.644306 & 0.646191 & 2.789507 & 0.790519 \\
1.666854 & 0.650378 & 2.812246 & 0.792231 \\
1.689307 & 0.654469 & 2.835174 & 0.793849 \\
1.711855 & 0.658464 & 2.857913 & 0.795466 \\
1.734309 & 0.66246 & 2.880746 & 0.796988 \\
1.756857 & 0.666456 & 2.90358 & 0.798606 \\
1.779405 & 0.670357 & 2.926414 & 0.800033 \\
1.801953 & 0.674163 & 2.949247 & 0.801555 \\
1.824501 & 0.677873 & 2.971986 & 0.802887 \\
1.84705 & 0.681584 & 2.994915 & 0.804314 \\
1.869598 & 0.685294 & 3.017748 & 0.805646 \\
1.892241 & 0.688814 & 3.040487 & 0.806978 \\
1.914789 & 0.692334 & 3.063415 & 0.808215 \\
1.937433 & 0.695855 & 3.086249 & 0.809547 \\
1.959981 & 0.69928 & 3.108988 & 0.810593 \\
1.982624 & 0.702609 & 3.131916 & 0.81183 \\
2.005267 & 0.705939 & 3.15475 & 0.812972 \\
2.027911 & 0.709174 & 3.177584 & 0.814019 \\
2.050554 & 0.712409 & 3.200417 & 0.815065 \\
2.073197 & 0.715549 & 3.223346 & 0.816112 \\
2.095841 & 0.718593 & 3.24618 & 0.817158 \\
2.118484 & 0.721638 & 3.269013 & 0.81811 \\
2.141128 & 0.724682 & 3.291752 & 0.819061 \\
2.163866 & 0.727631 & 3.31468 & 0.819917 \\
2.186509 & 0.730486 & 3.337609 & 0.820773 \\
2.209248 & 0.73334 & 3.360443 & 0.82163 \\
2.231891 & 0.736099 & 3.383372 & 0.822486 \\
2.25463 & 0.738858 & 3.406205 & 0.823247 \\
2.277368 & 0.741617 & 3.428944 & 0.824008 \\
2.300011 & 0.744186 & 3.451777 & 0.824769 \\
2.32275 & 0.74685 & 3.474706 & 0.825435 \\
2.345488 & 0.749418 & 3.497635 & 0.826101 \\
2.368227 & 0.751892 & 3.520564 & 0.826672 \\
2.390965 & 0.754366 & 3.543492 & 0.827243 \\
2.607124 & 0.775582 & 3.778108 & 0.831619 \\
2.402287 & 0.755603 & 3.566421 & 0.827814 \\
2.425026 & 0.757981 & 3.589255 & 0.828385 \\
2.447764 & 0.76036 & 3.612183 & 0.82886 \\
2.470598 & 0.762643 & 3.635017 & 0.829336 \\
2.493336 & 0.764926 & 3.657851 & 0.829812 \\
2.516075 & 0.767114 & 3.680779 & 0.830192 \\
2.538813 & 0.769303 & 3.703423 & 0.830573 \\
2.561647 & 0.771491 & 3.726352 & 0.830953 \\
& 0.77758 & 3.797611 & 0.831905 \\
& 0.779578 & 3.800656 & 0.832
\end{tabular}




\section{Appendix C: List of all measured and calculated parameters in the data set for run 14.7}

The following section lists the raw data measurements and the parameters calculated from the raw data collected from one run at the time slice used as the blowout point. Note that "NA" added to the end of a parameter means it is not applicable for the present run. Plots to describe the location of instrumentation on the test rig and plots of transient response of tests parameters during a run are shown after the data list. The detailed list of data in this appendix can serve as a data set for validation of flameholding and flowfield modeling. Similar data lists from other runs are also available from the author, see the runs listed in Appendix A.

Table C.2. Measurements in the data set during run 14.7, at $99.4 \mathrm{sec}$.

\begin{tabular}{|c|c|c|}
\hline Measurement & Units & \\
\hline Flowrate measurements & & \\
\hline F Wwater htrA & $\mathrm{Hz}$ & 287.8 \\
\hline F Wwater cal & $\mathrm{Hz}$ & 113.9 \\
\hline F Water nozzle & $\mathrm{Hz}$ & 190.9 \\
\hline F Wmicromotion & $\mathrm{Hz}$ & 246.1 \\
\hline F Wwater cavity & $\mathrm{Hz}$ & 221.0 \\
\hline F Wwater throttle door & $\mathrm{Hz}$ & 126.0 \\
\hline F WJP fuel NA & $\mathrm{Hz}$ & 0.0 \\
\hline Pt air venturi 1 & PSID & 109.6 \\
\hline Pt O2 venturi 2 & PSID & 150.1 \\
\hline $\mathrm{Pt} \mathrm{H} 2$ venturi 3 & PSID & 140.7 \\
\hline Pt air heater & PSID & 45.6 \\
\hline Pt air venturi dnstrm 5 & PSID & 55.8 \\
\hline Pt O2 venturi dnstrm 6 & PSID & 83.3 \\
\hline Pt H2 venturi dnstrm 7 & PSID & 52.8 \\
\hline Pt 5000 air venturi 8 NA & PSID & 52.9 \\
\hline Pt 5000 air venturi dnstrm 9 NA & PSID & 1624.1 \\
\hline Tt 400 air venturi 100 & $\mathrm{~F}$ & 56.3 \\
\hline Tt O2 venturi 101 & $\mathrm{~F}$ & 37.0 \\
\hline Tt H2 venturi 102 & $\mathrm{~F}$ & 59.8 \\
\hline Tt 5000 air venturi 103 & $\mathrm{~F}$ & 61.0 \\
\hline Paccumulator 10 & PSID & 720.2 \\
\hline Combustor pressures & & \\
\hline Pinlet B0050 15 & PSID & -9.289 \\
\hline Pisolator B0640 16 & PSID & -8.501 \\
\hline Pcavity B2230 17 & PSID & 4.359 \\
\hline Fuel injection pressures & & \\
\hline Pfuel CE manifold 24 & PSID & 3.7 \\
\hline Pfuel CC manifold 25 & PSID & 193.0 \\
\hline Other measurements & & \\
\hline
\end{tabular}

Paddle meter frequency for cooling water Paddle meter frequency for quench water Paddle meter frequency for cooling water Micromotion frequency for ethylene flowrate Turbinemeter frequency for cooling water Turbinemeter frequency for cooling water Turbinemeter frequency for JP flowrate Pressure upstream of venturi Pressure upstream of venturi Pressure upstream of venturi Air heater wall pressure to indicate stagnation pressure in air heater Pressure downstream of venturi Pressure downstream of venturi Pressure downstream of venturi Pressure upstream of venturi Pressure downstream of venturi

Temperature upstream of venturi Temperature upstream of venturi Temperature upstream of venturi Temperature upstream of venturi

Ethylene supply pressure

Extra comb pressure not on Scanivalve sys Extra comb pressure not on Scanivalve sys Extra comb pressure not on Scanivalve sys

Pressure in CE fuel injection manifold

Pressure in CE fuel injection manifold 


\begin{tabular}{|l|c|r|} 
P_baro & PSIA & 14.69517 \\
\hline V Spark on? & $\mathrm{V}$ & -0.00027 \\
\hline V throttle position, V & $\mathrm{V}$ & 0.760882 \\
\hline camera trigger & $\mathrm{V}$ & 5.2 \\
\hline
\end{tabular}

\section{Water system temperatures}

\begin{tabular}{|l|c|r|}
\hline Twater inlet 116 & F & 65.3 \\
\hline Twater air heater exit 117 & F & 66.6 \\
\hline Twater transition exit 118 & F & 86.8 \\
\hline Twater nozzle exit 119 & F & 71.8 \\
\hline Twater cavity upstream exit 120 & F & 81.4 \\
\hline Twater cavity floor exit 121 & F & 85.1 \\
\hline Twater throttle door exit 122 & F & 88.9 \\
\hline Twater_cal_quench 124 & F & 66.3 \\
\hline
\end{tabular}

\begin{tabular}{|l|l|l|}
\hline Heat sink wall temperatures & & \\
\hline Twi B0500 200 & F & 452.8 \\
\hline
\end{tabular}

\begin{tabular}{|l|l|r|}
\hline Twm B0450 201 & F & 414.7 \\
\hline Twi B1223 202 & F & 485.3 \\
\hline
\end{tabular}

\begin{tabular}{|l|l|r|}
\hline Twm B1223 203 & F & 464.9 \\
\hline
\end{tabular}

\begin{tabular}{|l|l|r|}
\hline Twi B3404 204 & F & 528.1 \\
\hline Twm B3404 205 & F & 382.0 \\
\hline
\end{tabular}

\begin{tabular}{|l|l|r|}
\hline Twi B4710 206 & F & 382.0 \\
\hline Twm B4710 207 & F & 158.9 \\
\hline Twi C1380 212 & F & 149.0 \\
\hline Twm C1380 213 & F & 476.4 \\
\hline Twi C4521 216 & F & 393.2 \\
\hline Twm C4545 217 & F & 432.4 \\
\hline Twi S3100 221 & F & 257.7 \\
\hline Twi S3800 223 & F & 497.4 \\
\hline Fuel system tempertures & F & 376.9 \\
\hline
\end{tabular}

\begin{tabular}{|c|c|c|c|}
\hline & & & \\
\hline Fuel system temperatures & & & \\
\hline Tfuel supply 300 & $\mathrm{~F}$ & 61.8 & JP system, fuel supply, used for turbine meter \\
\hline
\end{tabular}

\begin{tabular}{|l|c|r|}
\hline Tfuel 720kW htr inlet NA & $\mathrm{F}$ & 294.2 \\
\hline Tfuel 720kW htr exit NA & $\mathrm{F}$ & 2412.3 \\
\hline & & \\
\hline Tfuel CE 310 & $\mathrm{F}$ & 59.2 \\
\hline Tfuel CC 311 T \\
\hline Wall TCs in new hardware & $\mathrm{F}$ & 43.8 \\
\hline
\end{tabular}

\begin{tabular}{|l|r|r|} 
Wall TCs in new hardware & & \\
\hline T313 Twall_throttle_door & $\mathrm{F}$ & 99.6 \\
\hline T314 Twall_body_inner_15.90 & $\mathrm{F}$ & 417.1 \\
\hline T315 Twall_body_inner_17.12 & $\mathrm{F}$ & 116.7 \\
\hline T316 Twall_body_inner_17.72 & $\mathrm{F}$ & 117.6 \\
\hline T317 Twall_body_inner_18.49 & $\mathrm{F}$ & 116.8 \\
\hline T318 Twall_body_inner_19.20 & $\mathrm{F}$ & 131.8 \\
\hline T319 Twall_body_inner_20.39 & $\mathrm{F}$ & 158.7 \\
\hline T320 Twall_body_inner_21.14 & $\mathrm{F}$ & 110.6 \\
\hline T321 Twall_body_inner_21.59 & $\mathrm{F}$ & 149.4 \\
\hline T322 Twall_body_inner_22.76 & $\mathrm{F}$ & 149.8 \\
\hline T323 Twall_body_inner_23.71 & $\mathrm{F}$ & 138.9 \\
\hline T324 Twall_body_inner_24.67 & $\mathrm{F}$ & 125.2 \\
\hline
\end{tabular}

Barometric pressure, add to PSID for PSIA Voltage to indicates spark is on Throttle position potentiometer voltage Voltage to indicate when HSV was triggered

Naming convention for heat sink wall TCs:

For example, Twi B0500 200

Tw for Twall

i for inner position, $\mathrm{m}$ for mid position

$\mathrm{B}$ for body wall, $\mathrm{C}$ for cowl wall

0050 axial position in tenths on an inch

200 is port name on DAQ system
JP system, fuel heater inlet

JP system, fuel heater exit

TC in CE fuel injector manifold

TC in CC fuel injector manifold

Mechanical throttle wall TC

Upstream side steel cavity wall frame

Copper cavity wall TCs, number is $\mathrm{x}$ location

Copper cavity wall TCs, number is $x$ location

Copper cavity wall TCs, number is $\mathrm{x}$ location

Copper cavity wall TCs, number is $x$ location

Copper cavity wall TCs, number is $\mathrm{x}$ location

Copper cavity wall TCs, number is $\mathrm{x}$ location

Copper cavity wall TCs, number is $\mathrm{x}$ location

Copper cavity wall TCs, number is $x$ location

Copper cavity wall TCs, number is $\mathrm{x}$ location

Copper cavity wall TCs, number is $\mathrm{x}$ location 


\begin{tabular}{|c|c|c|}
\hline T325 Twall_body_inner__ & $\mathrm{F}$ & 94.7 \\
\hline T326 Twall_body_inner_27.35 & $\mathrm{F}$ & 257.2 \\
\hline Tcavity gas & $\mathrm{F}$ & 1364.5 \\
\hline \multicolumn{3}{|l|}{ Wall pressures on Scanivalve } \\
\hline PSB0050A 101 & psig & -0.059 \\
\hline PSB0050B 102 & psig & -9.092 \\
\hline PSB0050C 103 & psig & -9.265 \\
\hline PSB0050D 104 & psig & -9.295 \\
\hline PSB0050E 105 & psig & -9.213 \\
\hline PSB0125C 106 & psig & -9.404 \\
\hline PSB0225C 107 & psig & -9.063 \\
\hline PSB0325C 108 & psig & -9.259 \\
\hline PSB0425C 110 & psig & -9.235 \\
\hline PSB0525C 111 & psig & -8.686 \\
\hline PSB0641C 112 & psig & -8.607 \\
\hline PSB0691D 113 & psig & -9.225 \\
\hline PSB0773B 114 & psig & -8.962 \\
\hline PSB0873C 115 & psig & -8.723 \\
\hline PSB0973C 201 & psig & -8.104 \\
\hline PSB1073C 202 & psig & 0.012 \\
\hline PSB1173C 203 & psig & -5.397 \\
\hline PSB1273C 204 & psig & -2.551 \\
\hline PSB1536C 206 & psig & 1.305 \\
\hline PSB1711C 207 & psig & 3.513 \\
\hline PSB1771C 208 & psig & 4.012 \\
\hline PSB1848C 209 & psig & 4.495 \\
\hline PSB1918C 210 & psig & -0.039 \\
\hline PSB2038C 211 & psig & 4.350 \\
\hline PSB2113C 212 & psig & 4.884 \\
\hline PSB2157C 213 & psig & 5.622 \\
\hline PSB2209C 301 & psig & 5.671 \\
\hline PSB2276C 302 & psig & 5.332 \\
\hline PSB2323C 303 & psig & 3.832 \\
\hline PSB2371C 304 & psig & 4.205 \\
\hline PSB2418C 305 & psig & 4.251 \\
\hline PSB2466C 306 & psig & 4.486 \\
\hline PSB2514C 307 & psig & 4.672 \\
\hline PSB2562C 308 & psig & 4.777 \\
\hline PSB2610C 309 & psig & 4.876 \\
\hline PSB2734C 310 & psig & 4.959 \\
\hline PSB4263C 401 & psig & -7.278 \\
\hline PSB4363C 402 & psig & -7.577 \\
\hline PSB4463C plugged 403 & psig & 22.307 \\
\hline PSB4563C 404 & psig & -7.509 \\
\hline PSW2950A 405 & psig & 5.545 \\
\hline PSW2950E slow 406 & psig & 1.891 \\
\hline
\end{tabular}

Copper cavity wall TCs, number is $\mathrm{x}$ location

Downstream side steel cavity wall frame

TC in cavity floor, partially contacts cavity gas

Naming convention for Scanivalve pressures:

For example: PSB0050A

$P S$ for static pressure

$B$ is for body wall, or top wall

(C is for cowl wall, or bottom wall)

SW for side wall

0050 is axial location in tenths of an inch

$A$ at end for negative lateral position, $-Z$

$(A, B, C, D, E$, is from $-z$ to $+z), C$ is center 


\begin{tabular}{|c|c|c|}
\hline PSW4200A 407 & psig & -7.672 \\
\hline PSW4200E 408 & psig & -7.258 \\
\hline PSB3154C 409 & psig & 5.745 \\
\hline PSB3254C 410 & psig & 0.009 \\
\hline PSB3354C 411 & psig & 5.743 \\
\hline PSB3853C 412 & psig & 2.632 \\
\hline PSB3883 413 & psig & 1.908 \\
\hline PSB3894 414 & psig & 1.689 \\
\hline PSB3905 415 & psig & 1.600 \\
\hline PSB3954C 416 & psig & -2.371 \\
\hline PSC0050A 501 & psig & -9.301 \\
\hline PSC0050B 502 & psig & -9.567 \\
\hline PSC0050C 503 & psig & -9.405 \\
\hline PSC0050D 504 & psig & -9.532 \\
\hline PSC0050E 505 & psig & -9.471 \\
\hline PSC0125C 506 & psig & -7.983 \\
\hline PSC0225C 507 & psig & -9.025 \\
\hline PSC0325C 508 & psig & -8.978 \\
\hline PSW0425A 509 & psig & -8.817 \\
\hline PSW0425E 510 & psig & -8.857 \\
\hline PSC0425C 511 & psig & -9.541 \\
\hline PSC0525C 512 & psig & -9.014 \\
\hline PSC0641C 513 & psig & -9.158 \\
\hline PSC0691D 514 & psig & -9.644 \\
\hline PSC0791B 515 & psig & -9.041 \\
\hline PSC0891C 516 & psig & -8.468 \\
\hline PSC0991C 601 & psig & -8.260 \\
\hline PSC1091C 602 & psig & -7.402 \\
\hline PSC1191C 603 & psig & -5.285 \\
\hline PSC1291C 604 & psig & -2.535 \\
\hline PSC1391C 605 & psig & -0.570 \\
\hline PSC1513C 606 & psig & 1.135 \\
\hline PSC3100C 702 & psig & 7.210 \\
\hline PSC3475C 705 & psig & 5.963 \\
\hline PSC $3900 \mathrm{C} 710$ & psig & 1.245 \\
\hline PSC4263C 713 & psig & -0.089 \\
\hline PSC4363C 714 & psig & -0.067 \\
\hline PSC4463C 715 & psig & -0.038 \\
\hline PSC4563C 716 & psig & -0.088 \\
\hline PSC4663C 801 & psig & -4.540 \\
\hline PSCC4763 802 & psig & -9.584 \\
\hline PSCC4863 803 & psig & -9.490 \\
\hline PSC5065A 804 & psig & 22.659 \\
\hline PSC5065C 805 & psig & -0.002 \\
\hline PSC5065E 806 & psig & 0.000 \\
\hline PSC5222D 807 & psig & -7.584 \\
\hline PSW4800A 808 & psig & -7.475 \\
\hline PSW4800E 809 & psig & -7.500 \\
\hline
\end{tabular}




\begin{tabular}{|l|c|r|} 
PSB4863C 810 & psig & -7.954 \\
\hline PSB5063A 811 & psig & -7.364 \\
\hline PSB5063C 812 & psig & -7.287 \\
\hline PSB5063E 813 & psig & -7.339 \\
\hline PSB5222B 814 & psig & 1.780 \\
\hline PSB5222D 815 & psig & -8.113 \\
\hline Pexhaust 816 & psig & -4.854 \\
\hline
\end{tabular}

Table C.2. Calculated parameters in the data set from run 14.7, at $99.4 \mathrm{sec}$

\begin{tabular}{|c|c|c|}
\hline Calculated parameters & Units & \\
\hline Air heater conditions & & \\
\hline Pt air venturi 1 & psia & 124.33 \\
\hline $\mathrm{Pt} \mathrm{O} 2$ venturi 2 & psia & 164.79 \\
\hline $\mathrm{Pt} \mathrm{H} 2$ venturi 3 & psia & 155.44 \\
\hline Pt air heater & psia & 60.32 \\
\hline Pt air venturi dnstrm 5 & psia & 70.52 \\
\hline Pt O2 venturi dnstrm 6 & psia & 98.01 \\
\hline Pt H2 venturi dnstrm 7 & psia & 67.53 \\
\hline Pt 5000 air venturi 8 NA & psia & 67.61 \\
\hline Pt 5000 air venturi dnstrm 9 NA & psia & 1638.83 \\
\hline Wair & pps & 3.557253 \\
\hline WO2 & pps & 0.247353 \\
\hline WH2 & pps & 0.019165 \\
\hline Winlet, pps & pps & 3.823771 \\
\hline W/A, pps/in2 & pps/in^2 & 0.38299 \\
\hline $\mathrm{XO} 2$ & & 0.212171 \\
\hline $\mathrm{YO} 2$ & & 0.240228 \\
\hline Tt inlet, $\mathrm{R}$ & $\mathrm{R}$ & 1460 \\
\hline Pratio air venturi & & 1.76318 \\
\hline Pratio $\mathrm{O} 2$ venturi & & 2.732102 \\
\hline Pratio H2 venturi & & 2.577184 \\
\hline JP fuel supply & & \\
\hline P JP fuel supply 12 NA & psia & 21.97 \\
\hline Pfuel htr inlet $13 \mathrm{NA}$ & psia & 10.05 \\
\hline Pfuel htr exit 14 NA & psia & 15.90 \\
\hline F/A stioc JP-7 NA & & 0.070093 \\
\hline density JP7 NA & $\mathrm{lbm} / \mathrm{ft}^{\wedge} 3$ & 49.88545 \\
\hline Wcomb JP7 NA & pps & $-2.3 \mathrm{E}-05$ \\
\hline ER JP-7 NA & & $-8.6 \mathrm{E}-05$ \\
\hline Gaseous fuel supply & & \\
\hline
\end{tabular}

Upstream of low pressure air sys venturi Upstream of oxygen sys venturi Upstream of hydrogen sys venturi Air heater wall pressure on downstream end Downstream of low pressure air sys venturi Downstream of oxygen sys venturi Downstream of hydrogen sys venturi Upstream of high pressure air sys venturi Downstream of high pressure air sys venturi Air flowrate into air heater Oxygen flowrate into air heater Hydrogen flowrate into air heater Sum of three flowrates into air heater Flow per unit area at rig inlet Oxygen mole fraction in vitiated air Qxygen mass fraction in vitiated air Equillibrium calculated inlet air total temp with correction for heat loss from water cooled inlet devices, this is the air temperature at blowout presented in the report figures Check if venturi is choked Check if venturi is choked Check if venturi is choked

JP fuel supply

JP fuel heater inlet JP fuel heater exit Stoichiometric fuel-to-air ratio JP-7 density calc from T fuel supply JP-7 flowrate from turbine meter Overall equivalence ratio 


\begin{tabular}{|l|c|r|} 
Paccumulator 10 & psia & 734.94 \\
\hline F/A stoic ethylene & & 0.070203 \\
\hline Wethylene & pps & 0.02453 \\
\hline & & \\
ER ethylene & & 0.091379 \\
\hline F/A stoic H2 fuel & & 0.030269 \\
\hline W H2 & pps & 0 \\
\hline ER H2 fuel & & 0 \\
\hline Fuel injection conditions & psia & 18.38 \\
\hline Pfuel CE manifold 24 NA & psia & 207.73 \\
\hline Pfuel CC manifold 25 & F & 59.18 \\
\hline Tfuel inj &
\end{tabular}

\section{Heat loss calculations}

\begin{tabular}{|l|c|r|}
\hline Whtr_water & pps & 14.276 \\
\hline Wthrottle_water & pps & 1.225 \\
\hline Wnozzle_water & pps & 5.302 \\
\hline Wcal_water & pps & 3.112 \\
\hline Wcavity_water & pps & 1.608 \\
\hline qloss air heater & BTU/s & 19.4 \\
\hline qloss trans flange & BTU/s & 2.3 \\
\hline qloss nozzle & BTU/s & 34.5 \\
\hline qloss inlet & BTU/s & 56.3 \\
\hline & BTU/s- & \\
qflux B5 & in^2 & 0.0576 \\
\hline & BTU/s- & \\
qflux B12 & in^2 & 0.0526 \\
\hline & BTU/s- & \\
qflux B34 & in^2 & 0.3043 \\
\hline & BTU/s- & \\
qflux C15 & in^2 & 0.1304 \\
\hline Twall B12, F & $\mathrm{F}$ & 491.1 \\
\hline Twall B34, F & $\mathrm{F}$ & 569.8 \\
\hline Twall C15, F & $\mathrm{F}$ & 491.5 \\
\hline Twall avg, F & $\mathrm{F}$ & 517.5 \\
\hline & & \\
\hline Combustor Pressures & & \\
\hline Pinlet B0050 15 & psia & 7.39 \\
\hline Pisolator B0640 16 & psia & 6.09 \\
\hline Pcavity B2230 17 & psia & 17.76 \\
\hline P inlet center - & psia & 5.603612 \\
\hline P inlet center & psia & 5.430541 \\
\hline P inlet center + & psia & 5.400383 \\
\hline P inlet corner & psia & 5.481838 \\
\hline P isol sidewall - & psia & 5.878566 \\
\hline P isol sidewall + & psia & 5.838559 \\
\hline P isol x=10 & psia & 6.591282 \\
\hline P cavity & psia & 19.04498 \\
\hline P downstream & psia & 20.44008 \\
\hline
\end{tabular}

Ethylene supply pressure

Stoichiometric fuel-to-air ratio

Ethylene fuel flowrate,from Micromotion

Overall equivalence ratio of ethylene, this is

the value of $\Phi$ presented in the report figures

Stoichiometric fuel-to-air ratio

$\mathrm{H} 2$ fuel flowrate, sometimes used for ignition

Overall equivalence ratio

Pressure in CE manifold, not used this run

Fuel injection pressure in CC supply manifold

Fuel injection temperature in supply manifold

Cooling water flowrate

Cooling water flowrate

Cooling water flowrate

Quench water injected in exhaust duct

Cooling water flowrate

Heat loss from air heater walls

Heat loss from flange that holds nozzle

Heat loss from inlet nozzle

Sum of heat loss from three inlet devices

Heat flux to heat sink wall

Heat flux to heat sink wall

Heat flux to heat sink wall

Heat flux to heat sink wall

Extrapolated heat sink rig inner wall temp

Extrapolated heat sink rig inner wall temp

Extrapolated heat sink rig inner wall temp

Avg of three Twall values

Extra comb pressure not on Scanivalve sys

Extra comb pressure not on Scanivalve sys

Extra comb pressure not on Scanivalve sys

$x=0.5, z=-0.75$, top wall

$x=0.5, z=0$, at center

$x=0.5, z=+0.75$, top wall

$x=0.5 z=+2$, top wall

$x=4.25, z=-3$, middle of sidewall in isolator

$x=4.25, z=+3$, middle of sidewall in isolator

$x=9.73$, center of top wall in isolator

$x=20.38$, floor of cavity

$x=31.54$, top wall downstream of cavity 


\begin{tabular}{|c|c|c|c|}
\hline$P$ ratio & & 3.526599 & \multirow{5}{*}{$\begin{array}{l}\text { Pcavity/Pinlet } \\
\text { Used for Pinlet } \\
\text { Used for Pcavity } \\
\text { Used for Pratio } \\
\text { Exhaust duct downstream of rig }\end{array}$} \\
\hline Pinlet & psia & 5.413128 & \\
\hline Pcavity & psia & 19.3442 & \\
\hline Pratio & psia & 3.573572 & \\
\hline Pexhaust & psia & 9.841683 & \\
\hline \multicolumn{4}{|c|}{ Other parameters } \\
\hline Spark on? & & $-2.7 \mathrm{E}-05$ & Indicates spark on \\
\hline $\mathrm{h}$ throttle, in & in & 0.892415 & Throttle height from potentiometer \\
\hline camera trigger & & -0.03362 & Indicates high speed video trigger \\
\hline
\end{tabular}

Figures C.1 and C.2 show plots of the pressure tap and wall temperature instrumentation locations on the locations on the test rig. Figures C.3 to C.6 show transient data during run 14.7 to give a better idea of how a test is performed. These are typical of the data collected in other runs. 


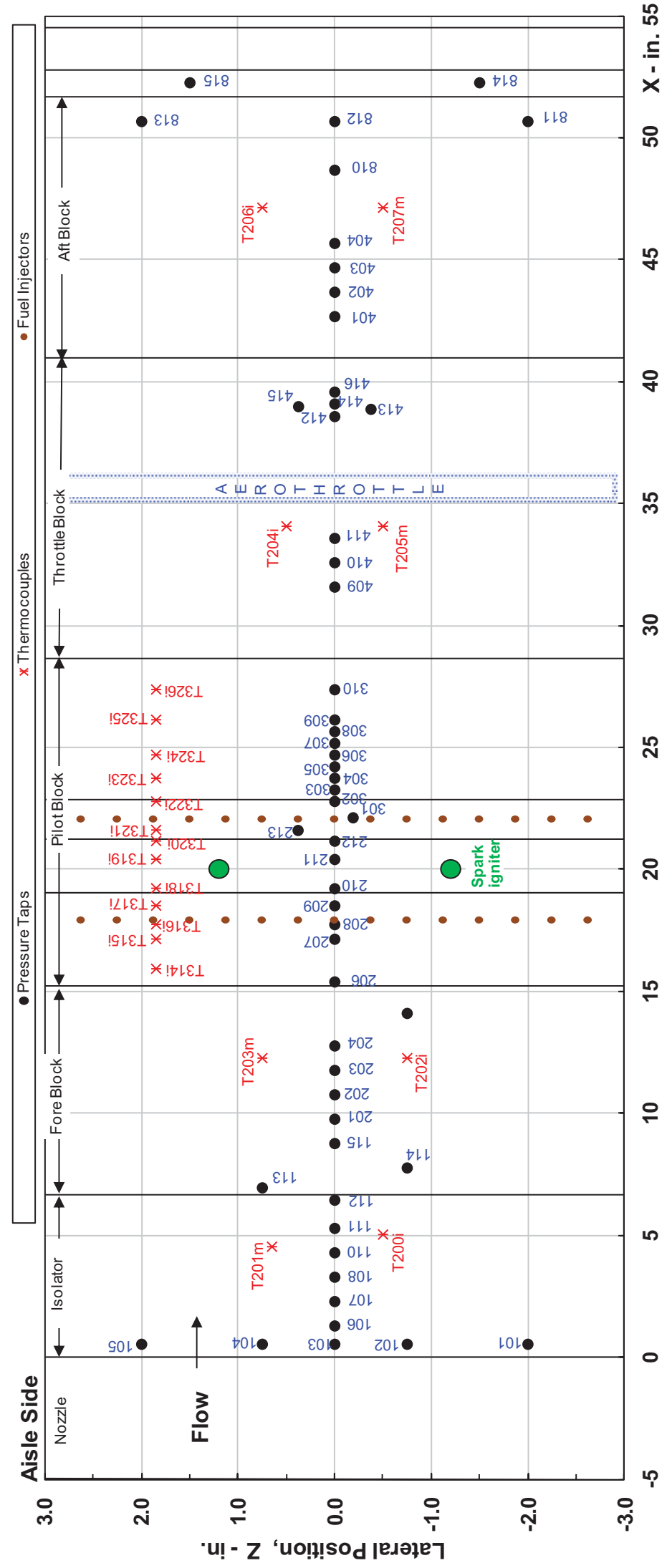

Figure C.1 Location Instrumentation on top wall of test rig 


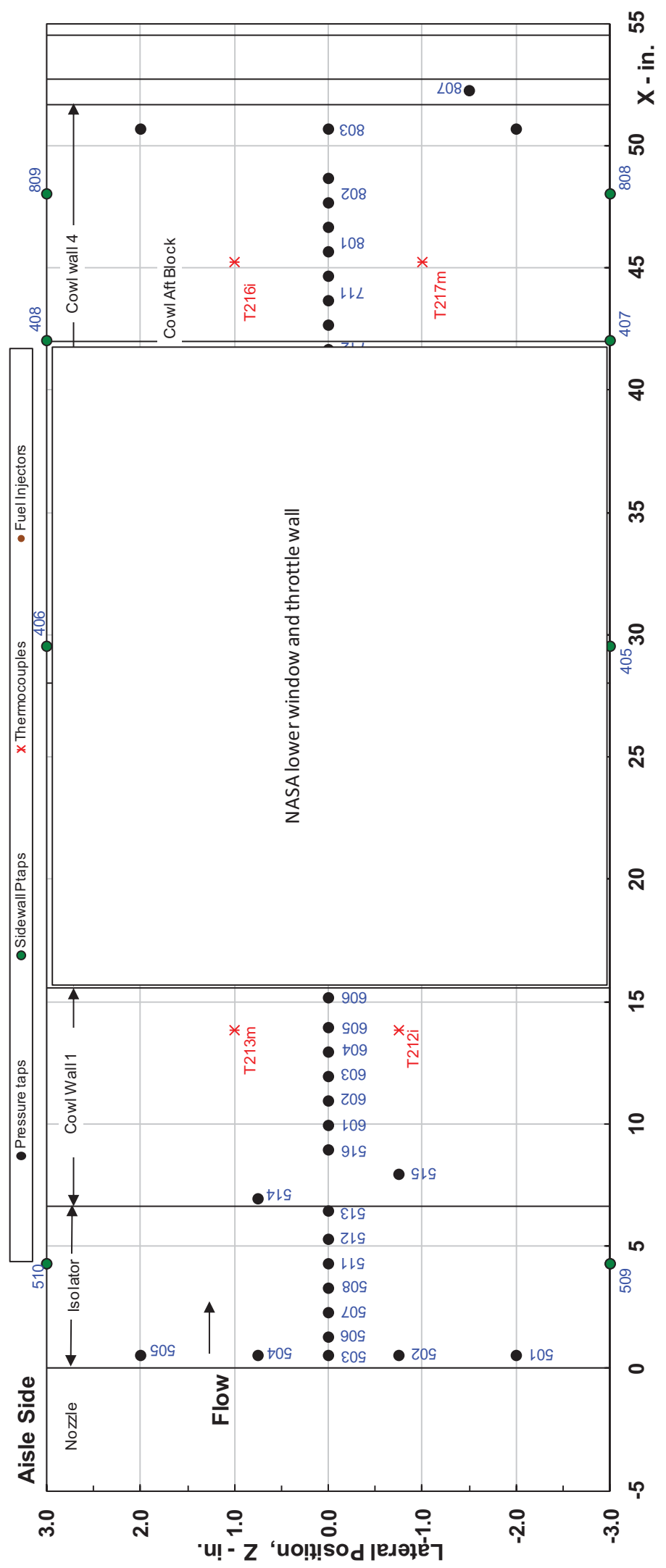

Figure C.2 Location Instrumentation on bottom and side walls of test rig 


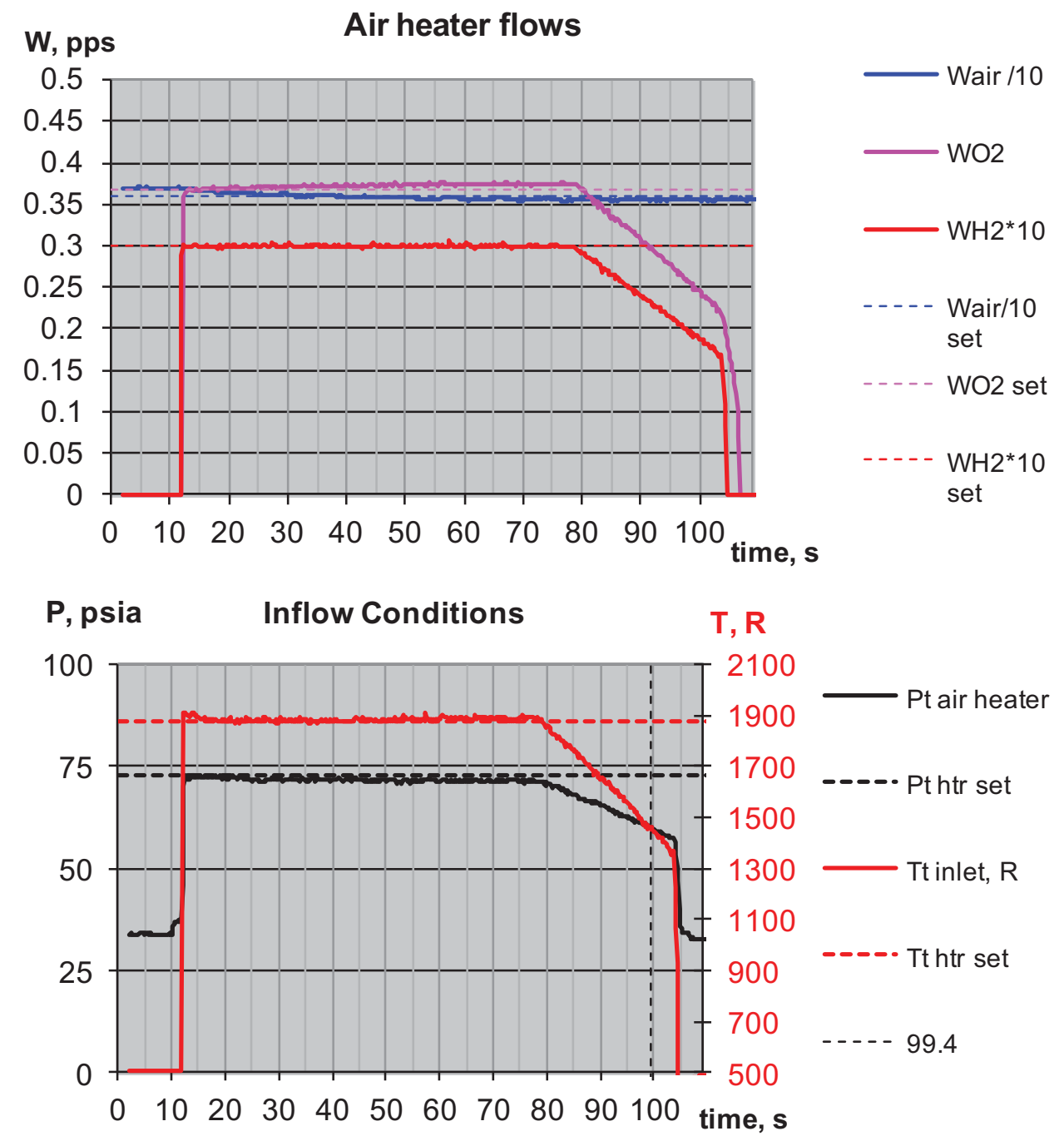

Figure C.3 Transient plot of the air heater conditions 

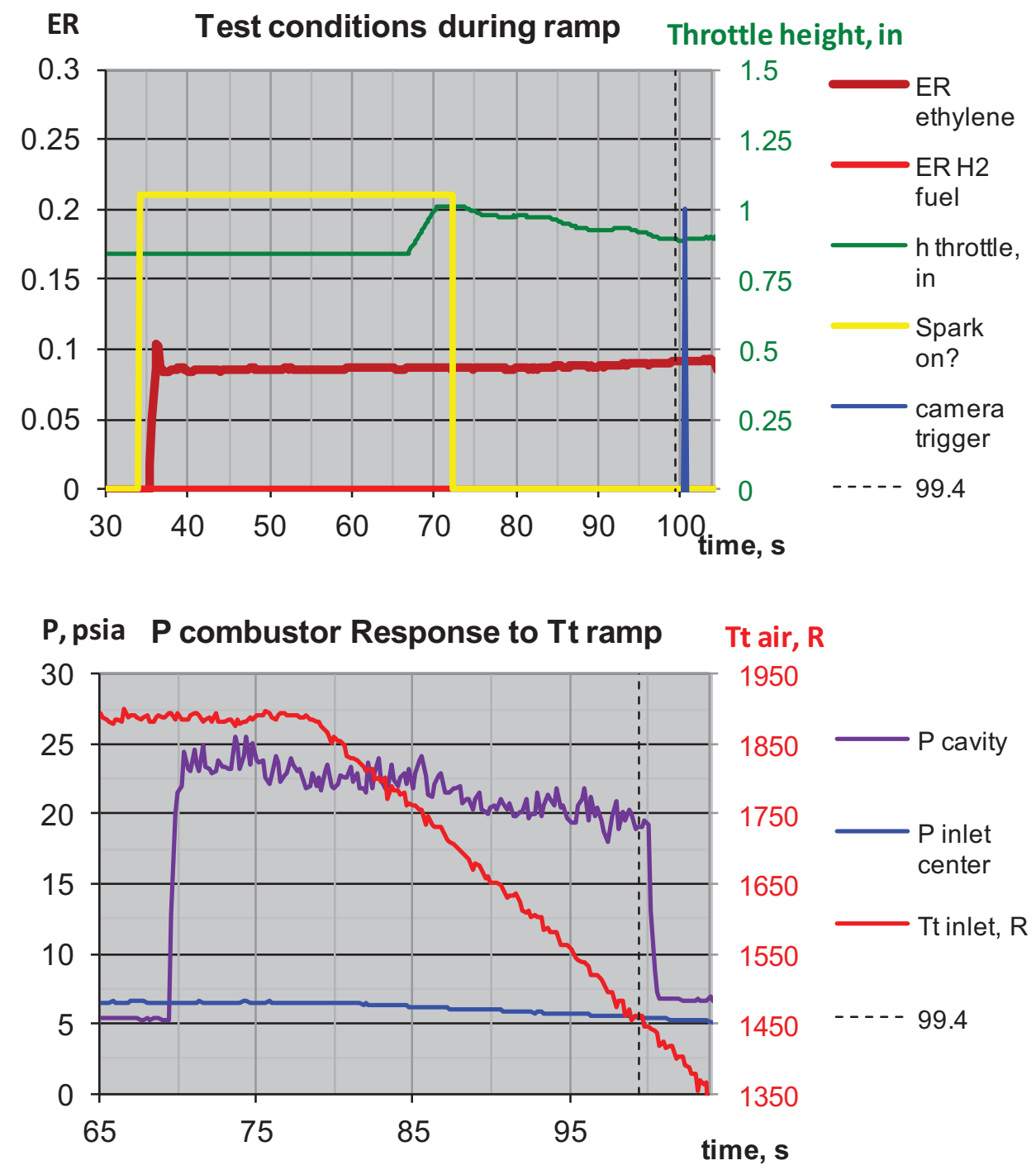

Figure C.4 Transient response of the combustor 


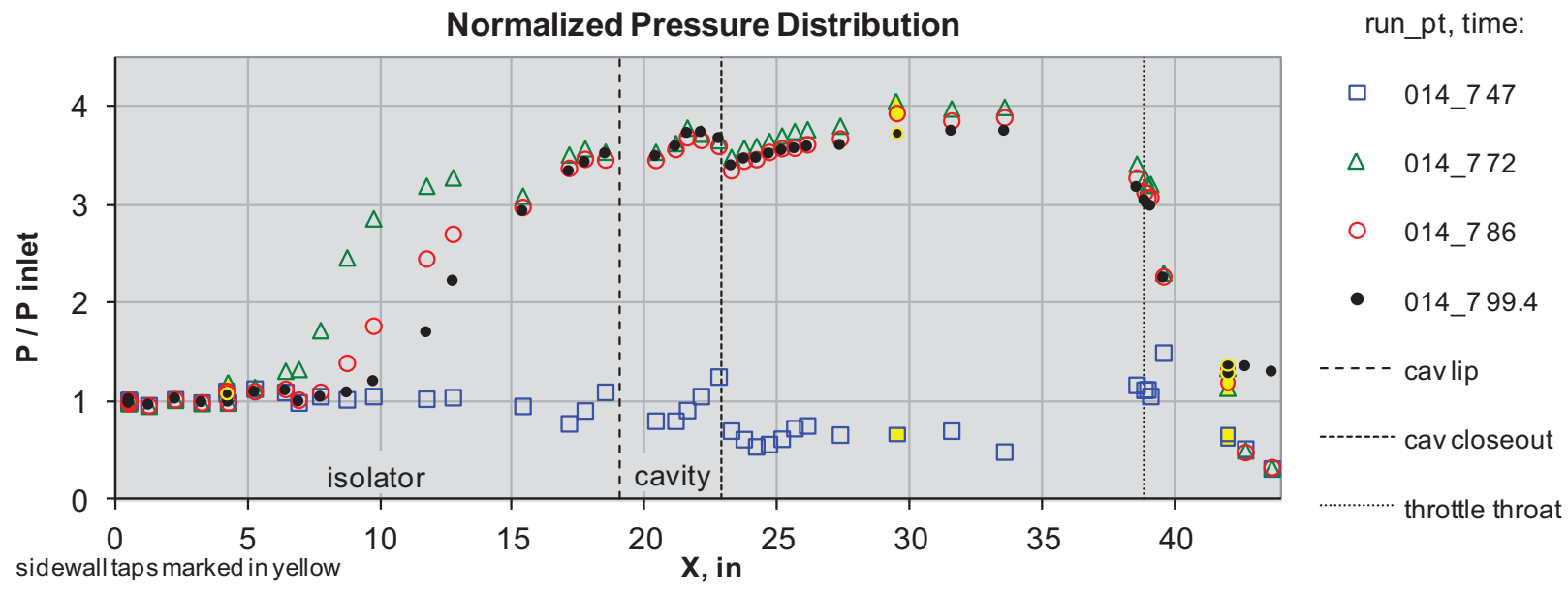

Figure C.5. Pressure distribution through the flowpath at various times during the run 


\begin{abstract}
Appendix D: UVa report: Experimental Study of Vitiation Effects on Flameholding in a Hydrocarbon Fueled Dual-Mode Scramjet Combustor
\end{abstract}




\title{
Experimental Study of Vitiation Effects on Flameholding in a Hydrocarbon Fueled Dual-Mode Scramjet Combustor
}

\author{
Benjamin J. Tatman, ${ }^{1}$ Robert D. Rockwell, ${ }^{2}$ Chris P. Goyne ${ }^{3}$ and James C. McDaniel ${ }^{4}$ \\ Univeristy of Virginia, Charlottesville, Virginia 22904 \\ and \\ James M. Donohue ${ }^{5}$ \\ United Technologies Research Center, East Hartford, Connecticut 06108
}

\begin{abstract}
Wind tunnel tests were performed to determine the effect of vitiation on flameholding limits in a hydrocarbon fueled dual-mode scramjet flameholder. The test air was generated both clean and with $6.7 \%$ water by mole to examine the effect of hydrogen combustion vitiation on flameholding. The tests were performed in a direct-connect configuration, with a Mach 2 inlet, a constant area isolator, a directly fueled cavity flameholder, and a rectangular divergent combustor. Ethylene was chosen as the test fuel. An air throttle was used as an independent back pressure source to hold the position of the shock train constant, minimizing the variation of the flow field upstream of the cavity so that the sensitivity of flameholding to chemical kinetics could be better isolated. Both the test medium total temperature and fuel equivalence ratio, in separate tests, were lowered until blowout, to determine the lower limits of flight Mach number and lean fuel operation, respectively. The measurements showed no distinguishable difference between the clean-air and vitiated tests. This indicates that, when evaluating combustion heated wind tunnel data on flameholding limits in directly fueled cavity flameholders, it is unnecessary to compensate for vitiation effects when combustor pressure is held constant.
\end{abstract}

\section{Introduction}

ual-mode scramjets are being developed as a promising propulsion technology for practical high speed and trans-atmospheric flight. To better understand the technology's mission capabilities, it is necessary to determine the limits on possible flight trajectories. Such trajectories are often bounded by 
thermal and structural limits and by the engine's ability to sustain steady combustion. Flameholding is particularly important in that it is necessary for combustion and thrust production. Wind tunnel investigations are useful as a low cost alternative to flight testing for determining an engine's flameholding limits and other performance parameters. It is difficult however to reproduce a hypersonic vehicle's high enthalpy engine flow conditions on the ground. In heating the air flow, many tunnels introduce combustion vitiation into their test medium, and the effect of this vitiation on experimental data must be understood before extrapolations to flight are possible.

Flameholding is a difficult problem in scramjets because, in supersonic combustors, mixing, ignition and combustion must occur within a very short residence time, on the order of a millisecond [1]. This problem applies especially to hydrocarbon fuels such as JP class fuels that are often used in scramjets. Such fuels consist of long chains of hydrogen and carbon molecules with longer reaction times than smaller molecules (such as hydrogen), and thus have long ignition delay times, often exceeding a millisecond. For this reason, supersonic combustors that burn hydrocarbons usually have a recessed cavity in the wall of the engine to provide a low speed recirculation zone, increasing the residence time of the fuel-air mixture. Extensive testing has been performed on burning hydrocarbons in cavity fueled combustors, evaluating their operability and performance [2-5]. Studies on flameholding limits by Lin et al. [2] and Rasmussen et al. [3] have shown that cavity flameholders should be functional over a range of fueling conditions. The investigators showed this by decreasing and increasing fuel equivalence ratio until blowout at various test medium total temperatures. Equivalence ratio, is the fuel to oxygen ratio, divided by the stoichiometric fuel to oxygen ratio. Flameholding tests are also being performed at the UTRC Scramjet Test Facility in a directly fueled cavity flameholder, by lowering the test medium total temperature until blowout. Although different from the more prevalent method of varying equivalence ratio until blowout, changing freestream flow conditions such as total temperature is relevant to a scramjet's flight trajectory envelope, as it provides a lower limit for simulated flight Mach number.

A previous study on flameholding, performed by Zukoski and Marble [6], proposed that blowout occurs when the residence time of the fuel in the reaction zone is equal to the ignition delay time of the fuel. Based on this theory, many experiments have been dedicated to defining a stability parameter that 
will determine when blowout will occur, usually depending on the engine geometry and on flow conditions. If the stability parameter accurately describes the flow physics, then this analysis can be used to predict the behavior of larger scramjet engines, based on a characteristic flameholder length, which is included in the stability parameter [7]. Ozawa et al. [8] and Huelmantel et al. [9] have compiled many data sets on flameholding in premixed flames, and have defined stability parameters that make reasonably accurate predictions to flameout behavior in high speed combustors. Unfortunately, these stability parameters have been shown to be inaccurate for non-premixed flames [7], and scramjet combustors are essentially non-premixed. Unlike premixed flows, the position of the reaction zone in non-premixed flows depends on where the fuel injection is relative to the recirculation region. The position of the reaction zone changes factors that are critical in flameholding, such as air entrainment, and the temperature of the reaction zone. Using cavity flameholding limit databases by Rasmussen et al. [3] and Gruber et al. [4], Driscoll et al. [7] have successfully correlated a stability parameter for non-premixed cavity flows, although they noted that the correlation depends on air entrainment rates in the cavity, and the fuel flow path to the reaction zone. They emphasize that more research is required to help define these characteristics for various non-premixed cavity configurations. Further flameholding tests are required to provide validation for the numerical models developed in these studies.

To perform relevant flameholding tests on the ground, it is necessary to simulate the high enthalpy of hypersonic flight. The simplest and most common method to achieve this is to use combustion to heat the airflow. However, this contaminates the flow with combustion products that are not present in atmospheric air in similar quantities. For example, the UTRC Scramjet Test Facility burns hydrogen in the heater section, producing a test medium of air at $1200 \mathrm{~K}$ with a composition of $12 \%$ water by mole. To extrapolate ground test data obtained in vitiation heated facilities to flight, it is necessary to understand the effects of this vitiation on flameholding and combustion.

Combustion vitiation can affect both the thermodynamics of the flow and the chemical kinetics of combustion. Water vapor can affect the chemistry of combustion by acting as a third body in the reaction, recombining reaction products, and breaking the reaction chain by forming $\mathrm{HO}_{2}$, a long-lived radical.

This has the effect of suppressing the reaction rate. Chinitz and Erdos [10] showed numerically that water 70 
vapor can increase the ignition delay time of ethylene by $40 \%$ at a test medium temperature of $1000 \mathrm{~K}$, with an increasing trend as temperature decreases. Fuller et al. [11] have compared numerical and experimental studies of water vapor vitiation effects on decane Bunsen burner flames. The results showed that the model over predicted flame speed when comparing to experimental results, unless it treated the water as a reactive third body. Because of the difference in heat capacity between vitiated and clean-air, and because steam absorbs heat when it dissociates at high temperatures, water vapor can also affect the thermodynamics by decreasing the pressure and temperature rise from combustion [12]. Rockwell et al. [13] showed experimentally the effects of vitiation by burning hydrogen fuel with and without water vapor and carbon dioxide in a dual-mode scramjet flow path. They saw as much as $23 \%$ reduced combustor pressure at $6 \%$ water by mole [13]. However, in the same tests, there was very little additional reduction in combustor performance with water levels higher than $6 \%$. The effects observed were attributed to both thermodynamic and chemical kinetic effects of vitiation. As flameholding is limited by coupled fluid/chemical phenomena such as strain rate, entrainment rates, ignition delay time, thermodynamics and chemical kinetics of the fuel-air system, water vapor may have a significant effect on flameholding limits. This justifies the need for experimental research, to study the magnitude of the effect of vitiation on flameholding, and whether it must be compensated for, or if it can simply be ignored.

In flameholding tests, it can be difficult to determine the mechanism of flameout. In a standard fueling configuration, which consists of main duct combustion with or without direct cavity fueling, a thermal throat forms downstream due to heat release in the combustor. This throat causes a pressure rise that pushes the shock train into the isolator, resulting in dual-mode operation of the scramjet and significantly modifying the flow field approaching the flameholder. In flameholding tests, it is difficult to tell whether flame extinction was caused by a change in reaction kinetics, or because reduced combustion eliminated the thermal throat, thus causing the collapse of the shock train and a large reduction in combustor pressure, and increase in combustor speed. In addition, as the shock train is relatively unsteady, this can cause a lack of repeatability in experimental results. However, a throttle can be used to provide the same back pressure as the thermal throat, thus holding the shock train in a constant position, 
without the need for mainstream combustion. Therefore, tests can be performed that specifically study the sensitivity of flameholding limits to the chemical kinetics of combustion. Also, the throttle should have the added benefit of making the tests more repeatable. The throttle can be mechanical or aerodynamic. For example, the UTRC Scramjet Test Facility uses a mechanical throttle, or valve, to achieve back pressure control. Lin et al. [2] have achieved independent back pressure control by means of air injection downstream of the flameholding cavity in a hydrocarbon fueled scramjet combustor. Here the investigators studied lean and rich blowout limits. The investigators in the above studies were not able to study the effect of vitiation on their flameholding limit tests.

Therefore, the purpose of this study is to investigate the effects of vitiation on flameholding limits in a hydrocarbon fueled dual-mode scramjet. The results are intended to aid interpretation of test data in any hydrogen combustion heated facility. However, the experiment was developed with the intention of complementing a companion, direct-connect, hydrocarbon fueled scramjet experiment in the UTRC Scramjet Test Facility. In that experiment a mechanical throttle is placed in the downstream duct to provide back pressure to form a shock train in the isolator duct upstream of the flameholder so that flameholding measurements capture the effect of the upstream shock train. In this study a throttle device will be designed and implemented. The experiment in the UTRC facility will be reported and compared with the present experiment in the NASA contract final report. Therefore, the objectives of this study are to:

1. Design, manufacture and install a hydrocarbon fueled dual-mode scramjet cavity flameholder with independent back pressure control for testing at in the University of Virginia Supersonic Combustion Facility,

2. Confirm that the throttle is capable of positioning the shock train at a specified location in the scramjet isolator throughout testing, 
3. Demonstrate flameholding capability with a hydrocarbon fuel in a directly fueled cavity flameholder, and

4. Examine the effects of water vapor vitiation on low temperature flameholding limits in a hydrocarbon fueled cavity flameholder, with the shock train position decoupled from combustor behavior.

This paper begins with a description of the facility, flow path, fuel system, air throttle and instrumentation. The results include axial pressure distributions showing shock train throttle control, and pressure sensitivity to combustion and vitiation, as well as flameout limit data, taken with both clean-air and water vapor vitiation. The results are intended to provide information for other facilities, to help them determine if the effects of vitiation must be compensated for, and if so, to what extent. The present study is novel because there has been no published experimental data regarding vitiation effects on scramjet flameholding limits. It is also represents an important test case, studying the chemical kinetic dependence of flameholding, and providing data for model validation. These models are important for developing flameout prediction tools, thus aiding the sizing of flameholders in larger scramjets. In addition, the use of ethylene, a more complex molecule than hydrogen, provides a stepping stone for modelers, with the goal of eventually simulating the even more complex chemistry present in typical jet fuel combustion.

\section{Experimental Technique}

The experiments were conducted using the University of Virginia Supersonic Combustion Facility (UVaSCF). The facility air was supplied by a compressor that allows for continuous operation. It was processed through a dryer and then electrically heated by a $300 \mathrm{~kW}, 14$ stage resistance heater. This makes it possible to generate freestream air with no vitiation present. The test medium total temperature can be maintained as high as $1200 \mathrm{~K}$ in this heating system. The total temperature can also be reduced during wind tunnel runs, although it takes approximately one half hour to reduce to room temperature. The facility has the capability to inject up to $12 \%$ water by mole in the form of steam and 
$4 \%$ carbon dioxide by mole, in order to match the freestream air conditions typical in combustion heated facilities. During testing, make up oxygen was added to return the test medium to standard atmospheric levels of $21 \%$ by mole. The steam and oxygen were injected upstream of the heater to allow for mixing in the freestream before entering the nozzle. In addition, the steam was injected where the air is already partially warmed so that condensation cannot form.

The flow path shown in figure 1 includes the cavity flameholder and fuel injector designed for this study. The flowpath takes lineage from the HIFiRE Flight 2 flow path [9], and a flow path in UTRC's Scramjet Test Facility. The flow path has the same profile as the above flow paths, with dimensions scaled by the duct height. However, the width of the flow path is different, even with scaling, as is the exact location of the throttle device. The flow path begins with a 2-Dimensional contoured Mach 2 nozzle with a $1.5 \mathrm{H}$ wide by $1 \mathrm{H}$ high exit. Here and elsewhere in this text, linear dimensions are normalized by the isolator height $\mathrm{H}, 25.4 \mathrm{~mm}$ or $1 \mathrm{inch}$. There is a $13.1 \mathrm{H}$ constant area isolator section followed by a 2.9 degree divergence beginning $3.7 \mathrm{H}$ upstream of fuel injection. The divergent wall includes the cavity flameholder with upstream, downstream, and direct cavity fueling capability. The cavity is $0.356 \mathrm{H}$ deep with an $\mathrm{L} / \mathrm{D}$ ratio of 5.25 , and a closeout angle of 22.5 degrees. For these experiments, ethylene fuel was injected directly into the cavity through five equally spaced sonic nozzles, $0.205 \mathrm{H}$ apart, with a diameter of $0.021 \mathrm{H}$, halfway along the cavity ramp closeout and parallel to the cavity floor. The nozzles have $60 \%$ more spacing from the side wall than the nozzle to nozzle spacing in an attempt to minimize side wall effects on flameholding. The fuel was ignited with a hydrogen-oxygen detonation driven igniter that injects high pressure, high temperature combustion products into the upstream end of the floor of the cavity. The engine was unable to auto-ignite at the given test conditions. The ethylene was heated upstream of the fuel control valve to about 40 degrees $C$ to ensure that it did not condense anywhere in the lines, although it cooled to room temperature before the point of injection. The exact range of fuel total temperatures is given in table 1. Also, the fuel control valve and a regulator located just downstream of the fuel supply were both wrapped in heat tape to prevent the mechanical parts from freezing due to the fuel pressure drop at these locations. 
An air throttle was chosen to provide back pressure control. A portion of the air from the main compressed air supply was taken and injected in the divergent section of the combustor, $9.08 \mathrm{H}$ downstream of fuel injection, from both side walls. The injector is a rectangular slot, dimensions 1.61 by $0.0625 \mathrm{H}$, covering the entire height of the duct at this axial location, and is designed to be sonic. The position is displayed in figure 1.

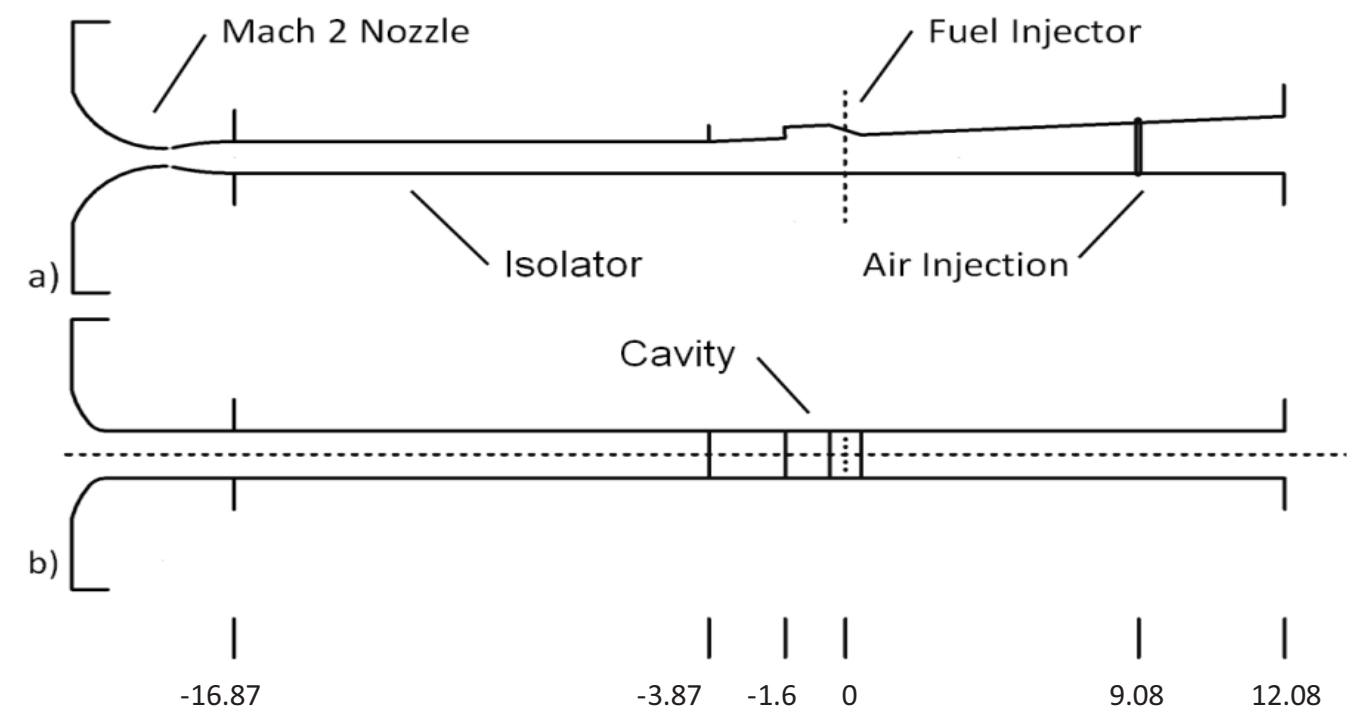

Fig. 1 UVaSCF flow path with cavity fuel injector and flameholder a) Side view and b) top view with key points labeled and distances from fuel injector given in isolator duct heights $(\mathbf{H}=\mathbf{2 5 . 4} \mathrm{mm})$.

The flow path was instrumented with low frequency pressure taps and thermocouples for pressure and temperature measurement. Forty pressure taps and ten thermocouples were spread along the centerline of the fuel injection side of the flow path. Six pressure taps were located on the cavity floor and just downstream of the cavity were placed in symmetrical pairs about the centerline, $0.626 \mathrm{H}$ apart. Pressure scans were an average of $10 \mathrm{~Hz}$ measurements taken over a period of 2 seconds. All pressure and temperature measurements were recorded through two National Instruments SCXI-1001 chassis, one SCXI-1000 chassis, and a Pressure Systems PSI Netscanner 98RK with three 9816 pressure scanner modules and a 9046 temperature scanner. Pressure and temperatures were typically measured with an experimental uncertainty of less than $1 \%$. Side windows in the combustor allowed live observation of flame and extinction through a video camera which was monitored from the control room. Actual time of flame extinction was taken from a wall temperature measurement in the cavity, which was seen to drop off dramatically within a second of flame extinction. This was considered to be a sufficiently accurate 
method, as tunnel conditions were varied relatively very slowly, taking 20 minutes to achieve a single flameout point. The reduction in wall temperature was also observed to be synchronous with the change in flame luminosity in the live video.

Flow rates of fuel, water, oxygen, and test medium air were set by using orifice plates and nozzles, and setting total temperature and pressure. Static temperatures and pressures, Mach numbers, velocities, and effective nozzle area are all necessary to calculate mass flow rate, using isentropic choked flow relations, and are given in tables 1 and 2 below. The flow rates are chosen to achieve a desired mole fraction or equivalence ratio, which are also given. The ranges covered for each of these parameters, and uncertainties for the mass flow rates are shown. Manufacturer values of uncertainty were used for pressure transducers and thermocouples. Mass flow uncertainty was calculated from the uncertainty in the orifice area, discharge coefficient and total temperature and pressure readings. 
Table 1 Inlet Test Conditions

\begin{tabular}{|c|c|c|c|c|}
\hline Parameter & Air & Water & Fuel & $\begin{array}{c}\text { Oxygen } \\
\text { (makeup) }\end{array}$ \\
\hline Total Pressure, $\mathrm{kPa}$ & $325-327$ & $684-922$ & $188-2845$ & $1013-1268$ \\
\hline Total Temperature, $\mathrm{K}$ & $1201-553$ & $423-436$ & $284-307$ & $275-285$ \\
\hline Mach Number & 2.02 & 1 & 1 & 1 \\
\hline Static Pressure, $\mathrm{kPa}$ & 41 & $371-500$ & $105-1583$ & $533-668$ \\
\hline Static Temperature, $\mathrm{K}$ & $725-312$ & $364-376$ & $254-274$ & $228-236$ \\
\hline Velocity, $\mathrm{m} / \mathrm{s}$ & $536-352$ & $471-479$ & $306-317$ & $289-294$ \\
\hline Mass Flow Rate, $\mathrm{g} / \mathrm{s}$ & $196-299$ & $11.8-15.6$ & $0.178-2.631$ & $5.687-7.208$ \\
\hline Equivalence Ratio & - & - & $0.013-0.14$ & - \\
\hline Mole Fraction, \% & $86-91$ & $6-11$ & $0.27-2.94$ & $21^{*}$ \\
\hline
\end{tabular}

The experiment was conducted by first setting the facility total temperature and pressure at $1200 \mathrm{~K}$ and $330 \mathrm{kPa}$, respectively. The air throttle was then activated, and the shock train was positioned approximately $3.3 \mathrm{H}$ through the isolator, from the nozzle exit. This position was chosen to provide primarily subsonic combustion, but not so far upstream that there would be danger of unstarting the nozzle. The fuel stagnation pressure was then set at one of several chosen test values, the range of which is shown in Table 1. The equivalence ratios chosen centered on $\Phi=0.1$, which was predicted to be the nose of the flameholding boundary curve. This was based on preliminary data from the UTRC Scramjet Test Facility, showing the nose of their boundary at this global equivalence ratio. We assumed, based on our design, that our air entrainment into the cavity would be similar, so that the nose of our flameholding boundary would be close to the same location. During testing, the total temperature was decreased, while constantly adjusting the air throttle to keep the shock train in position, until flameout occurred. The same test was then run with $6.7 \%$ water by mole. The shock train was positioned after the water level was set. This vitiation level was chosen to simulate the level of water that would be present in a hydrogen combustion vitiated heater facility at the predicted flameout temperature. The flameout temperature was 
predicted to be approximately $800 \mathrm{~K}$, based on preliminary data from the UTRC Scramjet Test Facility. Also, two lean blowout limits were obtained for clean-air, and one for the vitiated case, so that the results may also be applied to lean blowout limit tests at other facilities. Note that the equivalence ratio presented as the lean limit is an overall equivalence ratio, local stoichiometry was not measured. At flameout, stagnation values of air, fuel, steam, and oxygen temperature and pressure were recorded, to determine the mass flow rates of each and the equivalence ratios at flameout.

Table 2 Choked Orifice parameters and calculated mass flow rate uncertainties

\begin{tabular}{lcccc}
\hline & Facility Nozzle & $\mathrm{H}_{2} \mathrm{O}$ & Makeup $\mathrm{O}_{2}$ & Fuel \\
\hline Area, $\mathrm{mm}^{2}$ & $541.9 \pm 0.2$ & $2.48 \pm 0.2$ & $2.3 \pm 0.1$ & $1.12 \pm 0.04$ \\
Discharge Coefficient & $0.99 \pm 0.01$ & $0.95 \pm 0.03$ & $0.95 \pm 0.03$ & $0.38 \pm 0.02$ \\
Uncertainty in mass flow, \% & \pm 1.3 & \pm 3.4 & \pm 5.4 & \pm 6.4 \\
Uncertainty in $\phi, \%$ & - & - & - & \pm 6.5 \\
\hline \hline
\end{tabular}

\section{Results}

The following section describes the success of the air throttle and flameholder from a design perspective, and discusses the result of the flameholding limit tests and vitiation effects. The air throttle was tested first and the results are displayed in figure 2, showing axial pressure distributions with multiple levels of air throttle flowrates. The different curves are labeled in the legend with the control pressure sent to the air throttle supply valve, more control pressure produces higher air throttle flowrate and higher back pressure levels. The pressure is normalized by the average nozzle exit pressure, $\mathrm{P}_{\text {ref }}$, while the axial distance is normalized by $\mathrm{H}$ ( $\mathrm{Pref}=38.49 \mathrm{kPa}$ and $\mathrm{H}=1$ inch). With the air throttle turned off ( 0 psi control pressure), the pressure stays relatively constant through most of the flow path, except for weak waves in the isolator and low strength shocks and expansions propagating from the edges of the cavity. Near the exit, starting at $4 \mathrm{H}$ downstream of fuel injection, ambient back pressure creates a shock train that increases the wall pressure gradually towards the exit. When the air throttle is turned on, there is blockage due to the injected air, increasing back pressure and pushing the leading edge of the shock train into the isolator. 


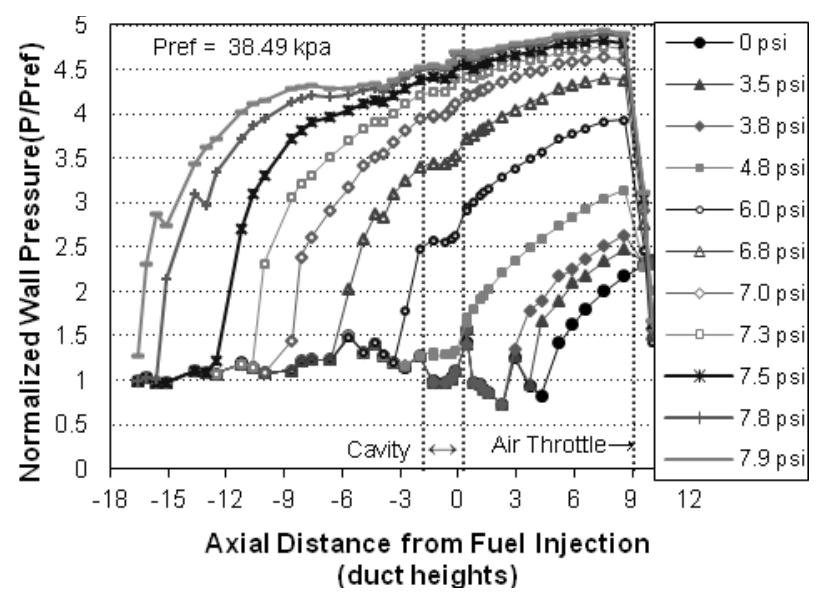

Fig. 2 Wall pressure distributions showing shock train control at various air throttle control pressures. Increasing control pressures correspond to increasing air injection flow rates. Axial distance is given in isolator duct heights $(\mathrm{H}=\mathbf{2 5 . 4} \mathbf{~ m m})$. Cavity and air throttle are marked. Experimental Uncertainty: $\mathbf{P} / \mathbf{P}_{\text {ref }}$ $\pm \mathbf{0 . 2} \%$.

A requirement for the flameholding tests was to achieve primarily subsonic combustion, and thus simulate the dual-mode operation of the dual-mode scramjet. According to a one-dimensional control volume analysis of this isolator following Heiser and Pratt [17], the combustor air flow is subsonic when the ratio of the combustor pressure and the nozzle exit pressure is greater than or equal to approximately 3, for both clean-air and vitiated cases. A pressure tap 13 duct heights upstream of fuel injection was chosen as the anchor position for the leading edge of the shock train, so as to ensure subsonic combustion, but not be in danger of unstarting the facility nozzle. As shown in the figure, for this shock train position, the pressure just upstream of the cavity is almost 4.5 times the nozzle exit pressure, indicating that the cavity air flow is at least primarily subsonic, although the one-dimensional calculation does not truly represent the three-dimensional flow. We are further validated of this, by reason that this amount of pressure rise is almost equal to that of a normal shock.

Once the operation of the air throttle was characterized, the behavior of the flameholder and combustion environment was examined. This is important because, as discussed in the literature, flameout depends on the position and characteristics of the flame. This information may determine whether these results are relevant for interpreting data produced on a flow path at a different facility. In these experiments, the combustor was able to achieve ignition and stable combustion at a total 
temperature of $1200 \mathrm{~K}$ and total pressure of $330 \mathrm{kpa}$, with an equivalence ratio of approximately 0.12 .

Lean ignition limit was not studied, although ignition was possible as low as an equivalence ratio of 0.06.

The low temperature ignition limit was $1150 \mathrm{~K}$ at an equivalence ratio of approximately 0.12 . The large difference between this ignition limit and the low temperature flameholding limit, discussed later on, is most likely due to the walls of the combustor being preheated during flameholding. The cavity flame was stable with no strong visible oscillations. These oscillations are often present in other facilities, and can be seen plainly on video. Figure 3 shows the flame luminosity at an equivalence ratio of 0.12 and at an equivalence ratio of 0.016 , the latter being near lean blowout. The images show that there was very little, if any, combustion upstream of the cavity. In the higher equivalence ratio flame, there is flame luminosity well downstream of the cavity, which may imply downstream combustion, or simply that $\mathrm{CH}$ or $\mathrm{C}$ species are still emitting radiation downstream of the cavity. The low equivalence ratio flame shows emissions almost entirely inside the cavity, showing that there is no downstream combustion. Although not pictured, at low total temperatures the visible emissions did not penetrate as far into the main duct, but still extended far downstream of the cavity. Near low temperature blowout, the flame luminosity decreased, the tunnel wall pressure became unsteady, and a small fuel-rich area in the center of the cavity closeout was devoid of flame. There was no evidence of initial blowout and re-ignition, as sometimes observed in other facilities. 

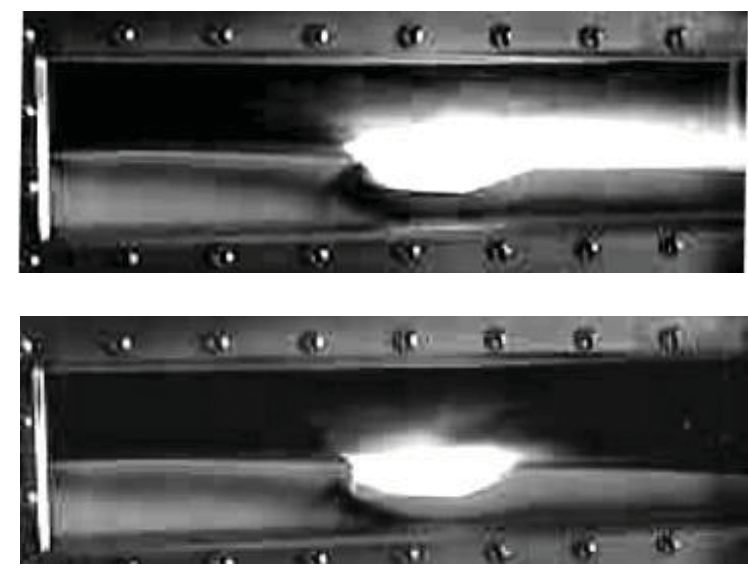

Fig. 3 Ethylene flame in cavity flameholder at equivalence ratios of approximately 0.12 (top) and 0.016 (bottom), both at $1200 \mathrm{~K}$ total temperature.

Before the effects of vitiation on flameholding limits are examined, the influence of vitiation on the combustion process itself is first discussed. The effect of vitiation on combustor pressure is important in understanding how vitiation might affect flameholding limits. Figure 4 presents axial pressure distributions of combustion with and without vitiation, and fuel-off with and without vitiation. The experiment was conducted by adjusting the fuel and air throttle flow rates so that the shock train was anchored at 13 duct heights upstream of combustion for the clean-air combustion case. The air throttle flow rate was then kept constant, while $12 \%$ water by mole was added, the fuel was turned off, and then the water was removed, taking pressure distributions for each condition. This level of water vapor corresponds to the amount that would be added by hydrogen vitiated heater at a test medium total temperature of $1200 \mathrm{~K}$, which is the initial temperature for this testing. The results show a reduction in pressure with vitiation during both the combustion and fuel-off cases. The fuel-off curve has a shallower slope with the addition of vitiation, but the same shock train leading edge location. This is due to a reduction in the specific heat of the test medium, which reduces the pressure rise across a shock, thus reducing the slope of the shock train curve. The combustion curve shows the shock train move downstream and a reduced combustor pressure with the addition of vitiation. This is due to the change in specific heat, but also because steam acts as a third body, recombining chemical reactants, and forming 
the radical $\mathrm{HO}_{2}$, suppressing the flame. These results are a physical verification of the expected thermodynamic and chemical effect of water vitiation discussed in the literature.

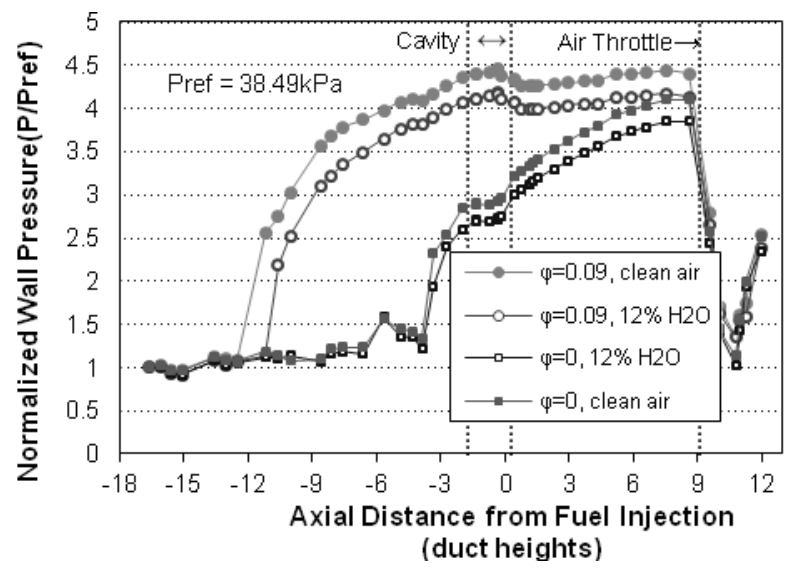

Fig. 4 The effect of directly fueled cavity combustion and test medium vitiation on axial wall pressure distribution. Duct height, $\mathrm{H}=\mathbf{2 5 . 4} \mathbf{\mathrm { mm }}$. Experimental uncertainty: $\mathrm{P} / \mathrm{P}_{\mathrm{ref}} \pm \mathbf{0 . 2} \%$.

It is also necessary to assess the effectiveness of the air throttle in decoupling shock train movement from combustion, and to establish what effect this has on the experimental results. Figure 5 displays axial pressure distributions that show the repeatability of shock train placement during variation in equivalence ratio and test medium total temperature. In this experiment, the air throttle and fuel equivalence ratio were set so that the shock train was positioned at $13 \mathrm{H}$ upstream of fuel injection. Then, both equivalence ratio and test medium total temperature were varied, while adjusting the air throttle control pressure to preserve the location of the shock train. We were able to maintain a consistent shock train position while changing both equivalence ratio and test medium total temperature. This shows that we are able to decouple the movement of the shock train from variations in combustion conditions in both lean blowout tests and low temperature blowout tests. Notably in figure 5, the pressure remains constant in the cavity, even as equivalence ratio and test medium total temperature change, and even though the pressure downstream of the cavity changes. As shown in figure 4, adding vitiation lowers combustor pressure, which is a critical parameter for flameholding. The air throttle eliminates the effect this pressure change would have on combustion. 


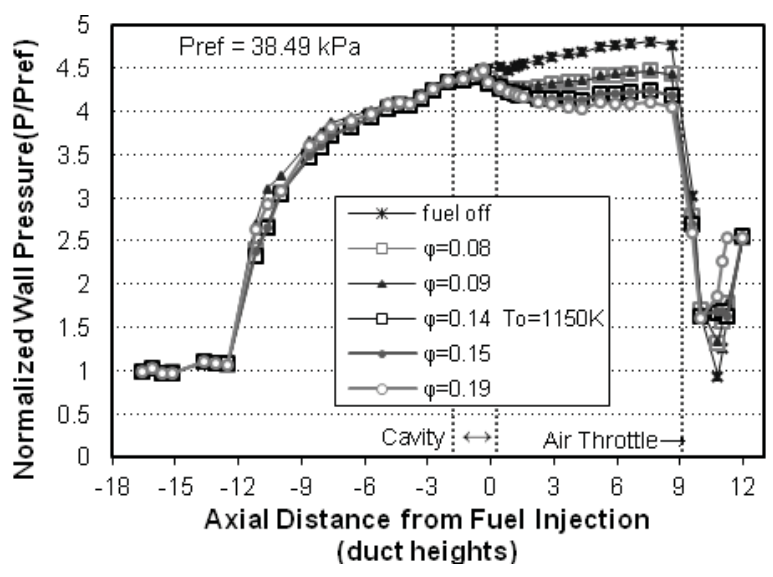

Fig. 5 Pressure distributions of combustion at various equivalence ratios, with shock train position held constant by adjusting air throttle flow rate. Test medium total temperature was held at $1200 \mathrm{~K}$, except for one curve taken at $1150 \mathrm{~K}$. Cavity opening and closeout, and air throttle injection are marked with dashed lines on the figure. Duct height, $H=25.4 \mathrm{~mm}$. Experimental uncertainty: $\mathrm{P} / \mathrm{P}_{\text {ref }} \pm \mathbf{0 . 2} \%$.

Figure 6 presents the results of the flameout tests, comparing the vitiated and clean-air data. As in the tests described above, the back pressure device was used to hold the shock train at $13 \mathrm{H}$ upstream of fuel injection. However, in this case only $6.7 \%$ water vapor by mole was added to the test medium. This simulated the level of vitiation in a hydrogen combustion heated facility with a total temperature near the expected flameout temperature of $800 \mathrm{~K}$. The figure shows the various flameout points on a graph of global equivalence ratio versus test medium total temperature. Three different values of the overall equivalence ratio, nominally $0.06,0.1$, and 0.14 , were studied for low temperature flameout in both clean and vitiated air (these points are on the right side of the figure, at $\mathrm{T}_{0} \sim 600 \mathrm{~K}$ ). The nose of the curve is at an overall equivalence ratio of approximately 0.1 , as we expected based on the preliminary UTRC results. Most Ozawa boundary curves center on 1.0, which would be a locally stoichiometric mixture of fuel and oxygen. However, since fuel is injected and burned in the cavity region in our case, where only a portion of the total tunnel oxygen is entrained, the local equivalence ratio is much higher than the overall equivalence ratio shown on the plot in figure 6 . The nose of the curve appears at an equivalence ratio of 0.1 , which provides close to a stoichiometric mixture for the cavity. The data points at an equivalence ratio of 0.06 were repeated for both clean-air and vitiated cases. Also, a lean blowout limit value was determined for both clean and vitiated cases at $1200 \mathrm{~K}$ total temperature (seen on the chart at $\mathrm{T}_{0} \sim 1200 \mathrm{~K}$ 
and $\phi \sim 0.015)$. The vitiated lean blowout limit was repeated for this condition. There was one outlier in the vitiation test data. During the repetition of the 0.06 data point in the vitiated case, the flame extinguished at a much higher total temperature than any other low temperature test point (at $\mathrm{T}_{0} \sim 900 \mathrm{~K}$ and $\phi \sim 0.08$, but not pictured). However, the usual visible phenomena preceding flameout, such as an unsteady flame and the small fuel-rich area with no combustion, were not visible preceding this flameout. In addition, the data point was subsequently repeated, and the temperature of the flameout grouped well with the previous points taken at the same equivalence ratio (0.06). This outlier is most likely evidence of unsteadiness still remaining in the fuel or air throttle systems. This paper is however primarily concerned with the sensitivity of flameholding to chemical kinetics. As shown by characteristics of this flameout point discussed above, this point is clearly not representative of the chemical kinetic limit of combustion, so it is not included in the figure.

The wall temperature is important because it can exchange heat with the cavity flow. Depending on the speed with which the total temperature or equivalence ratio is altered, as well as the path taken while altering the variables, the wall temperature may be different for different data points, which would influence the experimental results. This effect is called hysteresis. Wall temperature measurements show some small differences between flameout runs. For instance, the wall temperature was $387 \mathrm{~K}$ when the flame blew out at $\mathrm{T}_{0}=634 \mathrm{~K}$ and $\phi=0.116$ during a vitiated run. At $\mathrm{T}_{0}=564$ and $\phi=0.091$, the wall temperature was $381 \mathrm{~K}$ at flameout, also during a vitiated run. These small changes in wall temperature may have affected the flameout temperatures, but not enough to affect our findings, so there is probably only a negligible effect of hysteresis.

Mean low temperature limits and the $95 \%$ confidence intervals for the mean were calculated for both vitiated and clean-air cases. These values are indicated on the lower right corner of figure 6 . As shown in the figure, the means differ by only $7 \mathrm{~K}$, a difference that can be attributed to the uncertainty expressed in the confidence interval. The lean blowout points $\left(\mathrm{T}_{0} \sim 1200 \mathrm{~K}, \phi \sim 0.018\right)$ also showed no appreciable difference, that could not be attributed to experimental uncertainty. It is evident then, that vitiation has no effect on either the low temperature or low equivalence ratio flameouts, in the case of a directly fueled 
cavity with a combustion decoupled shock train and a hydrocarbon fuel. An attempt was made to apply something similar to an Ozawa correlation to the data, specifically a method designed by Rasmussen et. al. for non-premixed flows [3]. However, this method was designed for supersonic flow and a different fueling scheme, so it was found to be irrelevant for this data. Ozawa correlations themselves are irrelevant for this data [8], as discussed in the introduction, because they were formulated for premixed flows. Therefore, the boundary curve displayed is simply a curve fit meant to visualize the apparent flameholding boundary based on the experimental data.

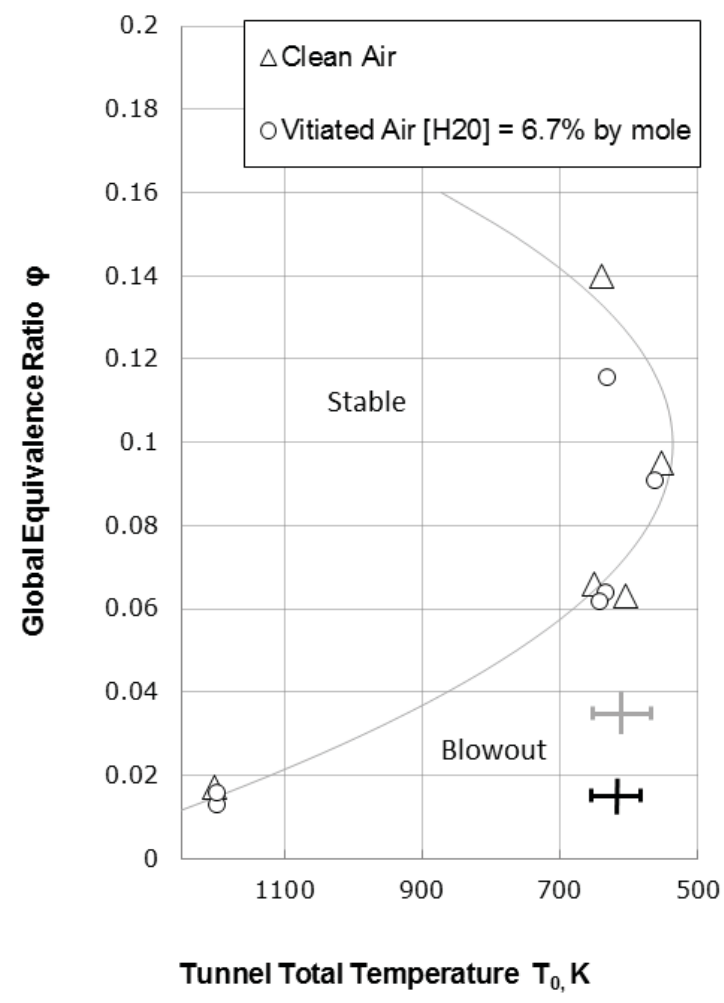

Fig. 6 Clean-air and vitiated flameholding limits, including the results of low temperature and lean blowout tests. Includes mean values of low temperature blowouts, with $95 \%$ confidence intervals, for both vitiated and clean-air. Experimental uncertainty: $\phi \pm 1.2 \%, \mathrm{~T}_{0} \pm 2 \%$.

This result is contrary to what may be expected based on the literature. Chinitz and Erdos [10] predicted a $40 \%$ increase in ethylene's ignition delay time at $1000 \mathrm{~K}$, and a water concentration of $10 \%$. Given that flameholding limits depend directly on ignition delay time, it may be expected that vitiation would reduce the ability of the cavity to hold a flame. However, in cavity combustion a portion of the combustion products are recirculated in the cavity. If one assumes that there is no left over fuel or oxygen 
at stoichiometric conditions, the level of combustion products present in the cavity can be estimated. This rough analysis predicts a level of $11 \%$ total water vapor and carbon dioxide by mole in the recirculation zone, during clean-air testing. This provides a maximum for recirculated combustion products, based on fuel injected. The actual level may be much lower, but even 5 or 6 percent would be significant. These cavity combustion products would greatly reduce the impact of the water vapor added during testing and may be one reason we see no difference between the vitiated and clean-air data. If this is the cause of our results, they may be extended to other hydrocarbon fuels as well as hydrogen fuel. Hydrogen fuel would not produce carbon dioxide, but because we are only adding water vapor in our test, the hydrogen combustion in the cavity would most likely still reduce the impact of test medium vitiation.

The position of the reaction zone is also important in understanding why there is no effect of vitiation on flameholding limits in this test case. We have so far assumed the flame to be located in the recirculation zone, as opposed to the shear layer. If the reaction zone is anchored on the floor of the cavity, in the recirculation zone, the fuel would have a very long residence time in the reaction zone. In this case, whether the ignition delay time is affected by vitiation or not, the residence time may be long enough that the increased ignition delay time with vitiation would have a negligible effect on flameholding. As discussed above, Chinitz and Erdos [10] showed numerically that steam can increase the ignition delay time of ethylene. This study unfortunately did not include temperatures as low as the blowout temperatures in this study, but the change in ignition delay would be expected to be slightly higher at these temperatures. Based on the ignition delay correlation by Saxena et al. [15], near the predicted reaction zone temperature of $700 \mathrm{~K}$, an increase in ignition delay time by $40 \%$ only increases the blowout temperature by $10 \mathrm{~K}$. This difference would be even smaller if you take into account that the cavity contains combustion products, as discussed above. Such a small deviation in the experimental data may go unnoticed due to experimental uncertainty, which would explain why we see no difference in our vitiated and clean-air data. If this is the primary cause for our results, they could be applied to all other fuels as well, as the residence time is largely independent of the type of fuel selected.

If the reaction zone is primarily held in the shear layer, the fuel would have a very short residence time, and the previous two reasons would not be sufficient to explain why we see no difference between 86 
the clean-air and vitiated data. As discussed, this would affect how we are able to extend our results to other fuels and fueling configurations. Thus, it would be very beneficial to know where the flame is being held in our experiments. In high speed images of a hydrocarbon fueled dual-mode scramjet flow path, Lin et al. [5] showed a flame rooted on the cavity floor near fuel injection. Their setup used for obtaining these images was very similar to the configuration used in this paper, including the use of back pressurization, and the position and direction of direct cavity fueling. This would suggest that the flame in our tests was also located in the recirculation zone on the floor of the cavity, although only a reaction zone visualization technique (such as $\mathrm{OH}$ Planar Laser Induced Fluorescence) would confirm this. The flame images shown in figure 3 are due to $\mathrm{CH}$ emissions (which continue after the reaction is complete), and are not representative of the position of the reaction zone.

We can at this point say that there is no observable difference between the clean-air and vitiated flameholding data, and that the two factors discussed above are the most likely reasons for this.

\section{Conclusions}

The effect of vitiation on the flameholding characteristics of a hydrocarbon fueled cavity flameholder was studied experimentally using a unique hypersonic ground test facility that was capable of running with clean-air and also with major combustion vitiation species added to the flow. The experiment was conducted at test medium total temperatures up to $1200 \mathrm{~K}$, simulating Mach 5 flight. Through the course of this study, an ethylene fueled dual-mode scramjet, was installed and operated in the University of Virginia Supersonic Combustion Facility. An air throttle was installed for independent back

pressurization. Stable flameholding was achieved in the directly fueled cavity flameholder, with no main duct combustion, and the air throttle was shown to be an effective and stable back pressure device.

The vitiated flameout cases were run with $6.7 \%$ water vapor by mole, which is the amount added by a hydrogen combustion heated facility at a test medium total temperature of $800 \mathrm{~K}$. The effect of vitiation on lean blowout and low temperature flameholding limits was studied, as was the effect on combustor wall pressure. An air throttle was used to hold the isolator shock train flow field constant, keeping the shock train position and the combustor pressure constant. The results showed a decrease in wall pressure 
due to vitiation, but showed no discernible effect on flameholding limits. This result is most likely because the long residence time of a directly fueled cavity flow means that a moderate change in ignition delay time would have a very small percent change on flameout temperature. Also, combustion products are already recirculated in the cavity from combustion, which reduces the effect of additional vitation. The results have the fortunate outcome that flameholding limit data obtained using hydrogen combustion heated facilities does not have to be altered, and can be considered to be unaffected by water vapor vitiation. Specifically, the results are relevant for dual-mode scramjet facilities using hydrocarbon fuel, in a directly fueled cavity, with a shock train that has been decoupled by an independent back pressure source. Because the air throttle keeps the shock train flow field constant, the results also show specifically how chemical kinetics limit flameholding in a cavity flow. This information is critical in developing relevant models for predicting flameholding limits in dual-mode scramjets. The test points had good repeatability, and there were no cases of initial blowout and re-ignition, making this data a promising source for model validation.

\section{Acknowledgments}

This work was funded by the United Technologies Research Center through NASA contract NNC08CA79C with technical monitor Scott Thomas. The authors would like to thank Roger Reynolds and Roland Krauss of the University of Virginia for assistance in preparing and performing the experiment. The authors would also like to thank Harsha Chelliah of the University of Virginia and Mark Gruber of the Air Force Research Laboratory for helpful discussions.

\section{References}

[1] Ben-Yakar, A., and Hanson, R. K., "Cavity Flame-Holders for Igntion and Flame Stabilization in Scramjets: An Overview," Journal of Propulsion and Power, Vol. 17, No. 4, 2001, pp. 869-877.

doi: $10.2514 / 2.5818$

[2] Lin, K. C., Tam, C. J., and Jackson, K., "Study on the Operability of Cavity Flameholders Inside a Scramjet Combustor," AIAA paper 2009-5028, 2009. 
[3] Rasmussen, C. C., Driscoll, J. F., Hsu, K. Y., Donbar, J. M., Gruber, M. R., and Carter, C. D., "Stability Limits of CavityStabilized Flames in Supersonic Flows," Proceedings of the Combustion Institute, Vol. 30, The Combustion Institute, Pittsburgh, PA, 2005, pp. 2825-2831.

[4] Gruber, M. R., Donbar, J.M., Carter, C. C., and Hsu, K.-Y., "Mixing and Combustion Studies Using Cavity-Based Flameholders in a Supersonic Flow,” Journal of Propulsion and Power, Vol. 17, No. 4, 2001, pp.869-877.

[5] Lin, K. C., Tam, C. J., "Flame Characteristics and Fuel Entrainment Inside a Cavity Flame Holder in a Scramjet Combustor," AIAA paper 2007-5381, 2007.

[6] Zukoski, E. E., and Marble, F. E., "Experiments Concerning the Mechanism of Flame Blowoff from Bluff Bodies," Proceedings of the Gas Dynamics Symposium on Thermochemistry, Northwestern Univ., Evanston, IL, 1956, pp. 205-225.

[7] Driscoll, J. F., and Rasmussen, C. C., "Correlation and Analysis of Blowout Limits of Flames in High-Speed Airflows," Journal of Propulsion and Power, Vol. 21, No. 6, 2005, pp. 1035-1044.

[8] Ozawa, R. I., "Survey of Basic Data on Flame Stabilization and Propagation for High Speed Combustion Systems," U.S. Air Force AFAPL Technical Rept. TR-70-81, Wright-Patterson AFB, OH, Jan. 1971.

[9] Huellmantel, L.W., Ziemer, R.W. and Cambel, A.B., "Stabilization of Premixed Propane-Air Flames in Recessed Ducts," Journal of Jet Propulsion, Vol. 27, No. 1, 1957, pp. 31-43.

[10] Chinitz, W., and Erdos, J. I., “Test Facility Chemistry Effects on Hydrogen Flames and Detonations,” AIAA paper 95-2467, 1995.

[11] Fuller, C. C., Gokulakrishnan, P., Klassen, M. S., Adusumilli, S., Kochar, Y., Bloomer, D., Seitzman, J., Kim, H. H., Won, S. H., Dryer, F. L., Ju, Y., and Kiel, B. V., "Effects of Vitiation and Pressure on Laminar Flame Speeds of n-Decane," AIAA paper 2012-167, 2012.

[12] Pellett, G. L., Bruno, C., and Chinitz, W., "Review of Air Vitiation Effects on Scramjet Ignition and Flameholding Combustion Processes,” AIAA Paper 2002-3880, 2002.

[13] Rockwell, R. D., Goyne, C. P., Haw, W., Krauss, R. H., McDaniel, J. C., Trefny, C. J., "Experimental Study of TestMedium Vitiation Effects on Dual-Mode Scramjet Performance,” Journal of Propulsion and Power, Vol. 27, No. 5, 2011, pp. $1135-1142$. doi: $10.2514 / 1 . B 34180$

[14] Heiser, W. H., and Pratt, D. T., Hypersonic Airbreathing Propulsion, AIAA Education Series, AIAA, Washington, D.C., 1994, pp. 342-346.

[15] Saxena, S., Kahandawala, M. S. P., Sidhu, S. S., "A Shock Tube Study of Ignition Delay in the Combustion of Ethylene," Combustion and Flame, Vol. 158, No. 6, June 2011, pp. 1019-1031. 


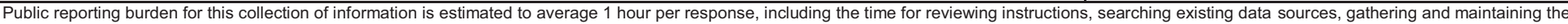

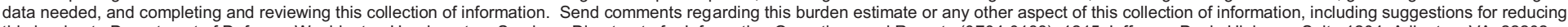

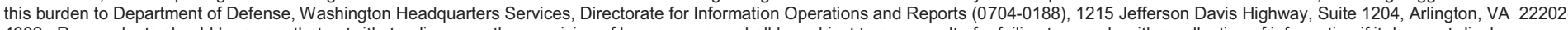

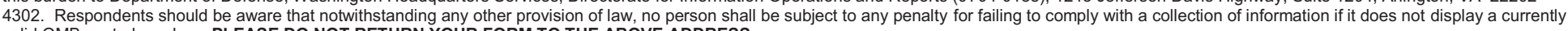
valid OMB control number. PLEASE DO NOT RETURN YOUR FORM TO THE ABOVE ADDRESS

1. REPORT DATE $(D D-M M-Y Y Y Y)$ 2. REPORT TYPE

$30-09-2012$

\section{TITLE AND SUBTITLE}

Dual-Mode Scramjet Flameholding Operability Measurements

Final

3. DATES COVERED (From - To)

$05 / 09 / 2008$ to $09 / 30 / 2012$

5a. CONTRACT NUMBER

NNC0 8CA79C

5b. GRANT NUMBER

5c. PROGRAM ELEMENT NUMBER

6. AUTHOR(S)

James M. Donohue

5d. PROJECT NUMBER 5e. TASK NUMBER

5f. WORK UNIT NUMBER

7. PERFORMING ORGANIZATION NAME(S) AND ADDRESS(ES)

United Technologies Research Center

8. PERFORMING ORGANIZATION REPORT NUMBER

411 Silver Lane

East Hartford, CT 06108-1127

\section{SPONSORING / MONITORING AGENCY NAME(S) AND ADDRESS(ES)}

National Aeronautics and Space Administration

Washington, DC 20546-0001
10. SPONSOR/MONITOR'S ACRONYM(S)

NASA GRC

11. SPONSOR/MONITOR'S REPORT NUMBER(S)

\section{DISTRIBUTION / AVAILABILITY STATEMENT}

Unclassified - Unlimited

\section{SUPPLEMENTARY NOTES}

\section{ABSTRACT}

Flameholding measurements were made in two different direct connect combustor facilities that were designed to simulate a cavity flameholder in the flowfield of a hydrocarbon fueled dual-mode scramjet combustor. The presence of a shocktrain upstream of the flameholder has a significant impact on the inlet flow to the combustor and on the flameholding limits. A throttle was installed in the downstream end of the test rigs to provide the needed back-pressurization and decouple the operation of the flameholder from the backpressure formed by heat release and thermal choking, as in a flight engine. Measurements were made primarily with ethylene fuel but a limited number of tests were also performed with heated gaseous JP-7 fuel injection. The flameholding limits were measured by ramping inlet air temperature down until blowout was observed. The tests performed in the United Technologies Research Center (UTRC) facility used a hydrogen fueled vitiated air heater, Mach 2.2 and 3.3 inlet nozzles, a scramjet combustor rig with a 1.666 by 6 inch inlet and a 0.65 inch deep cavity. Mean blowout temperature measured at the baseline condition with ethylene fuel, the Mach 2.2 inlet and a cavity pressure of 21 psia was $1502 \mathrm{oR}$. Flameholding sensitivity to a variety of parameters was assessed. Blowout temperature was found to be most sensitive to fuel injection location and fuel flowrates and surprisingly insensitive to operating pressure (by varying both back-pressurization and inlet flowrate) and inlet Mach number. Video imaging through both the bottom and side wall windows was collected simultaneously and showed that the flame structure was quite unsteady with significant lateral movements as well as movement upstream of the flameholder. Experiments in the University of Virginia (UVa) test facility used a Mach 2 inlet nozzle with a 1 inch by 1.5 inch exit cross section, an aspect ratio of 1.5 versus 3.6 in the UTRC facility. The UVa facility tests were designed to measure the sensitivity of flameholding limits to inlet air vitiation by using electrically heated air and adding steam at levels to simulate vitiated air heaters. The measurements showed no significant difference in blowout temperature with inlet air mole fractions of steam from 0 to $6.7 \%$.

\section{SUBJECT TERMS}

PM, emissions, soot, particulates, gas turbines, aircraft engines

\begin{tabular}{|c|c|c|c|c|c|}
\hline \multicolumn{3}{|c|}{ 16. SECURITY CLASSIFICATION OF: } & \multirow{2}{*}{$\begin{array}{l}\text { 17. LIMITATION } \\
\text { OF ABSTRACT } \\
\text { SAR }\end{array}$} & \multirow{2}{*}{$\begin{array}{l}\text { 18. NUMBER } \\
\text { OF PAGES }\end{array}$} & 19a. NAME OF RESPONSIBLE PERSON \\
\hline $\begin{array}{l}\text { a. REPORT } \\
\text { Unclassified }\end{array}$ & $\begin{array}{l}\text { b. ABSTRACT } \\
\text { Unclassified }\end{array}$ & $\begin{array}{l}\text { c. THIS PAGE } \\
\text { Unclassified }\end{array}$ & & & $\begin{array}{l}\text { 19b. TELEPHONE NUMBER (include area } \\
\text { code) }\end{array}$ \\
\hline
\end{tabular}

